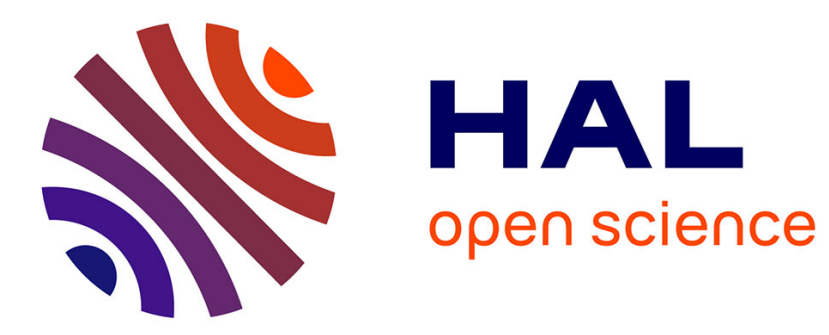

\title{
Les statères aux types de Philippe II de Macédoine: de l'Égée à la Gaule, des originaux aux imitations
}

Sylvia Nieto-Pelletier, Julien Olivier

\section{To cite this version:}

Sylvia Nieto-Pelletier, Julien Olivier. Les statères aux types de Philippe II de Macédoine: de l'Égée à

la Gaule, des originaux aux imitations. Revue Numismatique, 2016, 173, pp.171-229. hal-02164522

HAL Id: hal-02164522

https://hal-univ-orleans.archives-ouvertes.fr/hal-02164522

Submitted on 23 Mar 2021

HAL is a multi-disciplinary open access archive for the deposit and dissemination of scientific research documents, whether they are published or not. The documents may come from teaching and research institutions in France or abroad, or from public or private research centers.
L'archive ouverte pluridisciplinaire HAL, est destinée au dépôt et à la diffusion de documents scientifiques de niveau recherche, publiés ou non, émanant des établissements d'enseignement et de recherche français ou étrangers, des laboratoires publics ou privés. 


\section{REVUE}

NUMISMATIQUE

Dirigée par

Fr. Duyrat, C. Grandjean, C. Morrisson,

M. Bompaire, A. Suspène
Secrétaires de la rédaction

V. Drost, J. Jambu, J. Olivier

2016

(173 volume) 


\title{
REVUE NUMISMATIQUE
}

\author{
COMITÉ DE PUBLICATION
}

\section{Directeurs}

Frédérique DUYRAT | Catherine GRANDJEAN | Cécile MORRISSON | Marc BOMPAIRE | Arnaud SUSPÈNE

\section{Secrétaires de la rédaction}

Articles

Jérôme JAMBU (jerome.jambu@bnf.fr) | Vincent DROST
Comptes rendus

Julien OLIVIER (julien.olivier@bnf.fr)

\section{COMITÉ DE LECTURE}

Michael ALRAM, Michel AMANDRY, Philip ATTW00D, François BARATTE, Patrice BAUBEAU, Cécile BRESC, François DE CALLATAŸ, Michel CHRISTOL, Yves COATIVY, Sylviane ESTIOT, Bruno FOUCRAY, Stefan HEIDEMANN, Antony HOSTEIN, Marie-Christine MARCELLESI, Jens Christian MOESGAARD, Sylvia NIETO-PELLETIER, Olivier PICARD, Séléné PSOMA, Andrea SACCOCCI, Thierry SARMANT, François THIERRY, Lucia TRAVAINI, Benedikt ZÄCH.

La Revue numismatique paraît annuellement. Elle est la propriété de la Société française de numismatique qui en est l'éditeur et en assure le service à tous ses membres à jour de cotisation pour l'année concernée, lors de sa parution. La cotisation a été fixée pour 2016 à $54 €$ et $60 €$ pour les membres résidant à l'étranger.

\author{
Société Française de Numismatique \\ Reconnue d'utilité publique \\ Bibliothèque nationale de France, 58 rue de Richelieu, 75002 PARIS \\ http://www.sfnumismatique.org | sfnum@hotmail.fr
}

La Revue numismatique est également diffusée par

Belles Lettres Diffusion Distribution

25 rue du Général Leclerc, F-94270 LE KREMLIN-BICÊTRE

Tél. : 0145151989 | Fax : 0145151980

Les abonnements sont payables à la Société d'édition «Les Belles Lettres»

Le champ couvert par la Revue numismatique comprend la numismatique et l'histoire monétaire et s'étend à l'archéologie, l'histoire économique, l'histoire de l'art ainsi qu'à l'épigraphie, la sigillographie ou la glyptique dans leurs rapports avec l'étude des monnaies, médailles et documents monétiformes.

La Revue recherche des études de haut niveau et de première main, publication de documents nouveaux ou nouvelle interprétation de documents connus. Les articles sont retenus en fonction de leur qualité scientifique et de l'intérêt du document présenté. Les rubriques de la Revue sont indicatives et correspondent aux divisions historiques traditionnelles : numismatique celtique, grecque, romaine, byzantine, médiévale, moderne et contemporaine, orientale, médailles et jetons, histoire de la numismatique et des collections. Des notes synthétiques faisant le point sur une question ou un débat ont leur place dans les Miscellanea (la Société française de numismatique préférant réserver la publication des articles brefs au Bulletin de la Société française de numismatique).

Les langues admises sont, outre le français, l'allemand, l'anglais, l'espagnol et l'italien.

Les manuscrits complets et conformes aux instructions doivent être remis au secrétariat le $1^{\mathrm{er}}$ septembre de l'année qui précède la parution. Après avoir été confiés à plusieurs rapporteurs et examinés par le comité de lecture, ils sont définitivement retenus lorsque le conseil de gestion de la Revue numismatique se réunit, en février, pour adopter le budget de la Revue qui paraît dans l'année.

La Revue ne rend compte que des ouvrages qui sont adressés au secrétariat avec la mention «Revue numismatique». Les ouvrages sont remis à des spécialistes proposés par les directeurs au Comité de lecture. La publication rapide dans le bulletin bibliographique ne doit pas nuire au caractère informatif et critique des comptes rendus et il est possible de rendre compte simultanément et synthétiquement de plusieurs ouvrages. La Revue se réserve le droit de refuser toute publicité sans avoir à fournir de motif à sa décision. 


\title{
Sylvia NIETO-PELLETIER*, Julien OLIVIER**
}

\section{Les statères aux types de Philippe II de Macédoine : de l'Égée à la Gaule, des originaux aux imitations}

\begin{abstract}
Résumé - Les statères aux types de Philippe II de Macédoine représentent un sujet d'étude crucial autant pour les spécialistes du monde grec - au sein duquel ils constituent un des principaux monnayages d'or - que pour ceux de la Gaule, où ils furent abondamment imités. Cet article propose un regard croisé sur ces statères, à la fois comme monnayage grec mais également comme modèle à l'origine d'un grand nombre de monnayages en or gaulois. En nous appuyant sur la documentation existante, nous proposons tout d'abord un inventaire révisé des statères originaux aux types de Philippe II trouvés en Gaule, ainsi qu'un tableau synthétique des premières séries d'imitations. Dans un second temps, nous tentons de mieux cerner les circonstances et l'ampleur du phénomène d'importation des philippes originaux en Gaule à travers l'étude des principales séries émises en Macédoine et dans le nord de l'Asie Mineure. Nous reprenons enfin les différentes hypothèses avancées pour expliquer l'arrivée des philippes en Gaule et leur succès tout en replaçant ces phénomènes dans le contexte de transition et d'expansion de l'ensemble du monde celtique au Ive et au IIIe siècle av. J.-C.
\end{abstract}

Mots clés - Statère de Philippe II de Macédoine, circulation monétaire, imitation celtique.

Summary - The staters with types of Philip II of Macedonia are as crucial an issue for specialists of the Greek world - in which they are one of the main gold coinages - as for those of Gaul, where these coins were much imitated. This article aims to provide a cross-perspective on these staters, both as a Greek coinage and as the model for a large number of Gaulish gold coinages. We first offer a revised inventory of original staters found in Gaul based on the existing literature and a table summarizing the first series of imitations. Through the study of the main series issued in Macedonia and in northern Asia Minor, we then try to give a more accurate view of the circumstances and extent of import the gold coins of Philip in Gaul. Finally, after replacing these phenomena in the context of transition and expansion of the Celtic world in the $4^{\text {th }}$ and $3^{\text {rd }}$ centuries $\mathrm{BC}$, we discuss the various hypotheses explaining the arrival of these coins in Gaul.

Keywords - Gold stater of Philip II, coin circulation, Celtic imitation.

* Chargée de recherche CNRS, IRAMAT Centre Ernest-Babelon, UMR 5060 CNRS-univ. Orléans, 3D rue de la Férollerie, CS 60061, 45071 Orléans cedex 2. Courriel : nieto@cnrs-orleans.fr.

** Chargé de la collection des monnaies grecques, département des Monnaies, médailles et antiques, BnF, 5 rue Vivienne, 75002 Paris. Courriel : julien.olivier@bnf.fr. 


\section{Introduction}

Il est d'usage de considérer que c'est au cours du IIIe siècle que la monnaie fait son apparition en Gaule par l'intermédiaire de mercenaires celtes recrutés au moment des conflits qui opposent Carthage, Syracuse, Tarente et Rome entre 320 et 270 av. J.-C. À leur retour en Gaule, ces mercenaires auraient introduit des statères aux types de Philippe II de Macédoine qui, par la suite, servent de prototypes à la frappe des premières monnaies d'or gauloises. C'est donc en utilisant des originaux grecs, puis en les copiant que les Gaulois adoptent la monnaie. Dans un premier temps, les imitations gauloises reprennent de façon très fidèle le type des philippes (ce sont les monnaies dites de la première génération). Dans un second temps, ces imitations évoluent, s'éloignant de façon significative du prototype initialement copié (deuxième génération $)^{1}$. Si les statères aux types de Philippe II de Macédoine constituent le modèle majoritairement imité, il n'est cependant pas le seul. Des imitations de monnaies frappées à Tarente et à Néapolis ont également été recensées, notamment dans le Nord de la Gaule, et des emprunts au statère du diadoque Lysimaque, pour le droit, sont attestés dans le Centre-Est.

L'approche anthropologique développée ces dernières années pour la période du second âge du Fer a conduit à aborder la naissance du fait monétaire sous un angle nouveau en intégrant les mutations qui touchent l'ensemble du monde celtique au IVe et au III siècle av. J.-C. ${ }^{2}$ Aussi féconde soit-elle, cette approche ne doit pas déconnecter l'étude de son objet principal, non seulement la monnaie gauloise mais également, et peut-être surtout, la monnaie gréco-macédonienne dans toutes ses composantes.

Cet article propose une relecture des données actuellement disponibles de la Gaule à l'Égée pour tenter de mieux caractériser le phénomène d'importation en Gaule des monnaies aux types de Philippe II de Macédoine, au-delà de l'hypothèse du mercenariat habituellement avancée.

\section{Le dossier celtique : des originaux et des imitations}

\section{A. Inventaire des exemplaires découverts en Europe et discussion}

Les statères aux types de Philippe II de Macédoine découverts en Europe ont fait l'objet de très nombreuses mentions dans la littérature numismatique et archéologique. Du simple signalement, lors de la publication d'inventaires ${ }^{3}$,

\footnotetext{
1. Voir particulièrement SCHEERS, BARRANDON 1994 pour la question des deux générations d'imitations.

2. PION 2012, repris par MARTIN 2015, p. 333-352.

3. Par exemple RichaRd 1980, p. 790 ; FEUGÈRE, RichaRd 2004, p. 110 ; RichaRD, RALITE 2012, p. 1.
} 
à l'étude plus fournie 4 , ces exemplaires à l'origine des monnayages d'or gaulois ont suscité un vif intérêt. Plusieurs recensements plus ou moins concordants leur ont été consacrés (annexe 1).

Depuis A. Blanchet en 1905 qui considérait que seuls deux statères aux types de Philippe II avaient été découverts en France, leur nombre n'a cessé d'évoluer : J. Sills en comptabilise 17 en 2003 (France, Angleterre, Belgique et Allemagne), mais 14 exemplaires seulement sont répertoriés par S. Scheers en $2004^{5}$.

La documentation existante sur ces monnaies révèle parfois des incohérences sinon des lacunes et, dans le cadre de cette étude, il paraissait opportun de reprendre et de rassembler les informations disponibles sur chacun de ces exemplaires (figures 15-16).

a. Les exemplaires issus de l'atelier de Pella

- Groupe II, au canthare : vers 340-328 ou 336-328 av. J.-C. ${ }^{7}$

Monaco
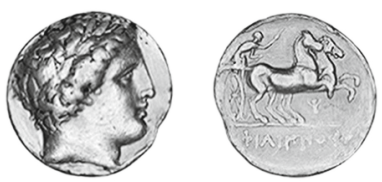

Figure 1 - Statère conservé au Musée des Timbres et Monnaies à Monaco.

À la fin du XIXe siècle, l'intense activité immobilière qui anime Monaco est à l'origine de nombreuses découvertes archéologiques parmi lesquelles figure un statère de Philippe II de Macédoine. Mis au jour en 1877 lors de la reconstruction de la chapelle de Sainte Dévote située à la Condamine, cet exemplaire est d'abord déposé au Musée d'anthropologie préhistorique de Monaco avant d'être exposé, à partir de 2008, au nouveau Musée des Timbres et Monnaies ${ }^{8}$.

4. Par exemple SCHEERS 1980 et 2004 ; FISCHER 1991 ; SILLS 2003.

5. BLANCHET 1905, p. 210-211, n. 1 et 2 ; SILlS 2003, p. 6-8 ; SCHEERS 2004, p. 7-8, n. 2 et p. 24-25.

6. Les groupes, dates et attributions sont d'après LE RIDER 1977 pour les ateliers macédoniens de Pella et Amphipolis et d'après Thompson 1991 pour les ateliers de Lampsaque et d'Abydos.

7. Nous avons eu connaissance tardivement d'un statère conservé dans le médaillier du musée de l'Avallonnais (Avallon, Yonne) qui pourrait avoir été découvert dans le département de l'Yonne. Cette monnaie, actuellement non recensée, sera présentée à la SFN en janvier 2017.

8. Le Journal de Monaco, Journal Officiel de la Principauté, signale cette trouvaille dans son édition du 18 décembre 1877, elle est également mentionnée dans REYMOND, DUGAND 1970, p. 52-53. Cette monnaie a fait l'objet d'une étude menée en collaboration avec Christian 
Les coins de droit et de revers de ce statère sont répertoriés par G. Le Rider qui situe la frappe de cette série vers 340-328 ou 336-328 av. J.-C. 9 .

Cette monnaie semble apparaître pour la première fois dans les inventaires des originaux macédoniens découverts en Europe en 1982 dans l'article de J.-Cl. Richard consacré au médaillier de Carcassonne ${ }^{10}$. En 1983, M. Sireix et alii précisent que cette monnaie serait à examiner ; elle est citée en 1989 et en 1995 par R. Boudet, puis par J. Sills en $2003^{11}$. Elle n'est cependant jamais illustrée, seul son poids - faible - de 8,21 g est indiqué.

L'opportunité, grâce à l'obligeance de Christian Charlet et des autorités monégasques, de pouvoir étudier et analyser à l'IRAMAT-CEB le statère de Monaco a permis d'apporter un éclairage nouveau sur cet exemplaire.

Les observations effectuées à la loupe binoculaire et au microscope électronique à balayage ainsi que les analyses réalisées par LA-ICP-MS nous ont amenés à la conclusion suivante : l'exemplaire exposé à Monaco est un faux, très certainement monté en bijoux dans des circonstances indéterminées. Cette conclusion soulève, en premier lieu, la question de la découverte du statère. La mise au jour en 1877 de plusieurs autres monnaies antiques ainsi que la publication de la trouvaille dans le Journal de Monaco nous conduit à admettre qu'un statère macédonien a effectivement été découvert à la Condamine. Cela signifie donc que la monnaie originale a été, à un moment, remplacée par la contrefaçon.

À partir des informations mentionnées dans l'ouvrage de G. Le Rider, il a été possible de retrouver la monnaie qui a vraisemblablement servi de modèle au faux monégasque. Il s'agit d'un exemplaire issu de la collection Arthur Löbbecke (1850-1932), dont une partie fut mise en vente par la maison Hess le 6 janvier 1926 , lot no 166 (8,60 g, 18,5 mm).

S'il est probable que l'exemplaire vendu en 1926 soit le statère découvert en 1877 à Monaco, il n'est pas possible, en l'état actuel des connaissances, de déterminer les circonstances exactes de la substitution, aucune archive relative à l'histoire de cette monnaie n'étant conservée à Monaco ${ }^{12}$.

Quoiqu'il en soit, cet épisode ne remet pas en cause l'authenticité et donc l'intérêt de la découverte ${ }^{13}$.

Charlet et Maryse Blet-Lemarquand. Les résultats, que nous reprenons brièvement ici, ont été présentés à la Société française de numismatique lors de la séance de mai 2015 (Nieto-PelLETIER et alii 2015).

9. LE RIDER 1977, p. 146, no 166 : groupe «Pella II.1», D45-R119.

10. RICHARD et alii 1982, p. 38.

11. SIREIX et alii 1983, p. 39, n. 27 ; BOUDET 1989, p. 54 ; BOUDET et alii 1995, p. 1023 ; SILLS 2003, p. 7.

12. Recherches menées par Christian Charlet au Musée des Timbres et Monnaies de Monaco.

13. Cet exemplaire ne figure pas dans l'inventaire de S. Scheers de 2004 (SCHEERS 2004, p. 24). Il est vrai que son lieu de découverte à Monaco et donc en Ligurie le situe peut-être quelque peu à la marge de notre zone d'étude. 
- Groupe III, au canthare : vers 323/322-315 av. J.-C.

Avène Montpellier (Hérault)
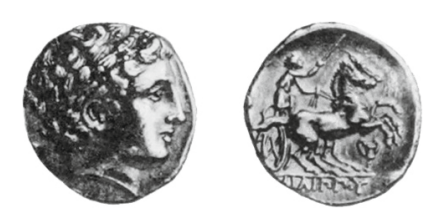

Figure 2 - Statère découvert à Avène conservé dans le médaillier de la Société archéologique de Montpellier (no 1083) (Extrait de Bonnet 1896, pl. I).

Découvert dans les environs d'Avène (Hérault) en 1843, ce statère est aujourd'hui conservé dans le médaillier de la société archéologique de Montpellier ${ }^{14}$. Cet exemplaire, qui semble mentionné pour la première fois par E. Bonnet en 1896, est l'un des deux statères, avec celui découvert à SaintSilvain-Montaigut (Creuse), qu'A. Blanchet considère comme un original et qu'il attribuait alors à l'atelier de Téos ${ }^{15}$. Le statère est référencé dans l'ouvrage de G. Le Rider ${ }^{16}$.

Carcassonne (Aude)
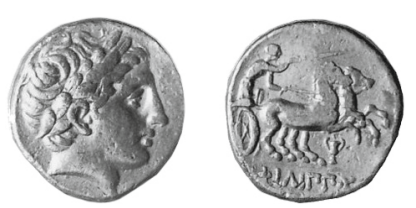

Figure 3 - Statère découvert dans les environs de Carcassonne et conservé au musée de Carcassonne (Extrait de RICHARD et alii 1982, p. 44, no 1).

En 1868 , au $35^{\mathrm{e}}$ congrès archéologique de France, M. de Bonnefoy signale la découverte de deux statères d'or de Philippe lors « des travaux récemment exécutés près de Carcassonne ${ }^{17}$. Aucune description ni illustration n'est

14. BONNET 1896, p. 57-58, no 1083, pl. I, 1083.

15. BLANCHET 1905, p. 210-211, pl. I, 1.

16. LE RIDER 1977, p. 176, no 443b, D201-R330, pl. 67, no 443.

17. BONNEFOY 1869, p. 142 ; RICHARD et alii 1982, p. 38. 
fournie mais l'Album Barthélemy, non daté, reproduit un frottis du statère au canthare conservé au musée de Carcassonne avec la mention «bon or trouvée à Carcassonne $»^{18}$. Absent par la suite des inventaires rassemblant les statères macédoniens découverts en France, il réapparaît en 1974 dans une note de J.-B. Colbert de Beaulieu avant d'être étudié par J.-Cl. Richard en 1982 pour la publication du Catalogue des monnaies du musée de Carcassonne ${ }^{19}$. À l'exception de R. Boudet qui n'exclut pas qu'il puisse s'agir d'une imitation ${ }^{20}$, cet exemplaire a été considéré dès 1974 comme un original macédonien. Les coins de droit et de revers sont répertoriés dans l'ouvrage de G. Le Rider ${ }^{21}$.

- Groupe III, au foudre : vers 323/322-315 av. J.-C.

Saint-Aubin-de-Lanquais (Dordogne)
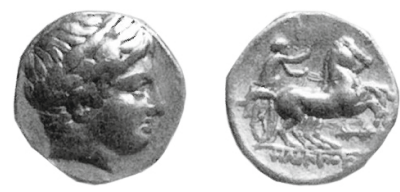

Figure 4 - Statère découvert à Saint-Aubin-de-Lanquais (Extrait de BOUDET et alii 1995, p. 1023).

Ce statère a été découvert fortuitement à la fin de l'année 1993. Déclaré au Service régional de l'archéologie d'Aquitaine, il fait l'objet d'une notice dans le Bilan scientifique régional de 1994, puis est publié en 1995 dans le BSFN. La photographie qui accompagne ce court article permet d'identifier les coins de droit et de revers ${ }^{22}$. Au moins jusqu'en 1995 il était conservé dans une collection privée de Bergerac ${ }^{23}$.

18. BARTHÉLEMY s.d., pl. 55 ; RICHARD et alii 1982, p. 38.

19. COlBERT DE BEAULIEU 1973, p. 201, n. 314 ; RiCHARD et alii 1982, p. 38.

20. En raison de la stylisation de la chevelure et parce que le droit a tout d'abord été rapproché, par J.-Cl. Richard (RICHARD et alii 1982, p. 38), du coin D234 qui n'était pas associé à un revers au canthare (BOUDET 1989, p. 44-45).

21. LE RIDER 1977, pl. 71, no 573 (D238 = D234' ? / R417), Pella IIIB. J. Sills identifie quant à lui les coins D238 = D234' ?/R416, pl. 71, no 572, Pella IIIB (SILLS 2003, p. 6, no 1) et S. Scheers propose, de façon incertaine, de rapprocher cet exemplaire des coins D195/R344 ou R345, pl. 68 nos 468-469, Pella IIIA (SCHEERS 2004, p. 24).

22. LE RIDER 1977, pl. 66, no 408, D181/R301.

23. BOUDET et alii 1994, p. 132 et 1995, p. 1023. 
b. Les exemplaires issus de l'atelier d'Amphipolis

- Groupe II, au croissant : vers 340-328 ou 336-328

Landerrouat (Gironde)

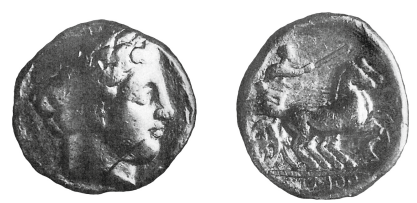

Figure 5 - Statère découvert à Landerrouat

(Extrait de BOUDET 1987, pl. 80).

En 1970, au cours d'une prospection de surface sur un site néolithique au lieu-dit La Verrière sur la commune de Landerrouat, P. Blanchard découvre une monnaie d'or identifiée par J. Yvon comme un statère de Philippe II de Macédoine ${ }^{24}$. Aujourd'hui disparu, ce statère de poids élevé selon R. Boudet (8,64 g) est connu par une photographie publiée en 1987 puis en $1989^{25}$.

Dans la publication de 1987, R. Boudet émet des doutes quant à l'authenticité de cet exemplaire en raison de son poids, trop important selon lui, et de son style, plus particulièrement de l'absence de détails et de l'empâtement des traits du visage. Il suggère alors que la monnaie de Landerrouat a été coulée ${ }^{26}$. Ses réserves sont moins prononcées en 1989 et il n'exclut pas de la compter parmi les originaux découverts en Europe ${ }^{27}$. Cette monnaie est considérée comme un statère macédonien dès 1978 par S. Scheers, puis par J. Sills en 2003. Pour B. Fischer en revanche, reprenant les arguments développés par R. Boudet, cet exemplaire doit être éliminé de la liste des originaux ${ }^{28}$.

La monnaie est usée et les photographies disponibles sont difficilement lisibles dans le détail. Néanmoins, il est possible de proposer une identification des coins de droit et de revers à partir de ceux répertoriés par G. Le Rider ${ }^{29}$.

24. BOUDET 1987, p. 91 ; YVON 1976, p. 330.

25. BOUDET 1987, pl. 80 ; BOUDET 1989, p. 30 et fig. 2 no 11. S. Scheers signale dans un premier temps un statère de 8,446 g découvert au cours d'un labour à Landerrouat au lieu-dit «Talon » à partir d'informations reçues de M. Mainjonet (SCHEERS 1980, p. 42, n. 4), puis, en 2004, reprend le poids indiqué par R. Boudet (8,64 g) (SCHEERS 2004, p. 24). En tenant compte de l'usure de la monnaie J. Sills suppose que le poids de $8,446 \mathrm{~g}$ semble le plus cohérent (SILLS 2003, p. 74).

26. BOUDET 1987, p. 91.

27. BOUDET 1989, p. 30-31.

28. FISCHER 1991, p. 154.

29. LE RIDER 1977, pl. 76 no 90 D41/no 93 R71 ? (SILLS 2003, p. 6). 
- Groupe III, au trident : vers 323/322-315 av. J.-C.

Feusines (Indre)
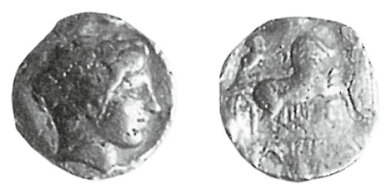

Figure 6 - Statère découvert à Feusines conservé au musée de Châteauroux (no 1938) (Extrait de SiLLS 2003, pl. 1, no 1).

Nous n'avons que peu d'information concernant les circonstances de la découverte de ce statère. Acquis par le musée Bertrand de Châteauroux en 1883 auprès de M. Chasset horloger à La Châtre, cet exemplaire aurait, d'après la documentation conservée au musée ${ }^{30}$, été trouvé à Feusines (Indre). B. Fischer, dans le catalogue des monnaies du musée Bertrand de Châteauroux, et les auteurs de la Carte archéologique de la Gaule consacrée à l'Indre, considèrent qu'il s'agit d'une imitation ${ }^{31}$. Il est reconnu comme un original par J. Hiernard ainsi que par O. Buchsenschutz et alii en 1982. J. Sills en 2003 propose de le rapprocher des exemplaires inventoriés sous les numéros 197 à 203 (pl. 80) dans l'ouvrage de G. Le Rider; nous le suivons sur ce point ${ }^{32}$. L'usure importante de la pièce rend difficile une identification plus précise.

\section{Buzançais (Indre)}
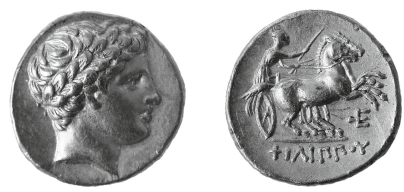

Figure 7 - Statère découvert à Buzançais conservé au musée de Châteauroux (no 1937).

30. Nous remercions $\mathrm{M}^{\mathrm{me}}$ Michèle Naturel, directrice des Musées de Châteauroux ainsi que M. Vincent Escudero, assistant de conservation du patrimoine des Musées de Châteauroux, pour nous avoir communiqué les informations relatives aux statères de Feusines et de Buzançais.

31. FISCHER 1988, p. 39, no 21 ; PROVOST et alii 1992, notice 204.

32. HieRNARD 1982, p. 570, 34 bis ; BuCHSENSCHUTZ et alii, 1982, p. 91, no 203 ; Sills 2003, p. 7, no 9 ; LE RIDER 1977, pl. 80, nos 197-203. 
En 1873, M. Barboux, conservateur du musée de Châteauroux, présente un statère de Philippe II de Macédoine acquis par le musée en 1865 et découvert sur le bord d'un fossé par un agriculteur à la Perrière sur la commune de Buzançais $^{33}$. Faute d'une documentation suffisante et parce qu'il ne l'a pas examiné, A. Blanchet l'exclut de sa liste des originaux découverts en France ${ }^{34}$. Cet exemplaire est par la suite signalé en 1971 par G. Coulon, qui hésite à le considérer comme un statère macédonien, puis par J. Dupoux en 1976 qui en propose une étude détaillée et qui l'identifie avec certitude comme un statère de Philippe $\mathrm{II}^{35}$. Il est par la suite régulièrement cité dans les inventaires des originaux découverts en France (annexe 1). Les coins de droit et de revers sont référencés par G. Le Rider ${ }^{36}$.

c. Les exemplaires attribués à l'atelier de «Lampsaque $»^{37}$

- Buste (tête d'Hélios) et monogramme АП :323/322-322/321 ${ }^{38}$

Méry-sur-Cher (Cher) et Berry (?)
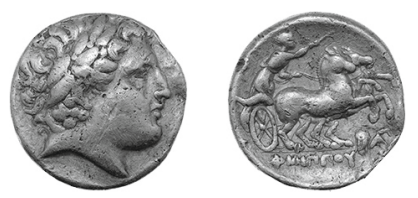

Figure 8 - Statère découvert à Méry-sur-Cher ou dans le Berry, conservé au musée de Bourges (no 898.3.1).

Quelques incertitudes et confusions entourent le lieu précis de cette découverte. Le musée de Bourges conserve un statère de Philippe II de 8,35 g (figure 8) dont le lieu de découverte indiqué est Méry-sur-Cher. En 1891-1892, D. Mater donne la description suivante d'un statère trouvé sur cette même commune : «D. - Tête laurée d'Apollon à droite. - R/. Bige allant à droite, l'aurige tient un fouet; au-dessous de l'attelage un symbole indéterminé, peut-être une main, et le monogramme arverne AP ; à l'exergue ФI IIППOY ${ }^{39}$. »

33. BARBOUX 1874, p. 556.

34. BLANCHET 1905, p. 210, n. 1.

35. Coulon 1971, p. 40 ; DuPOUX 1976, p. 241-245.

36. LE RIDER 1977, pl. 79, D85 (n॰ 180)/R142 (n॰ 182) ; SILLS 2003, p. 7, n॰ 8.

37. Pour la question de la localisation des ateliers de «Lampsaque » et d' «Abydos», voir infra partie 2.

38. THOMPSON 1991, série VI.

39. MATER 1891-1892, p. 387. 
Le poids indiqué est de $8,06 \mathrm{~g}$ et la monnaie est illustrée. Les auteurs considèrent cet exemplaire comme une imitation précoce. Aucun lieu de conservation n'est mentionné alors que les trois précédents exemplaires décrits dans ce même article par l'auteur sont conservés au musée de Bourges.

Dans le Bulletin paru en 1899, D. Mater signale qu'un nouvel exemplaire a été découvert dans le Berry, la description est la suivante : "Tête laurée d'Apollon à droite. - R/ Bige au galop à droite; l'aurige tient les rênes de la main gauche et un fouet de sa main droite; devant les chevaux le monogramme $\mathrm{A} \Pi$ (liés), qui est celui des Arvernes, et un symbole difficile à déterminer, buste radié dégénéré ou gerbe d'épi ; à l'exergue $\$ \mathrm{I} \mid \Lambda \mathrm{I} \Pi \Pi \mathrm{OY}^{40}$.» Cette monnaie pèse $8,35 \mathrm{~g}$ et un dessin en est proposé. Il est précisé que l'exemplaire est conservé au musée de Bourges. En s'appuyant sur le poids élevé et la «pureté du style», D. Mater place ce statère au début des imitations ${ }^{41}$. L'auteur rappelle qu'un premier exemplaire a été découvert «il y a quelques années, appartenant également aux premières imitations, avec le monogramme Arverne, mais toutefois d'un poids légèrement inférieur $(8 \mathrm{gr} .06)^{42}$.» On est alors tenté de faire le lien avec le statère de Méry-sur-Cher. Les dessins des deux monnaies présentés à huit ans d'intervalle sont très proches sans toutefois être identiques (figure 9).

L'étude de D. Nash puis celle de S. Scheers témoignent également de cette confusion. Si S. Scheers opte pour une découverte probable du statère conservé au musée de Bourges $(8,35 \mathrm{~g})$ à Méry-sur-Cher, D. Nash hésite entre les deux lieux de découverte ${ }^{43}$. Il n'est donc pas exclu qu'un second statère aux types de Philippe ait été trouvé dans cette région, le poids de 8,06 g constituant toutefois une sérieuse réserve.

40. MATER 1899 , p. 227.

41. MATER 1899, p. 227-228.

42. MATER 1899, p. 228.

43. D. Nash propose par ailleurs, à partir des dessins du XIXe siècle, que l'exemplaire découvert à Méry-sur-Cher (8,06 g) soit la même monnaie que BnF Fonds général 3620 (NASH 1978, p. 78, pl. 7). Le statère BnF FG 3620 présente des marques d'usure importante et était initialement classé avec les monnaies gauloises, comme imitation, avant d'intégrer le médaillier grec (MURET et CHABOUILLET 1889, 3620). Du point de vue du type une certaine parenté se dégage effectivement entre ces deux exemplaires, autant que l'on puisse en juger à partir du dessin représenté dans l'article de D. Mater. Les poids en revanche sont éloignés, 8,06 g (Méry-sur-Cher) et 8,15 g (BnF FG 3620). En outre, BnF FG 3620 faisait partie de la collection Saulcy acquise par le Cabinet des médailles en 1872. Or, D. Mater signale l'exemplaire de Méry-sur-Cher dans le volume des MSAC paru en 1892 en précisant qu'il s'agit de monnaies « venues à ma connaissance personnelle dans le cours des années précédentes » (MATER 1891-1892, p. 385). Aucune information n'est donnée quant à la date précise de la découverte ou du lieu de conservation. En l'état actuel des connaissances, il nous paraît difficile de confirmer le rapprochement entre ces deux exemplaires. 

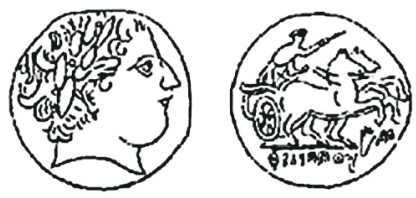

Exemplaire trouvé à Méry-sur-Cher ; 8,06 g

(Extrait de Mater 1891-1892, pl. I, no 4)
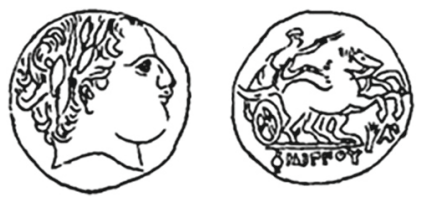

Exemplaire trouvé en Berry ; $8,35 \mathrm{~g}$

(Extrait de Mater 1899, pl. I, no 1)
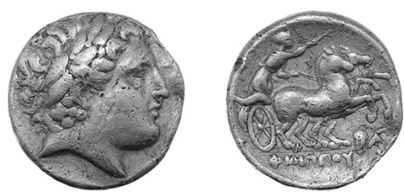

Exemplaire découvert à Méry-sur-Cher ou dans le Berry ; 8,35 g conservé au musée de Bourges (no 898.3.1)

Figure 9 - Exemplaires découverts à Méry-sur-Cher et dans le Berry.

Saint-Silvain-Montaigut (Creuse)
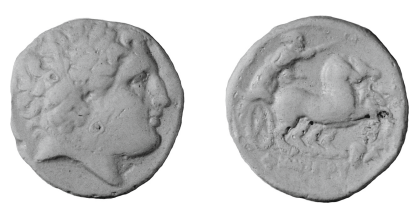

Figure 10 - Moulage issu de la documentation d'A. Blanchet (département des Monnaies, médailles et antiques).

G. Monnet, conservateur du musée de Guéret, semble le premier à faire connaître en 1890 le statère découvert à Saint-Silvain-Montaigut qu'il considère alors comme une imitation. La description est sommaire, le poids n'est pas indiqué et la monnaie n'est pas illustrée ${ }^{44}$. Entré dans les collections du musée de Guéret entre 1887 et 1890, le statère a disparu en $1944^{45}$. Le rapport

44. «Or. Philippe. (Imitation des Statères de Macédoine). Tête d'Apollon à droite. R/ Auriga conduisant un bige à droite. Treskel et tête de face sous les chevaux. Exe. PHILIPPOU (trouvée à Saint-Silvain-Montaigut)» (MoNNET 1887-1890, p. 395).

45. D'après les informations aimablement fournies par Olivier Brunet, chargé de la documentation, Service du Musée, ce statère est mentionné sur une liste de monnaies du musée de Guéret disparues le 5 juin 1944. 
établi par le conservateur de l'époque indique que le poids de ce philippe est de $8,60 \mathrm{~g}$. A. Blanchet a pu néanmoins examiner une empreinte de cet exemplaire. Il signale une pièce usée qui « porte, sous les chevaux, la tête de face du soleil et le monogramme $A \Pi$ » et dont le style et le poids élevé permettent de conclure en faveur d'un original. Il s'agit de l'un des deux seuls exemplaires, avec celui découvert à Avène, qu'A. Blanchet considère comme un statère aux types de Philippe II (annexe 1) ${ }^{46}$. Le musée de Guéret ne dispose actuellement d'aucun moulage, empreinte ou dessin ${ }^{47}$. Un moulage de cet exemplaire est en revanche conservé au département des Monnaies, médailles et antiques de la BnF dans une boîte qui porte la mention « 8 empreintes cire monnaies gauloises. Musée de Guéret». Conforme à la description fournie par A. Blanchet, cette reproduction a très probablement été réalisée à partir de l'empreinte consultée par ce dernier.

Milton (Kent, Grande-Bretagne)

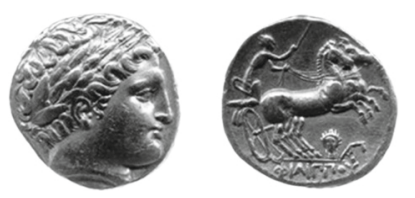

Figure 11 - Statère découvert à Milton et conservé au British Museum (BM 1919, 0213.2).

Unique statère aux types de Philippe II mis au jour en Angleterre, cet exemplaire $(8,49 \mathrm{~g})$ a été découvert avant 1890 . Passé en vente chez Sotheby en 1895 (collection de D.F. Kennard), il est finalement acquis par Sir J. Evans qui en fait don au British Museum en $1919^{48}$.

Les informations relatives au contexte de découverte sont contradictoires : dans une tombe à Milton près de Sittingbourne ${ }^{49}$ ou "in a brickfield» peut-être avec une imitation du statère de Philippe II, hémistatère dit «à la tête barbue ${ }^{50} »$.

46. BLANCHET 1905, p. 211 et n. 2.

47. Nous remercions Patrick Léger, président de la Société des sciences naturelles, archéologiques et historiques de la Creuse, pour sa grande disponibilité et l'aide qu'il nous a apportée.

48. BM 1919, 0213.2; SILLS 1999, p. 4.

49. Catalogue de vente Sotheby's, 28/1/1895, lot 1 ; Sills 2003, p. 8.

50. Voir Sills 1999, p. 4 pour le contexte incertain de cet exemplaire. 


\section{d. Les exemplaires attribués à l'atelier d'«Abydos»}

- Étoile, mu et omicron et pedum sous la légende : 323/322-320/31951

Hesbaye (Belgique)
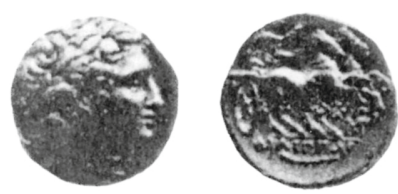

Figure 12 - Statère découvert en Hesbaye

(Extrait de BAR 1991, pl. no 32-0.01).

Ce statère de 8,60 g est mentionné en 1907 dans la Chronique archéologique du Pays de Liège et aussitôt identifié comme un statère de Philippe II. Découvert en Hesbaye vers 1905, le lieu précis n'est pas connu, il faisait partie, en 1907, de la collection du Dr. Simonis ${ }^{52}$. Ce n'est qu'à partir de 2003, qu'il apparaît dans les inventaires des originaux découverts en Europe avec l'importante étude de J. Sills ${ }^{53}$. Le coin de droit, autant que l'on puisse en juger à partir de la photographie, est référencé par M. Thompson ${ }^{54}$.

\section{e. Les exemplaires incertains}

Dans le cadre de cette étude, nous ne revenons pas sur les exemplaires un temps considérés comme incertains, voire comme originaux, mais qui ont été exclus depuis de la liste et dont le style ne fait pas de doute quant à l'imitation $^{55}$. Plus problématique sont les exemplaires suivants, soit parce que les coins, a priori de style gréco-macédonien, ne sont pas répertoriés dans l'ouvrage de G. Le Rider, soit parce que les données actuellement disponibles sont trop lacunaires.

51. THOMPSON 1991, série VII.

52. S. R. 1907, p. 10 ; BAR 1991, p. 63-64 et pl. no 32 (30.01).

53. SILLS 2003, p. 8 no 11.

54. THOMPSON 1991, pl. 23, 103 b.

55. Pour le statère au trident dit de Pons (Charente-Maritime) plus particulièrement, qui est l'exemplaire qui a peut-être suscité le plus d'échanges, voir BOUDET 1987, p. 108. R. Boudet est certainement l'un des premiers à donner une liste d'éléments typologiques précis permettant de considérer le statère de Pons, et de fait ceux de la même série, comme une imitation (même si tous les arguments avancés ne paraissent pas déterminants et qu'il conviendrait d'en ajouter; étude S. Nieto-Pelletier en cours). 
- L'exemplaire «À la barre brisée » découvert à Carcassonne (Aude)

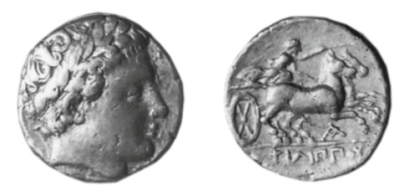

Figure 13 - Statère découvert dans les environs de Carcassonne et conservé au musée de Carcassonne (Extrait de RICHARD et alii 1982, p. 44, no 2).

Les auteurs du catalogue des monnaies d'or du musée de Carcassonne signalent un exemplaire pouvant correspondre, mais de façon incertaine, à un statère de Philippe II. G. Le Rider, qui a collaboré à la réalisation de la notice, précise qu'il s'agit d'une série non recensée dans son catalogue et suggère qu'il pourrait s'agir d'une «frappe tardive de Macédoine plutôt que d'Asie mineure. S'il s'agissait d'une imitation, elle serait d'excellente qualité et serait donc une des premières de la série ${ }^{56}$.»

Entre les jambes des chevaux figure un $\mathrm{A}$ avec la barre centrale brisée ; à l'exergue la légende grecque de $17,5 \mathrm{~mm}$ et les coins sont orientés à $11 \mathrm{~h}$. Cet exemplaire est problématique : la série n'est pas référencée dans les ouvrages de G. Le Rider et $\mathrm{M}$. Thompson, aucun équivalent n'a été recensé dans les catalogues de vente consultés à partir de CoinArchives ${ }^{57}$ et elle ne semble pas trouver de correspondance dans les imitations gauloises.

Avec toutes les précautions qui s'imposent, le style correspondrait à celui d'un original. Mais la position de l'aurige et le $\boldsymbol{\phi}$, qui semble davantage s'apparenter à une croix, pourraient aussi aller dans le sens d'une imitation. S'il s'agit effectivement d'une imitation, soit cet exemplaire copie un statère d'une série jusqu'à présent non recensée, soit il s'agit d'une forme de réinterprétation du type, pourquoi pas de la série au buste et monogramme AП de l'atelier de Lampsaque ${ }^{58}$ ?

56. RICHARD et alii 1982, p. 38 et n. 8 .

57. Consulté le 19 août 2015.

58. S. Scheers signale également un tétradrachme aux types d'Alexandre avec deux monogrammes dont un A à la barre brisée (SCHEERS 2004 ; PRICE 1991, no 870). M. J. Price place ce tétradrachme en «uncertain Greece or Macedonia » et le date de ca 325-ca 310. Si un rapprochement avec ce monogramme à la barre brisé, somme toute assez courant, est possible, aucun lien ne peut être affirmé entre les deux pièces. 
- L'exemplaire découvert à Ceffia (Jura)

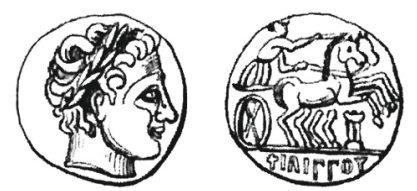

Figure 14 - Statère découvert à Ceffia

(Extrait de LAMBERT 1864, pl. III).

La découverte du statère de Ceffia est mentionnée dans le Journal des Débats du 4 février 1863 (lui-même reprenant le Journal del'Ain) et rapportée par J. de Witte : "Cette médaille est fort ancienne ; elle a pour le moins deux mille ans. Elle est large d'environ $18 \mathrm{~mm}$, pèse $25 \mathrm{fr}$. d'or [soit $8,06 \mathrm{~g}$ ] et est d'une conservation parfaite. Elle présente, d'un côté, une tête couronnée de laurier, d'un beau relief, de l'autre, un char attelé de deux chevaux lancés au galop. [...]. Dans le second plan, au revers, on remarque une sorte de lampe à trépied, et tout à fait au-dessous du char, le mot grec Philippoy (de Philippe). [...]. Elle est grecque assurément $[. . .]^{59}$.» J. de Witte, qui doute de l'exactitude des informations relatées dans le Journal des Débats, en conclut qu'il s'agit d'une imitation gauloise des statères d'or de Philippe II $^{60}$.

Cette monnaie n'est connue que par un dessin de E. Lambert au-dessus duquel ce dernier écrit «Présumé de coin gre ${ }^{61}$ » (figure 14). L'exemplaire est par la suite signalé dans le Catalogue des monnaies du Jura et considéré comme une imitation ${ }^{62}$. Seuls A. Blanchet puis S. Scheers considèrent, de façon incertaine, que la monnaie trouvée à Ceffia pourrait être un original ${ }^{63}$.

- Le cas particulier des dépôts dits de «Gironde» et de Gamshurst

Deux trésors réputés avoir contenu à la fois des statères aux types de Philippe II et des imitations gauloises sont régulièrement cités dans les études consacrées aux premiers monnayages d'or celtes. Si l'importance de ce type de dépôt pour comprendre la genèse du fait monétaire dans le monde celte est indéniable, il convient néanmoins de revenir sur leur faciès «entaché » de multiples zones d'ombre.

\footnotetext{
59. WITTE 1863 , p. 76-77.

60. WITTE 1863, p. 77.

61. LAMBERT 1864, pl. III, no 29 et p. 75, no 29.

62. Colbert de Beaulieu, Dayet 1962, p. 37 et p. 12 , no 6 .

63. Blanchet 1905, p. 210, n. 1 ; SCHEERS 1980, p. 42 ; SCHEERS 2004, p. 24.
} 


\section{Le dépôt monétaire dit de « Gironde» ou de «Bordeaux»}

Mentionné pour la première fois par S. Scheers en 1999, le dépôt dit de Gironde est un trésor reconstitué à partir de plusieurs exemplaires passés en vente à l'étranger (notamment ventes Sotheby's 1993 et Stack's 1996). Il a été découvert peut-être au début des années 1990, peut-être aux environs de Bordeaux ${ }^{64}$ ou dans le nord de la Gironde ${ }^{65}$. D'après les informations actuellement disponibles, le dépôt aurait contenu 4 statères aux types de Philippe de l'atelier de Pella II ${ }^{66}$ ainsi que plusieurs imitations au trident de la série Pons/ St-Eanne ${ }^{67}$. J. Gorphe a rassemblé 36 exemplaires qu'il suppose provenir d'un même ensemble en raison de «l'apparence superficielle un peu mat avec de petites incrustations noires ${ }^{68}$; aucun statère original aux types de Philippe II de Macédoine n'y figure.

S'il est effectivement très probable que les exemplaires réunis par J. Gorphe constituent tout ou partie d'un dépôt, son faciès reste très incertain. L'absence d'information manifeste quant à sa découverte, dont le caractère légal semble loin d'être assuré, nous a amenés à prendre contact avec le Service régional de l'archéologie d'Aquitaine ${ }^{69}$. Il ressort des recherches que nous avons menées que le dossier est confus et complexe. Force est de constater que le lieu de découverte comme la composition précise du dépôt ne reposent, actuellement, sur aucune base tangible.

\section{Le dépôt monétaire de Gamshurst}

Un ou deux statères originaux aux types de Philippe au canthare issus de l'atelier de Pella II et 5 imitations (un exemplaire des séries Xi, Stollhofen, Gamshurst et de façon incertaine des séries de Soy et de Brackenheim) auraient fait partie de ce dépôt. Découvert en plusieurs fois au cours du XIXe siècle ${ }^{70}$,

64. SCHEERS 1999, p. 51 ; SCHEERS 2004, p. 24-25. Nous remercions sincèrement S. Scheers qui nous a communiqué les informations dont elle disposait sur ce trésor.

65. GORPHE 2009, p. 134.

66. D'après les données fournies par S. Scheers (SCHEERS 2004, p. 24) : 2 exemplaires au canthare (LE RIDER 1977, pl. 57, no 151 et 59, no 190), 1 exemplaire à la victoire (LE RIDER 1977, pl. 64, no 356) et 1 exemplaire au trident (LE RIDER 1977, pl. 63, no 332). Voir également SiLLs 2003, p. 6.

67. SCHEERS 1999 , p. $51 ; 2004$, p. 25.

68. GoRPHE 2009, p. 134 et p. 44-49. En 2010, J. Gorphe a fait don de 16 exemplaires au département des Monnaies, médailles et antiques de la BnF.

69. Nous exprimons nos sincères remerciements à D. Barraud actuellement Inspecteur général des patrimoines, et conservateur régional de l'archéologie au SRA Aquitaine dans les années 1990, qui nous a fait part des informations dont il disposait. Aujourd'hui, le SRA Aquitaine ne semble détenir aucun renseignement sur le dépôt dit de Gironde (information P. Regaldo, SRA Aquitaine que nous remercions).

70. SILLS 2003, p. 360, no 23 ; FORRER 1925, p. 97-98. La succession des découvertes semble à mettre en relation avec les travaux agricoles. 
le trésor a par la suite été dispersé. R. Forrer signale notamment 2 pièces «sans indice de barbarisation entrées dans les collections de M. Gimbel à BadenBaden ${ }^{71}$. Si J. Sills ne doute pas qu'au moins un exemplaire soit un original macédonien, pour S. Scheers, en revanche, les seuls statères identifiables de ce dépôt sont des imitations ${ }^{72}$; nous aurions tendance à la suivre sur ce point autant que l'on puisse en juger à partir des illustrations disponibles ${ }^{73}$.

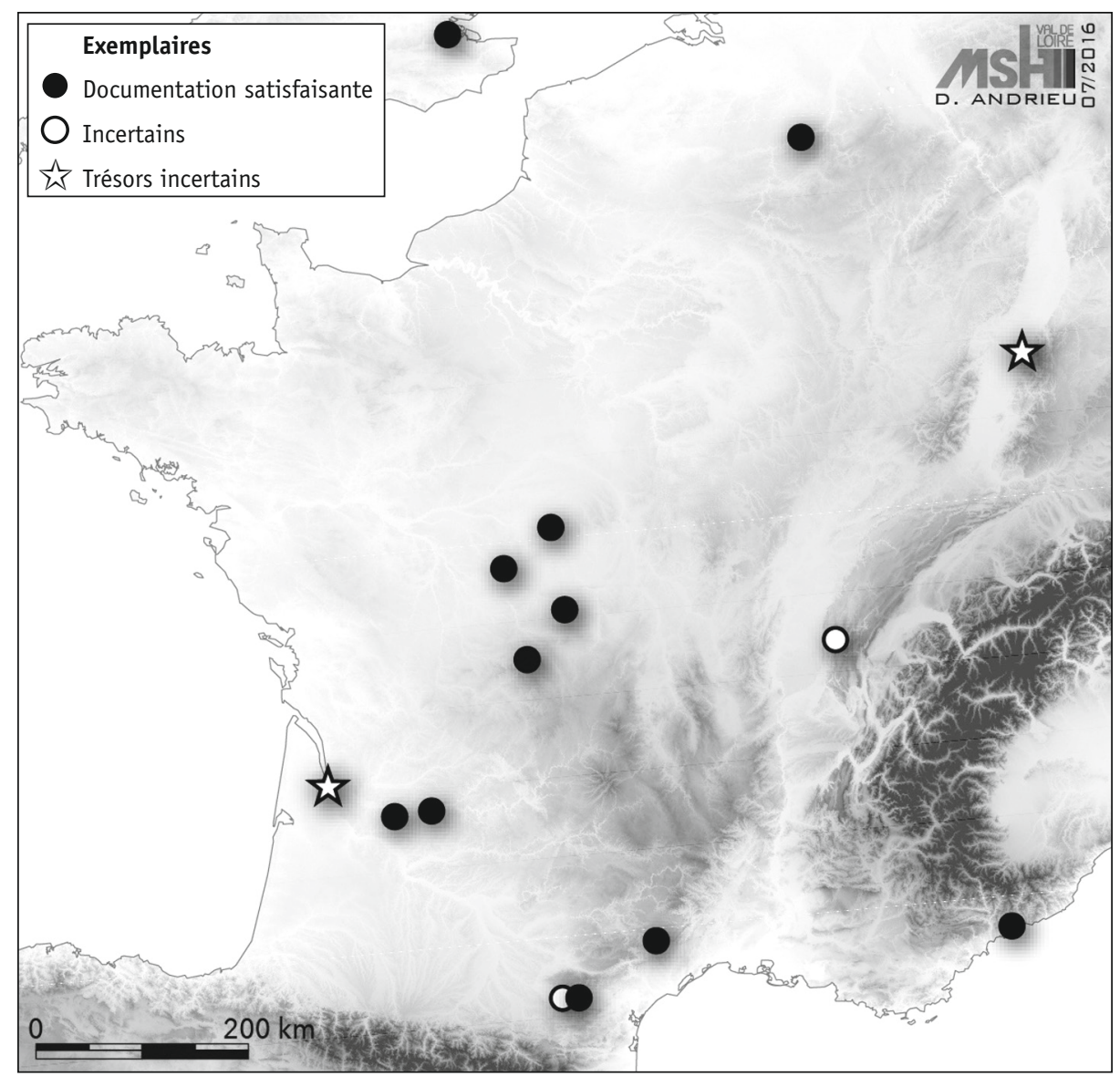

Figure 15 - Répartition des statères aux types de Philippe II en Europe (Sources : Shuttle Radar Topography Mission Global NASA/USGS).

71. FORRER 1925, p. 98, n. 2-3.

72. SILLS 2003, p. 8, no 12 et p. 360 , no 23.

73. SCHEers 2004, p. 7, n. 2 ; HARTMANN, NAU 1976, p. 27, no 18. 


\begin{tabular}{|c|c|c|c|c|c|c|c|c|c|c|c|c|c|c|c|c|c|c|c|c|c|}
\hline \multirow{3}{*}{ 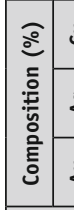 } & \multirow{3}{*}{ 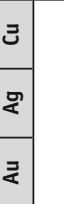 } & \multirow{3}{*}{ 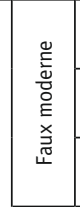 } & 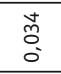 & ' & & & \begin{tabular}{|l|}
\multirow{3}{*}{} \\
0 \\
0
\end{tabular} & \begin{tabular}{|l|}
\multirow{O}{*}{} \\
0 \\
0
\end{tabular} & & ' & ' & & . & ' & ' & & $\stackrel{\simeq}{\approx}$ & ' & ' & ' & ' \\
\hline & & & $\underset{0}{\approx}$ & & & & $\mid \begin{array}{c}m \\
\tilde{o} \\
0\end{array}$ & $\begin{array}{l}\hat{o} \\
0 \\
0\end{array}$ & & & ' & & . & . & ' & & $\underset{\substack{0 \\
0}}{0}$ & . & ' & . & , \\
\hline & & & $\begin{array}{l}\circ \\
\text { ஃे }\end{array}$ & & & & 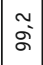 & $\begin{array}{l}\infty \\
\alpha \\
\sigma\end{array}$ & & ' & ' & & . & ' & ' & & $\hat{\sigma}$ & ' & ' & ' & ' \\
\hline 준르 & & & ' & $\exists$ & & & ' & a & 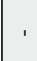 & ' & ' & & ' & ' & ' & & 0 & ' & $m$ & $\sim$ & $\Rightarrow$ \\
\hline 旑 & & 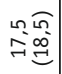 & 9 & 9 & $\stackrel{\infty}{\sim}$ & gे & $\stackrel{\substack{n \\
\beth}}{=}$ & $\stackrel{\infty}{\sim}$ & $\stackrel{\infty}{\sim}$ & ' & ' & & . & ' & ' & & $\stackrel{\infty}{\rightarrow}$ & ने & $\stackrel{\infty}{\sim}$ & $\stackrel{\infty}{\rightarrow}$ & 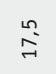 \\
\hline 등지 & & 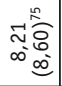 & 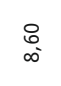 & $\mid \begin{array}{l}0 \\
0 \\
0 \\
\infty\end{array}$ & $\begin{array}{l}\stackrel{n}{n} \\
\infty \\
\infty\end{array}$ & 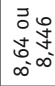 & $\mid \begin{array}{c}0 \\
0 \\
\infty \\
\infty\end{array}$ & $\begin{array}{c}\text { in } \\
\text { in } \\
\text {. }\end{array}$ & $\begin{array}{l}\stackrel{8}{0} \\
\infty\end{array}$ & $\begin{array}{l}\stackrel{n}{n} \\
\infty\end{array}$ & $\begin{array}{l}\text { in } \\
\text { con } \\
\infty\end{array}$ & $\begin{array}{l}\stackrel{f}{f} \\
\infty\end{array}$ & $\mid \begin{array}{c}0 \\
0 \\
\infty \\
\infty\end{array}$ & 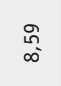 & $\begin{array}{l}\stackrel{\circ}{8} \\
\text { ¿ } \\
\text { in }\end{array}$ & & $\underset{\substack{n \\
\infty \\
\infty}}{0}$ & $\begin{array}{l}\stackrel{8}{\infty} \\
\infty\end{array}$ & \begin{tabular}{l}
9 \\
\multirow{2}{*}{} \\
$\infty$
\end{tabular} & $\begin{array}{l}0 \\
0 \\
\infty\end{array}$ & $\begin{array}{l}\underset{\sim}{*} \\
\infty\end{array}$ \\
\hline 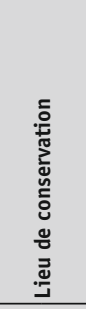 & & 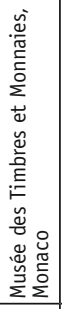 & 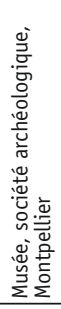 & 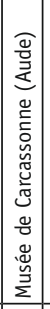 & 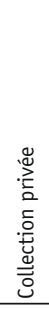 & 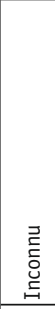 & 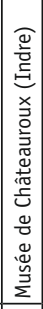 & 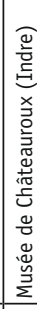 & 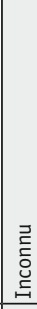 & 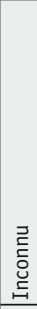 & 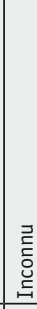 & 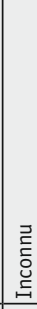 & 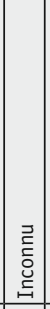 & 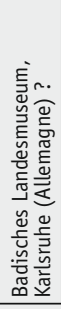 & 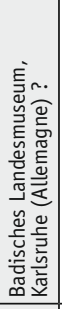 & & 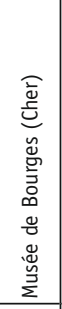 & 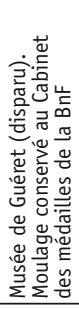 & 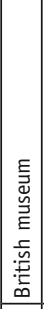 & 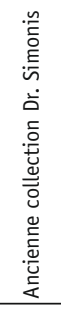 & 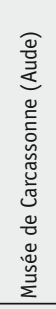 \\
\hline 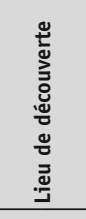 & & 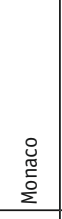 & 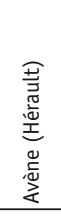 & 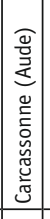 & 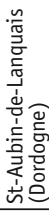 & 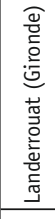 & 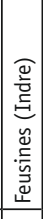 & 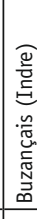 & 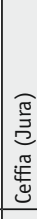 & 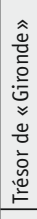 & 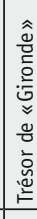 & 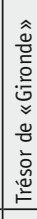 & 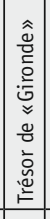 & 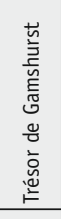 & 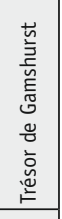 & & 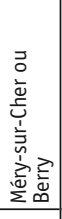 & 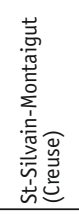 & 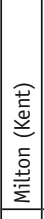 & 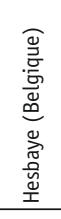 & 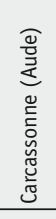 \\
\hline 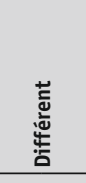 & & 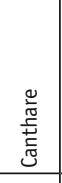 & 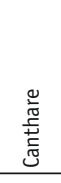 & 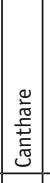 & 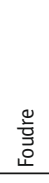 & 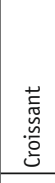 & 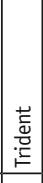 & 䓂 & 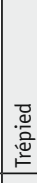 & 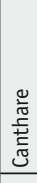 & $\begin{array}{l}\frac{0}{\pi} \\
\text { 荧 } \\
\text { 壳 } \\
\end{array}$ & 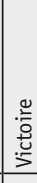 & 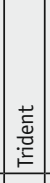 & 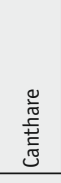 & 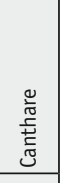 & & 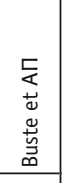 & 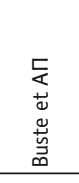 & 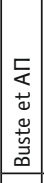 & 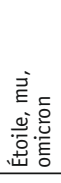 & 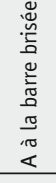 \\
\hline 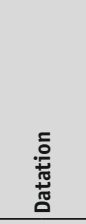 & & 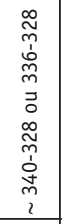 & 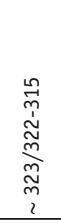 & $\mid$\begin{tabular}{|c}
$\stackrel{n}{\rho}$ \\
$\stackrel{\sim}{\sim}$ \\
$\tilde{N}$ \\
$\stackrel{\sim}{\sim}$ \\
$\sim$ \\
$\imath$
\end{tabular} & 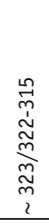 & 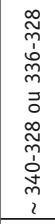 & 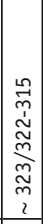 & $\begin{array}{l}\stackrel{\sim}{\sim} \\
\stackrel{\sim}{\sim} \\
\tilde{N} \\
\stackrel{\sim}{\sim} \\
\sim \\
2\end{array}$ & $\begin{array}{l}\stackrel{n}{\sim} \\
\stackrel{\sim}{\sim} \\
\tilde{N} \\
\tilde{N} \\
\sim \\
2\end{array}$ & 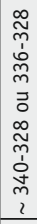 & 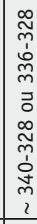 & 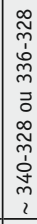 & 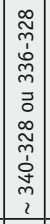 & 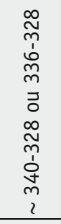 & 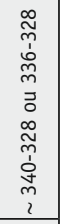 & & $\begin{array}{l}\underset{\tilde{N}}{\tilde{N}} \\
\underset{\sim}{N} \\
\underset{\sim}{\tilde{N}} \\
\underset{N}{\tilde{N}} \\
i\end{array}$ & 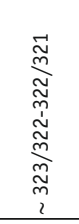 & 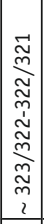 & 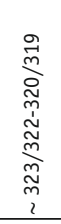 & \\
\hline 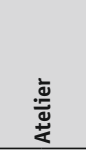 & 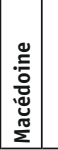 & $\begin{array}{l}\exists \\
\Xi \\
\bar{\Xi} \\
\alpha\end{array}$ & $\begin{array}{l}\text { 荘 } \\
\frac{\pi}{\bar{\Xi}} \\
\frac{0}{a}\end{array}$ & 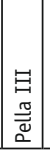 & 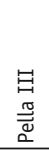 & 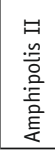 & 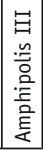 & 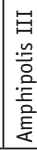 & 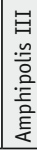 & $\begin{array}{l}\vec{G} \\
\frac{\pi}{\tilde{z}} \\
\frac{\vec{\sigma}}{2}\end{array}$ & 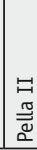 & 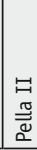 & 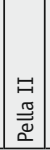 & $\begin{array}{l}\vec{H} \\
\frac{\pi}{0} \\
\overline{0}\end{array}$ & $\begin{array}{l}\text { ज } \\
\stackrel{\pi}{\bar{\Xi}} \\
\\
\end{array}$ & 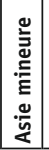 & 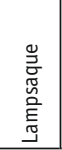 & 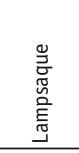 & 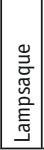 & 营 & 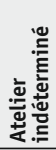 \\
\hline
\end{tabular}

Figure 16 - Tableau synthétique des statères aux types de Philippe II de Macédoine découverts en Europe. Les exemplaires incertains sont en grisé.

74. Entre parenthèses figurent les poids et diamètre de l'exemplaire de la vente Hess qui correspond très certainement au statère découvert à Monaco en 1877 (supra).

75. Moulage ou galvanoplastie (SILLS 2003, p. 361). 
Ainsi, 11 statères disposent d'une documentation suffisamment fiable ou précise pour pouvoir être considérés comme des originaux ${ }^{76}$. En revanche, et en l'état actuel des connaissances, il nous paraît préférable de considérer les 7-8 exemplaires restants comme incertains (figure 16).

Comparés au corpus réunit par G. Le Rider pour les ateliers de Pella et d'Amphipolis, les 11 statères découverts en Gaule présentent des poids généralement plus faibles qui traduisent une usure plus prononcée ${ }^{77}$ (figure 17). Alors que l'écrasante majorité des statères recensés par G. Le Rider se situe dans l'échelon pondéral 8,51-8,65 g, à peine plus de la moitié de ceux découverts en Europe s'inscrit dans la même fourchette; les autres exemplaires ayant des poids compris entre 8,26 et $8,50 \mathrm{~g}$.

\begin{tabular}{|c|c|c|}
\hline Poids $\mathbf{( g )}$ & $\begin{array}{c}\text { Nb d'exemplaires } \\
\text { d'après Le Rider 1977 }\end{array}$ & $\begin{array}{c}\text { Nb d'exemplaires recensés } \\
\text { pour l'Europe celtique }\end{array}$ \\
\hline $8,51-8,65$ & 339 & 6 \\
\hline $8,26-8,50$ & 19 & 5 \\
\hline
\end{tabular}

Figure 17 - Poids des statères de Philippe II attestés pour l'Europe celtique comparé à ceux recensés dans LE RIDER 1977.

Parmi les 7 statères conservés dans des collections publiques, 5 ont pu être analysés par activation protonique dans le cadre d'études antérieures ${ }^{78}$ ou, plus récemment, par LA-ICP-MS ${ }^{79}$. Que ce soit pour les éléments majeurs (figure 18) ou les teneurs en platine et palladium, marqueurs pertinents pour suivre les stocks d'or ${ }^{80}$ (figure 19), notre faible échantillonnage s'inscrit pleinement dans les tendances déjà observées. L'or monnayé est purifié et les teneurs en platine et palladium augmentent à partir du règne de Philippe III, témoignant d'un changement de stock métallique sans doute à mettre en relation avec la prise des trésors achéménides par Alexandre ${ }^{81}$.

76. Malgré l'attestation de découvertes fictives d'objets archéologiques grecs et italiques en France au XIXe siècle (MILCENT 2006), un phénomène semblable paraît exclu pour notre corpus, principalement en raison de l'usure des exemplaires retenus et de la cohérence des variétés représentées (voir la partie 2, le dossier grec).

77. À l'exception du statère découvert à Avène (Hérault), ces exemplaires ne figurent pas dans le catalogue de G. Le Rider (Avène = LE RIDER 1977, p. 176, no 443b, D201-R330, pl. 67, no 443).

78. GONDONNEAU et alii 1996.

79. Étude S. Nieto-Pelletier en cours. Nous n'avons pas eu l'autorisation d'analyser les deux statères conservés au musée de Carcassonne.

80. BLET-LEMARQUAND et alii 2014.

81. GONDONNEAU 2001 ; DUYRAT, OLIVIER 2010, p. 84-85. 


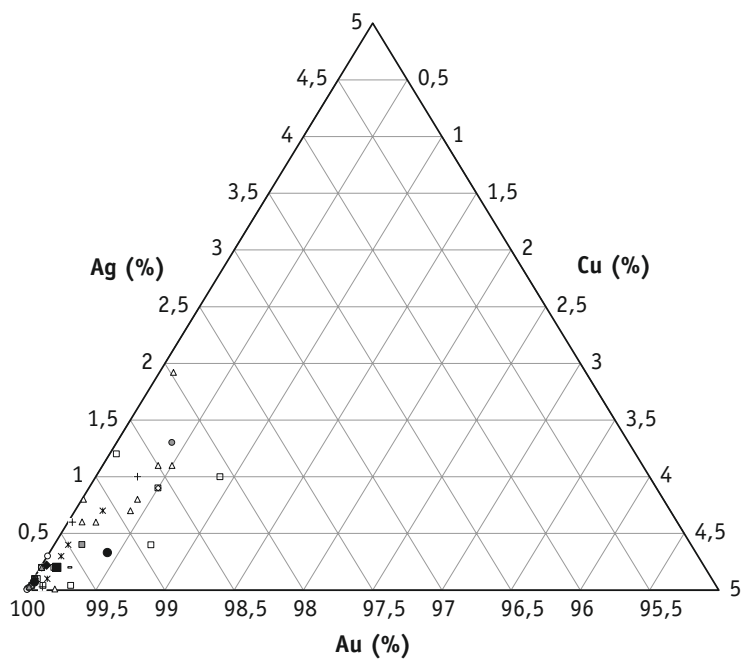

+ Pella Philippe II

- Pella Alexandre III

$\triangle$ Pella Philippe III

- Amphipolis ALexandre III

- Amphipolis Philippe III

* Lampsaque

- Abydos

$\triangle$ Téos

- Rhodes

- Magnésie

- Gaule Pella Philippe III

- Gaule Amphipolis Philippe III

- Gaule Lampsaque

Figure 18 - Composition des statères aux types de Philippe II.

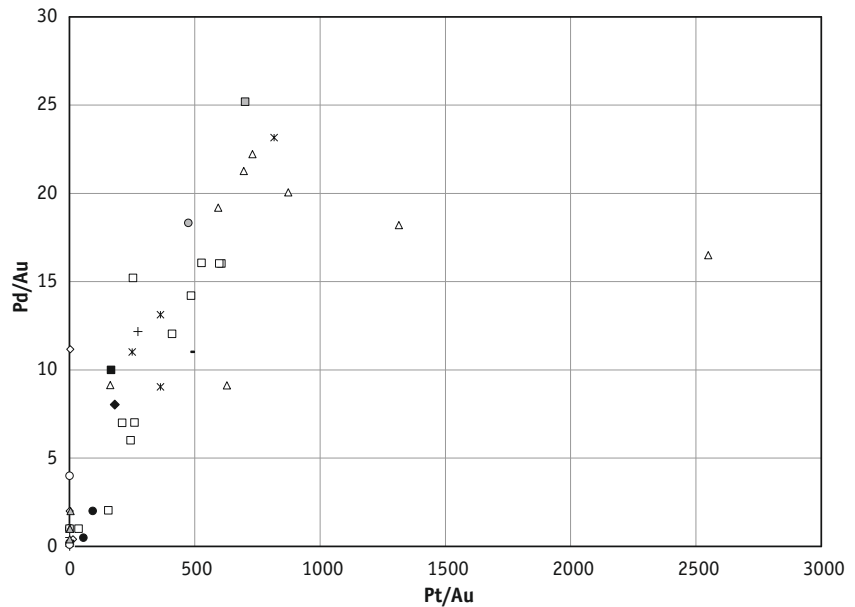

+ Pella Philippe II

- Pella Alexandre III

$\triangle$ Pella Philippe III

- Amphipolis ALexandre III

- Amphipolis Philippe III

* Lampsaque

- Abydos

$\triangle$ Téos

- Rhodes

- Magnésie

- Gaule Pella Philippe III

- Gaule Amphipolis Philippe III

- Gaule Lampsaque

Figure 19 - Rapports Pt/Au et $\mathrm{Pd} / \mathrm{Au}$ dans les statères aux types de Philippe II de Macédoine.

\section{$B$. Les grandes séries d'imitations gauloises}

L'inventaire des exemplaires originaux découverts en Europe (exemplaires «certains » et «incertains ») confronté aux séries d'imitations actuellement répertoriées (figure 20) indique que seule la variété «à la victoire », qui aurait 
appartenu au trésor de «Gironde», ne semble pas avoir été imitée ${ }^{82}$. Inversement, les séries d'imitations gauloises reprennent des variétés du statère de Philippe II actuellement absentes des découvertes occidentales. C'est le cas de celles «au grain», «à l'épi », «à la couronne perlée», «au serpent», «à l'abeille», «à l'étoile» et surtout de la série « au monogramme AP, épi et foudre » à l'origine d'une série d'imitations parmi les plus abondantes (figure 35$)^{83}$.

Il ressort également de cette synopsis qu'une même série d'imitations peut faire appel à plusieurs modèles. Deux cas peuvent être distingués. Certaines imitations reproduisent et rassemblent des types présents sur différentes émissions de philippes, c'est le cas des séries d'Hespérange (Lampsaque et Abydos) ou de Bondeval et Kreimbach (probable parenté au droit avec Magnésie et Colophon, Amphipolis ou Pella pour le revers). D'autres associent au bige de Philippe un droit varié : aux types de Néapolis (série Essey), de Lysimaque (Lysimaque/AP) ou une tête diadémée dérivée de la tête d'Héra présente sur les statères de Tarente (série à la tête diadémée).

\section{L'arrivée des philippes : terminus ante quem à partir des contextes archéologiques}

Si aucun contexte n'est actuellement connu pour les exemplaires originaux aux types de Philippe découverts dans notre zone d'étude, quelques rares imitations plus ou moins précoces pourraient constituer un terminus ante quem.

Au cours des fouilles menées en 2012-2013 sur la commune de Thézy (Somme), un hémistatère au type d'Hespérange a été mis au jour dans un silo daté du début de La Tène $\mathrm{C} 1$ ( $2^{\text {e }}$ tiers du IIIe siècle av. J.-C.) ${ }^{84}$ (figure $\left.21 \mathrm{a}\right)$. Cette émission du nord de la Gaule reprend assez fidèlement les types gréco-macédoniens ${ }^{85}$.

Des imitations du statère de Philippe II de la série «au glaive » et «au loup attaquant ${ }^{86}$ ont été découvertes en 1999 sur le site de Ribemont-sur-Ancre (Somme) dans un contexte La Tène C1b, vers 250-220 av. J.-C. ou vers le milieu

82. Précisons toutefois que ce thème iconographique n'est pas étranger au répertoire gaulois, puisque des séries de l'ouest de la Gaule dont l'attribution n'est pas toujours assurée (Aulerques Cénomans, Aulerques Diablintes, Andécaves) présentent au revers un cheval androcéphale, conduit par un aurige, au-dessous duquel est allongé un personnage ailé. Voir particulièrement AUBIN et alii 2011. Des statères attribués aux Bituriges Cubes (BnF 45864587) comportent également une victoire au revers, passablement éloignée toutefois de celle présente sur les exemplaires gréco-macédoniens.

83. 21 coins de droit pour les statères et 137 coins de droit pour les quarts de statère ont pu être estimés pour cette émission à partir de l'étude de J. Sills (méthode de Carter).

84. DELESTRÉE, LE BÉCHENNEC 2014.

85. SiLLON 2014, p. 95.

86. Respectivement séries GRH-3f et GRH-3g centrées dans l'actuelle Basse-Seine (GUIHARD 2012, p. 80, 194-195, pl. III - GRH-3f et IV - GRH-3g). 


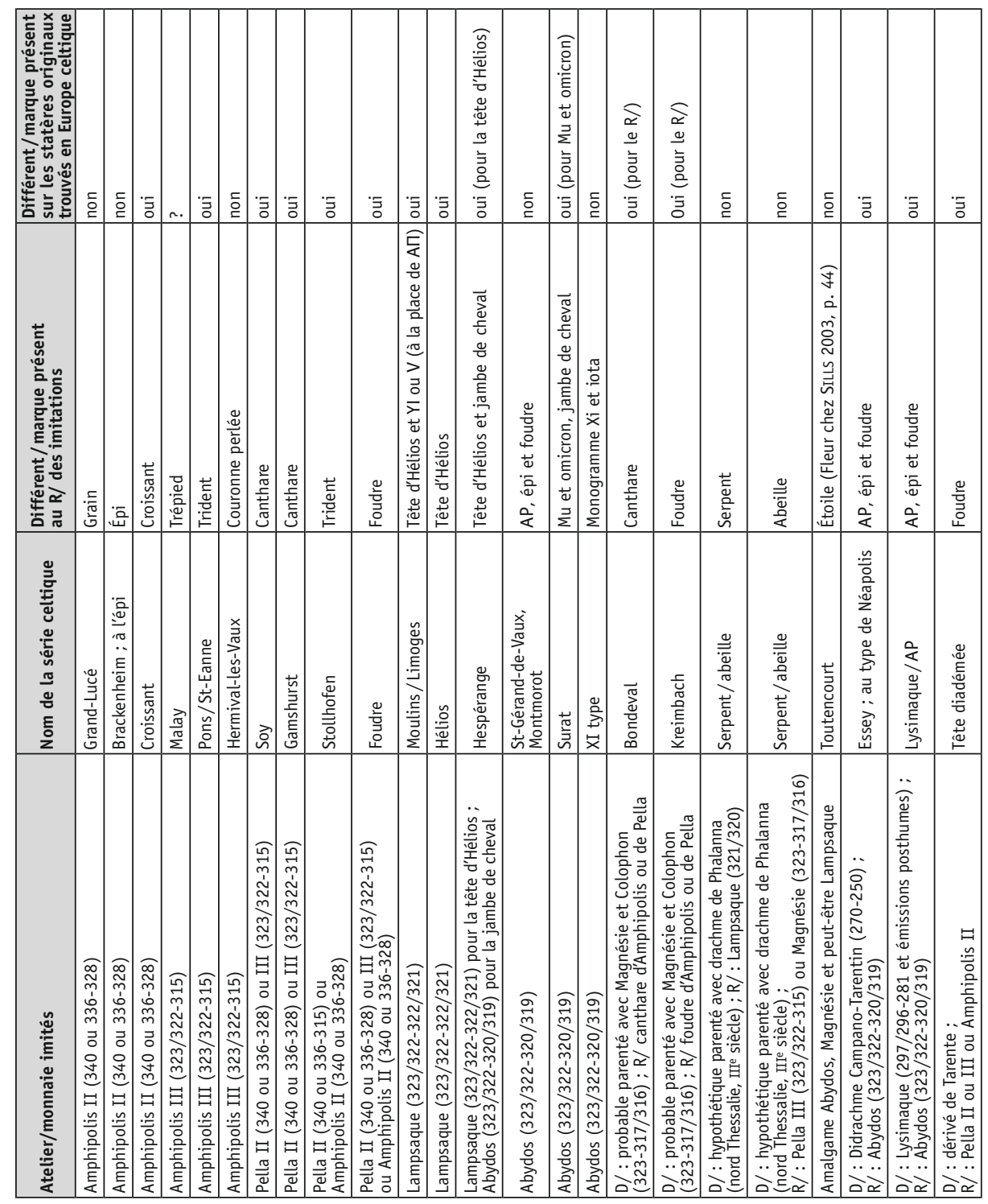

Figure 20 - Tableau synthétique des principales séries d'imitation du statère aux types de Philippe II que la copie soit fidèle ou très fortement inspirée du modèle gréco-macédonien (d'après SILLS 2003 complété par SCHEERS 1980 et MeNNESSIER-JOUANNET, Provost 1994, notice 214) ${ }^{87}$.

87. Sont exclues les imitations d'imitations ou dérivées d'imitations comme St-Ciergue, Torch, Ciney, etc., les séries dont la filiation avec un original gréco-macédonien est incertaine comme Graçay, ou les séries pour lesquelles, en l'absence de différent, le rapprochement avec un atelier macédonien ou d'Asie Mineure particulier n'est pas possible (au-delà de la simple imitation de Philippe avec bige et légende déformée) comme la série à la tête barbue. 
du IIIe siècle av. J.-C. (figure $21 \mathrm{~b})^{88}$. Ces séries, dont le type est passablement éloigné du prototype grec, appartiennent au groupe de l'hémistatère (période 2) qui aurait succédé aux exemplaires dits d'Hermival-les-Vaux (période 1) euxmêmes postérieurs aux imitations fidèles du statère original ${ }^{89}$.
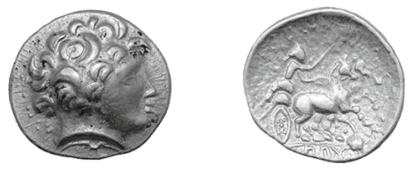

a - Hémistatère au type d'Hespérange (Thézy, Somme) ${ }^{90}$
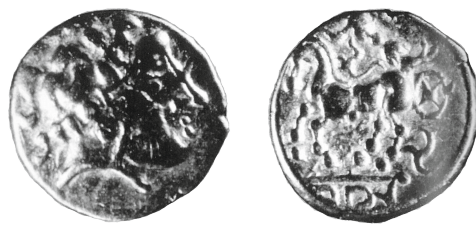

c - Quart de statère «à la branche d'aulne» (La Grande-Borne, Puy-de-Dôme) ${ }^{92}$ Éch. 2:1
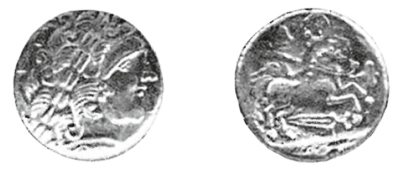

b - Hémistatère «au glaive» (type découvert à Ribemont-sur-Ancre, Somme) $)^{91}$
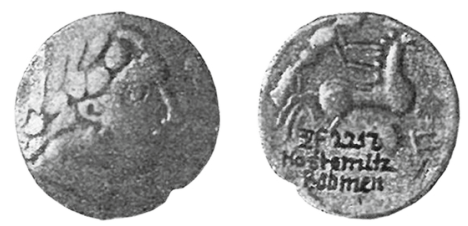

d - Statère "au trident, type Tayac/Soulac-sur-Mer » (Hostomice, République Tchèque) ${ }^{93}$

Figure 21 - Imitations du statère de Philippe II découvertes en contexte.

Les fouilles réalisées sur le site de La Grande Borne à Clermont-Ferrand entre 1972 et 1981 ont livré un quart de statère de la série dite «à la branche d'aulne » dans un contexte La Tène C1, vers 250-200 av. J.-C. (figure 21c). ${ }^{94}$ Cet exemplaire provient d'un fossé dont le scellement est daté par le mobilier présent (bracelets en verre, armement et céramique) de la fin du III ou du début du IIe siècle av. J.-C. ${ }^{95}$ Au droit figure une tête tournée à droite traversée par un trait habituellement interprété comme une branche d'aulne. Le revers

88. LejARS 2007, p. 267 pour la première datation; DeLESTRÉE 2001, p. 202 ; GUIHARD 2012, p. 70 pour la seconde. Des études sont encore en cours sur les données et le mobilier du site.

89. GUIHARD 2012, p. 53 et 70-71.

90. Photographie de Charlotte Parisot-Sillon qui nous a aimablement autorisés à la reproduire.

91. Extrait de DelestrÉE, TACHE 2004, pl. III (DT 2044).

92. Extrait de GUICHARD et alii à paraître.

93. Extrait de GORPHE 2009, p. 138.

94. Chantier IV de la fouille de la Grande Borne réalisée entre 1972 et 1981, resp. J. Collis (DEBERGE et alii 2007, p. 168).

95. DEBERGE et alii 2007, p. 197 ; GUICHARD et alii à paraître. Nous remercions Y. Deberge qui nous a communiqué cette dernière notice à paraître. 
comporte un cheval conduit par un aurige au-dessous duquel est représenté un motif à trois branches; à l'exergue seule la fin de la légende, incertaine, est visible ]П (?)О (?)Y. Si le type des philippes est conservé dans ses grandes lignes, le style de chacune des faces et l'ajout d'éléments typo-logiques comme la «branche d'aulne » ou le motif à trois branches font de cette monnaie une imitation dite de la «seconde génération ${ }^{96}$ ».

Plus problématique est le contexte fourni par la sépulture d'Hostomice (Bohème, République Tchèque). Découverte en 1890, cette sépulture à inhumation comportait des parures annulaires en bronze ainsi qu'un statère en or de la série au trident du type de Soulac-sur-Mer / Tayac (figure 21d) ${ }^{97}$. Toutes les datations proposées situent cette sépulture dans la première moitié du IIIe siècle av. J.-C. ${ }^{98}$ Or il est d'usage de considérer la série au trident de Tayac comme une imitation «tardive » produite dans l'ouest de la Gaule, en raison du type, du style et du poids - ces exemplaires succèderaient aux imitations serviles au trident aux types de Pons/St-Eanne - mais également en raison de la datation du dépôt de Tayac qui en contenait 195 exemplaires. Si la chronologie du dépôt de Tayac est aujourd'hui considérablement remontée, avec un enfouissement daté du milieu du IIe siècle voire avant ${ }^{99}$ ou de la fin du deuxième tiers du IIe siècle av. J.-C. ${ }^{100}$, il n'en demeure pas moins que le décalage avec la datation de la sépulture d'Hostomice est important. Cette divergence a conduit J. Sills à suggérer que l'exemplaire d'Hostomice serait en fait une monnaie du dépôt de Tayac qui aurait été ajoutée au mobilier de la sépulture au moment de sa vente pour rendre cette dernière plus attractive ${ }^{101}$. V. Kruta également a douté, dans un premier temps, de l'authenticité de l'ensemble avant de considérer l'homogénéité du mobilier de la sépulture comme probable ${ }^{102}$.

Ce contexte, s'il est fiable, invite donc à remonter considérablement la date des monnaies au trident de la série de Tayac ; pour autant, est-il surprenant si on accepte que les séries «au glaive» et « au loup attaquant» ont été émises au plus tard à La Tène $\mathrm{C} 1 \mathrm{~b}$ ?

96. S. Scheers et J.-N. Barrandon distinguent deux générations d'imitations (SCHEERS, BARRANDON 1994, p. 81-139). Les exemplaires de la première génération sont fidèles aux types des statères imités et présentent un poids généralement élevé, supérieur à $8 \mathrm{~g}$ pour les statères. Les monnaies dites de la seconde génération conservent de façon approximative le type des monnaies de Philippe et plusieurs changements apparaissent à la fois dans le type (ajout ou suppression d'éléments iconographiques), le style et la métrologie (poids des statères inférieurs à $8 \mathrm{~g}$ ) des exemplaires désormais frappés.

97. KRUTA 1982, p. 74. Photographie de l'exemplaire dans GORPHE 2009, p. 138. Le type de Soulacsur-Mer correspond au type IIc de KeLLNER 1970 et à la classe 3 de BOUDET 1987.

98. POLENZ 1982, p. 72-74 ; KRUTA 1982, p. 77 ; ZIEGAUS 1999, p. 113-117.

99. HASELGROVE 1999, p. 126-127.

100. DelestréE, TACHe 2007, p. 45.

101. SILLS 2003, p. 217. Il propose néanmoins de considérer cette découverte comme authentique en l'absence d'éléments contradictoires probants.

102. En s'appuyant sur le mobilier de la sépulture no 13 de Giengen (KRUTA 1982, p. 77-78). 
À n'en pas douter nous manquons de contextes archéologiques solides pour fonder un raisonnement qui reste somme toute très spéculatif. Les données rassemblées dans différentes régions ces dernières années et les interprétations qui en sont actuellement proposées ont tendance à remonter la chronologie des imitations du statère de Philippe II de Macédoine et à réduire l'intervalle qui sépare les premières imitations des prototypes ${ }^{103}$. Si les études les plus récentes se fondent principalement sur le contexte fourni par Ribemont-surAncre et le dépôt dit de Gironde (ou Bordeaux), dont le caractère incertain a précédemment été évoqué, il faut souligner que le quart de statère découvert à La Grande-Borne ne contredit pas cette chronologie haute.

Quoi qu'il en soit et avec toute la prudence qui s'impose, il semble que dès La Tène C1b (250-200 av. J.-C.) les monnaies présentent des stades d'évolution typologique plus ou moins avancés selon les régions, pouvant être assimilés à des formes d'individualisation ou d'appropriation de l'outil monétaire par les pouvoirs émetteurs alors en place. À cette période, le phénomène monétaire paraît donc bien installé et la monnaie gauloise s'éloigne progressivement de son modèle originel.

\section{Le dossier grec : au commencement étaient la Macédoine et l'Asie Mineure}

La reprise de la documentation concernant les découvertes de statères originaux aux types de Philippe en Europe ainsi que la présentation des plus anciennes séries d'imitation nous engage, à partir de l'étude des productions en Macédoine et en Asie Mineure, à mieux circonscrire les mécanismes et les circonstances qui amenèrent ces monnaies d'or si loin de leur aire d'émission et de circulation. Dans cette section, nous ferons dans un premier temps le point sur l'état de nos connaissances sur ce monnayage. Ensuite, nous nous fonderons sur les variétés attestées en Gaule (par la trouvaille d'originaux ou par l'imitation) pour mieux cerner l'ampleur et la chronologie du phénomène.

Le monnayage d'or inauguré par Philippe II de Macédoine (359-336) compte parmi les plus importants du monde grec. L'ampleur des frappes ainsi que la qualité de ces monnaies leur permettent de supplanter rapidement le darique perse en tant que numéraire d'or de référence en Grèce ${ }^{104}$. Ce succès explique sans doute que la production des philippes ait longtemps survécu au roi qui leur donna son nom. Parallèlement à l'émission des statères aux types d'Alexandre, de nombreux philippes sont frappés jusqu'au début du IIIe siècle en Macédoine mais également en Asie Mineure, où plusieurs ateliers émettent ce type à

103. V. Kruta envisageait dès 1982 une chronologie haute des premières émissions (KRUTA 1982). Plus récemment voir SiLLs 2003, p. 123 ; GUIHARD 2012, p. 53-60, 71 et MARTIN 2015, p. 333-334.

104. LE RIDER 1977, p. 435-438 ; 1996, p. 72 ; CALLATAŸ 2012, p. 176-177. Sur le rôle du darique en Grèce : BASLEZ 1989. 
partir de la seconde moitié des années $320^{105}$. C'est à la même période que de très nombreux statères de Philippe apparaissent dans plusieurs trésors au Levant, en Égypte, dans le sud de l'Italie et en Sicile. L'essentiel des découvertes est cependant localisé en Grèce et en Thrace, particulièrement sur le territoire de l'actuelle Bulgarie; ces concentrations de trouvailles étant généralement associées aux soldes versées en or par les souverains de Macédoine à leurs mercenaires thraces ${ }^{106}$.

\section{A. Présentation générale et historiographique}

Les monnaies de Philippe ont très tôt intéressé les numismates. Le premier travail d'ampleur est incontestablement dû à L. Müller (1855) lorsqu'il adjoint à sa monumentale Numismatique d'Alexandre le Grand un appendice consacré aux monnaies de Philippe $\mathrm{II}^{107}$. L'auteur propose un catalogue des types qu'il décrit et commente. Il conforte l'idée selon laquelle ces monnaies doivent être attribuées à Philippe II puis discute de la chronologie et des lieux d'émission. Presque 120 ans plus tard, en 1977, G. Le Rider publie le corpus des monnaies d'or et d'argent macédoniennes frappées au nom de Philippe II, depuis leur inauguration sous son règne jusqu'aux dernières frappes posthumes ${ }^{108}$. Dans cet ouvrage fondamental, l'auteur clarifie notamment la séparation du monnayage d'or entre les deux ateliers macédoniens que sont Pella et Amphipolis ${ }^{109}$. Il propose ensuite une chronologie qui s'articule en trois grands moments avec une inauguration des séries d'or seulement dans la seconde partie du règne de Philippe, vers 345 ou 342. L'un des apports majeurs de ce travail est sans aucun doute l'attribution de la grande majorité des émissions d'or à une période postérieure à la mort du roi, sous le règne de son fils Alexandre le Grand puis au temps des diadoques ${ }^{110}$.

Alors que l'essentiel des conclusions de G. Le Rider a été accepté, la chronologie des émissions d'or a suscité le débat. En 1985, T.R. Martin propose de dater les premiers statères dès 355-350 - notamment en raison des importantes dépenses que Philippe II doit engager au début de son règne contre les

105. Sur la Macédoine : LE RIDER 1977 ; 1996 (groupes II et III) ; TROXELL 1997, p. 109-110. G. Le Rider traite spécifiquement de cette question du double monnayage dans LE RIDER 1993. Pour l'Asie Mineure : THOMPSON $1982 ; 1983 ; 1991$; CALLATAŸ 1994.

106. Sur la question thrace, on consultera notamment un article récent : RUFIN-SoLAS 2014. Sur les Thessaliens, Fr. de Callataÿ (1994, p. 35, n. 62) rappelle les propos d'Arrien (III 19.5-7) qui évoque des cavaliers rentrant chez eux avec leur solde augmentée d'une prime de 2000 talents donnée par Alexandre. Pour exemple, une majorité des trouvailles de statères frappés à Milet provient de trésors enfouis hors de l'Asie Mineure : MARCELLESI 2004, p. 96-97.

107. MÜLLER 1855, appendice, p. 335-386.

108. LE RIDER 1977.

109. Cette séparation étant également valable pour les séries d'argent.

110. LE RIDER 1977, p. 435-438. 


\begin{tabular}{|l|c|c|}
\hline Classement & Pella & Amphipolis \\
\hline Groupe I & \multicolumn{2}{|c|}{ ca 345-340 ou ca 342-336 } \\
\hline Groupe II & \multicolumn{2}{|c|}{ ca 340-328 ou ca 336-328 } \\
\hline Groupe III (A et B) & \multicolumn{2}{|c|}{ ca 323/322-ca 315 } \\
\hline Groupe III (C) & ca 314-ca 310 & ca 323/322 - ca 315 \\
\hline
\end{tabular}

Figure 22 - Chronologie des statères d'or macédoniens aux types de Philippe II d'après LE RIDER 1977.

Thessaliens et les Phocidiens - et n'admet de production posthume que pour une faible part des séries ${ }^{111}$. Quelques années plus tard, M. B. Hatzopoulos place l'inauguration de ce monnayage en 352 en se fondant sur l'étude de douze actes de ventes d'Amphipolis dont plusieurs comportent des mentions

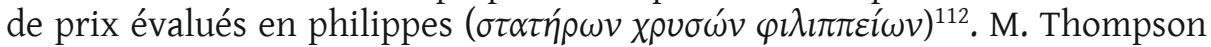
et M.J. Price valident quant à eux les propositions de G. Le Rider ${ }^{113}$. Ce dernier publie en 1996 un opus dans lequel il reprend plusieurs points de son travail de 1977 au regard des nouvelles documentations à disposition ainsi que pour discuter des critiques émises à l'encontre de sa chronologie ${ }^{114}$. Suite à cette nouvelle publication, et bien que plusieurs auteurs continuent à rappeler les différentes hypothèses soumises ${ }^{115}$, les datations de G. Le Rider font largement consensus.

Le cas des émissions micrasiatiques ne se présente pas sous un jour aussi favorable. En effet, parallèlement aux frappes macédoniennes de philippes posthumes, plusieurs ateliers d'Asie Mineure émettent à leur tour ce type. Si la plupart, comme Milet, Magnésie du Méandre, Colophon ou Sardes, ont des productions modestes - notamment au regard de l'importance des frappes d'alexandres - quelques ateliers comme Abydos, Lampsaque ou dans une moindre mesure Téos sont réputés avoir produit un nombre conséquent de ces statères. M. Thompson prêta un intérêt tout particulier à ces productions au travers de l'étude des ateliers d'alexandres d'Asie Mineure. Après un premier travail mené conjointement avec A.R. Bellinger au sujet d'un important trésor de drachmes d'Alexandre où un premier tour d'horizon des productions de la région est proposé ${ }^{116}$, l'auteur consacre en 1982 un article aux philippes d'Asie

111. MARTIN 1985, p. 271-292, appendice 4.

112. HATZOPOULOS 1991, p. 82-83.

113. THOMPSON 1982, p. 57 ; PRICE 1991, p. 106.

114. LE RIDER 1996. Cet ouvrage a également l'avantage de contenir un point bibliographique concernant Philippe et ses monnayages (p. 13-20) ainsi que des discussions approfondies sur les travaux publiés sur la question entre 1977 et les années 1990 (p. 33-47 pour l'argent, p. 55-66 pour l'or).

115. CALlatä̈ 2012, p. 176.

116. THOMPSON, BELLINGER 1955. 
Mineure ${ }^{117}$. Elle entreprend ensuite la rédaction d'une trilogie de monographies (intitulée Alexander's Drachm Mints) contenant de copieux catalogues des monnayages d'or et d'argent avec pour chaque atelier une étude de coins complète. Le décès prématuré de $\mathrm{M}$. Thompson fait que seuls paraissent les deux premiers volumes, consacrés respectivement aux ateliers de Sardes et Milet puis de Lampsaque et Abydos ${ }^{118}$.

Malgré ces importants travaux, les monnayages d'Asie Mineure posent aux spécialistes de multiples problèmes qu'un article de Fr. de Callataÿ daté de 1994 résume parfaitement ${ }^{119}$. Tout d'abord, les philippes demeurent bien souvent au sein de ces ateliers un sujet d'étude secondaire, particulièrement au regard des alexandres : statères, tétradrachmes et surtout drachmes. Pour preuve, M. Thompson intitule ses ouvrages Alexander's drachm mints alors même qu'en termes de valeur, les statères d'or - dont les philippes représentent parfois une part importante - constituent l'essentiel des numéraires émis ${ }^{120}$. Surtout, la chronologie des frappes est un point de discorde entre les différents spécialistes. M. Thompson postule un rythme annuel des émissions - idée aujourd'hui plus que contestable - et associe la frappe des philippes posthumes au règne de Philippe III (323-317) : l'homonymie renforçant la légitimité du demi-frère d'Alexandre.

\begin{tabular}{|c|c|c|c|}
\hline Lampsaque & Abydos & Sardes & Milet \\
\hline & & & Série I : ca 325-323 \\
\hline Série VI : 323/322-322/321 & \multirow{3}{*}{$\begin{array}{l}\text { Séries III - IX : } \\
\text { 323/322-320/319 }\end{array}$} & & \\
\hline Série VII : $321 / 320$ & & & \\
\hline Série VIII : 320/319 & & & \\
\hline Série IX (319/318-318/317) & Série $X: 319 / 318$ & Série XV : ca 319/318 & \\
\hline
\end{tabular}

Figure 23 - Chronologie des statères d'or d'Asie Mineure aux types de Philippe II (d'après THOMPSON 1983 et 1991).

En 1994, Fr. de Callataÿ montre de manière convaincante que si la datation des premières séries paraît assez bien assurée, rien n'empêche que cette production se soit poursuivie aussi longtemps qu'en Macédoine, donc bien au-delà du règne de Philippe III $^{121}$. Enfin, malgré la précocité et l'ampleur des

117. THOMPSON 1982.

118. THOMPSON 1983 ; 1991. Le troisième tome devait comprendre les ateliers de Colophon, Magnésie-du-Méandre et Téos

119. Callataÿ 1994. A.R. Meadows a récemment exprimé des doutes similaires : MEADOWs, à paraître.

120. CALlatä̈ 1994, p. 20.

121. Ibid., p. 23-24, l'auteur cite notamment à ce sujet une lettre de G. le Rider en date du 11 septembre 1992. Voir également MARCELLESI 2004, p. 84-85 sur le cas de Milet. 
travaux de savants tels L. Müller ${ }^{122}$ ou E.T. Newell ${ }^{123}$, l'identification des ateliers d'Asie Mineure est demeurée une question particulièrement débattue. En 1982, M. Thompson note elle-même au sujet des philippes de cette région : «Die transfers are surprisingly frequent ${ }^{124}$.» La découverte de ces liaisons de coins entre ateliers distincts - il en existe une entre Lampsaque et Abydos $^{125}$ contraint à questionner sérieusement la distribution actuelle des différentes variétés dans les ateliers d'Asie Mineure ${ }^{126}$. Les propositions de M. Thompson sont remises en question dès 1991 par M. J. Price dans son ouvrage consacré aux monnaies au nom d'Alexandre ${ }^{127}$. On retiendra ici que l'auteur britannique suggère que l'atelier de Lampsaque puisse aussi bien être placé sur l'autre rive de la Propontide, quelque part sur la côte thrace ${ }^{128}$, et que les monnaies données à Abydos pourraient être placées en tête des séries de Cyzique ${ }^{129}$. Ces deux ateliers seraient donc situés sur les pourtours du Bosphore, en Propontide ${ }^{130}$.

Malgré ces incertitudes qui persistent, quelques points font consensus et permettent de maintenir ces productions dans un espace-temps cohérent. Si l'idée de M. Thompson d'une frappe des philippes posthumes durant le seul règne de Philippe III (323-317) ne peut être acceptée en l'état, il demeure que ces monnaies d'or ne peuvent dater que du dernier quart du IVe siècle, probablement entre ca 325-323 et ca 310 ${ }^{131}$. Surtout, la localisation des émissions, si elle ne peut pas actuellement être définie avec précision, peut être circonscrite à l'Asie Mineure avec une ligne de partage nord/sud. Les rapprochements stylistiques, les liaisons de coins et les trésors permettent en effet de reconnaître au sud, en Ionie, des ateliers qui privilégient l'émission de drachmes et au nord, sur les rives de la Propontide, des centres de production où les statères aux types de Philippe II prédominent ${ }^{132}$.

122. MÜLLER 1855, p. 67-70 et surtout p. 232-254 («l'Asie Mineure occidentale»)

123. On consultera notamment les développements consacrés à l'Asie Mineure dans NEWELL 1923, p. 81-87 («the Propontis»), p. 87-93 (Sardes) et p. 93-96 (Milet).

124. THOMPSON 1982, p. 60. Cette citation ne concerne en 1982 que le cas des ateliers ioniens de Milet, Magnésie du Méandre et Colophon.

125. Thompson 1991, p. 18, ex. no 154 (Lampsaque) et p. 47, ex. no 101 (Abydos). Cette liaison est représentée ci-dessous, voir fig. 32.

126. La question se pose exactement en ces termes pour Milet et Magnésie du Méandre: MARCELLESI 2004, p. 71.

127. PRICE 1991, p. 209-210 (Lampsaque), p. 222-223 et p. 247-248 (Colophon), p. 225-226 (Abydos), p. 264-265 (Magnésie du Méandre), p. 294-295 (Téos), p. 320-321 (Sardes). Un utile texte introductif dédié aux «Drachmae Mints of Asia Minor » est également proposé aux p. 208-209.

128. Ibid., p. 210.

129. Ibid., p. 225-226.

130. Pour des raisons de commodité, et faute de réattribution ferme de ces productions, nous continuerons à évoquer les productions de «Lampsaque» et «Abydos» : des guillemets indiqueront toutefois les sérieux doutes quant à ces localisations.

131. CAllatä̈ 1994, p. 26-27.

132. Ibid., p. 34-35. 


\section{B. De l'Égée à la Gaule : mécanisme et ampleur du phénomène}

À l'issue de ce point historiographique, il convient d'examiner plus particulièrement les variétés représentées en Gaule. Pour cela, deux ensembles nous semblent pouvoir refléter le phénomène d'importation des philippes. En premier lieu, et prioritairement, les originaux mis au jour. Bien entendu l'échantillon est maigre, sans doute est-ce déjà une donnée en soi (ce point sera abordé plus loin). Les premières séries d'imitations - celles qui copient fidèlement les exemplaires originaux - doivent donc être adjointes à cette étude afin de dresser le tableau le plus complet possible de ce phénomène. Les deux ensembles contiennent souvent les mêmes symboles (trident, canthare, foudre, croissant, tête d'Hélios, trépied (?) ainsi que plusieurs lettres et monogrammes). Il est également notable que seul quatre ateliers (Pella, Amphipolis, «Lampsaque» et «Abydos») ${ }^{133}$, et pour chacun d'entre eux seulement quelques variétés, sont représentées (voir ci-dessus, figures 16 et 20). L'accolement de ces deux groupes doit nous permettre de dresser un tableau fidèle des variétés de philippes importées en Gaule. Or, il ressort dès à présent que le corpus de départ, qu'il s'agisse des monnaies originales ou des imitations, est caractérisé par le petit nombre des ateliers et surtout des symboles (ou combinaisons de symboles) représentés.

\begin{tabular}{|l|c|c|c|}
\hline Atelier & $\begin{array}{c}\text { Nb de symboles : exemplaires } \\
\text { originaux et imités en Gaule }\end{array}$ & $\begin{array}{c}\text { Nb total de } \\
\text { symboles }\end{array}$ & $\begin{array}{c}\text { Part } \\
\text { représentée }\end{array}$ \\
\hline Pella et Amphipolis ${ }^{134}$ & 8 & 38 & $21 \%$ \\
\hline «Lampsaque» & 2 & 6 & $33 \%$ \\
\hline «Abydos» & 4 & 13 & $31 \%$ \\
\hline
\end{tabular}

Figure 24 - Nombre de symboles ou combinaisons de symboles représentés en Gaule comparé au total connu.

Ce constat nous amène à réfléchir aux mécanismes qui ont conduit à cette sélection des variétés importées ou imitées. Nous rappelions en introduction de cette section que le statère d'or aux types de Philippe II comptait parmi les numéraires d'or grecs les plus massivement émis. L'argument quantitatif doit donc naturellement être questionné pour expliquer que des monnaies grécomacédoniennes aient été présentes en Gaule, à des milliers de kilomètres des rives de l'Égée. À cet égard, le fait qu'aucune variété de statère macédonien du groupe 1 n'ait été découverte ou imitée semble trouver pour explication

133. J. Sills note également la ressemblance entre quelques droits d'imitation et le portrait d'Apollon de coins gravés à Magnésie et Colophon (SILLs 2003, p. 42), séries de Bondeval, Kreimbach et Toutencourt (voir figure 20).

134. La présence de plusieurs symboles communs aux deux ateliers (foudre, trident, trépied) contraint ici à les regrouper. 
le très faible volume des émissions ${ }^{135}$. Suivant cette logique, il apparaît que la liste des ateliers représentés respecte scrupuleusement la hiérarchie des centres de production de philippes :

\begin{tabular}{|l|l|c|c|}
\hline \multirow{2}{*}{ Régions } & Ateliers & $\begin{array}{c}\text { Production des philippes } \\
\text { en nb de coins de droit }\end{array}$ & $\begin{array}{c}\text { Retrouvés et/ou } \\
\text { imités en Gaule ? }\end{array}$ \\
\hline \multirow{3}{*}{ Macédoine } & Pella & 264 \\
\cline { 2 - 3 } & Amphipolis & 128 & \multirow{2}{*}{ OUI } \\
\hline \multirow{3}{*}{ Propontide } & «Lampsaque» & 24 & \\
\cline { 2 - 3 } & «Abydos» & 22 & \multirow{2}{*}{ NON } \\
\hline \multirow{3}{*}{ Lonie } & Colophon et Magnésie ${ }^{136}$ & 19 & \\
\cline { 2 - 3 } & Téos & 14 & 2 \\
\cline { 2 - 3 } & Milet & 1 & \\
\hline
\end{tabular}

Figure 25 - Productions de statères aux types de Philippe II en nombre de coins de droit selon LE RIder 1977 (Pella et Amphipolis) et THOMPSON 1982 (Téos, Colophon et Mylasa ${ }^{137}$ ), 1983 (Sardes et Milet) et 1991 (Lampsaque et Abydos).

Pourtant, si l'écrasante prédominance des productions de Macédoine ne fait aucun doute, celle des ateliers de «Lampsaque» et «Abydos» est moins évidente; ces deux ateliers ne mettant finalement en œuvre que quelques coins de plus que «Colophon et Magnésie» et Téos. La composition des trésors va d'ailleurs dans le même sens, alors que les monnaies macédoniennes sont de très loin les plus abondantes, celles de «Lampsaque» et «Abydos» sont finalement à peine plus nombreuses que celles des ateliers ioniens.

\begin{tabular}{|l|c|}
\hline Régions & Nombre d'exemplaires \\
\hline Macédoine & 375 \\
\hline Propontide & 63 \\
\hline Ionie & 37 \\
\hline Lydie & 0 \\
\hline Incertain & 9 \\
\hline
\end{tabular}

Figure 26 - Nombre de statères aux types de Philippe II trouvé dans les trésors suivant la région d'émission ${ }^{138}$.

135. À Pella, 28 coins de droit référencés pour le groupe I sur un total de 264 ; à Amphipolis, 1 seul coin sur 118 .

136. Voir n. 131.

137. Les chiffres donnés ici par l'auteur sont approximatifs et ne peuvent être pris que comme des ordres de grandeur, comme le prouvent ceux donnés dans cette même publication pour Lampsaque ("at least 28 obverse dies») et Abydos (21) presque dix ans avant la publication de la monographie dédiée à ces ateliers.

138. Cinquante-trois trésors contenant des philippes enfouis entre le dernier quart du Ive siècle et le premier tiers du IIIe siècle ont été répertoriés dans l'Inventory of Greek Coin Hoards (IGCH) et les dix volumes de Coin Hoards ( $\mathrm{CH}$ ). Toutefois, nous ne prenons en compte que vingt-huit trouvailles dont le contenu est suffisamment bien connu pour permettre l'attribution des exemplaires aux types de Philippe II à un atelier ou une région précise. 


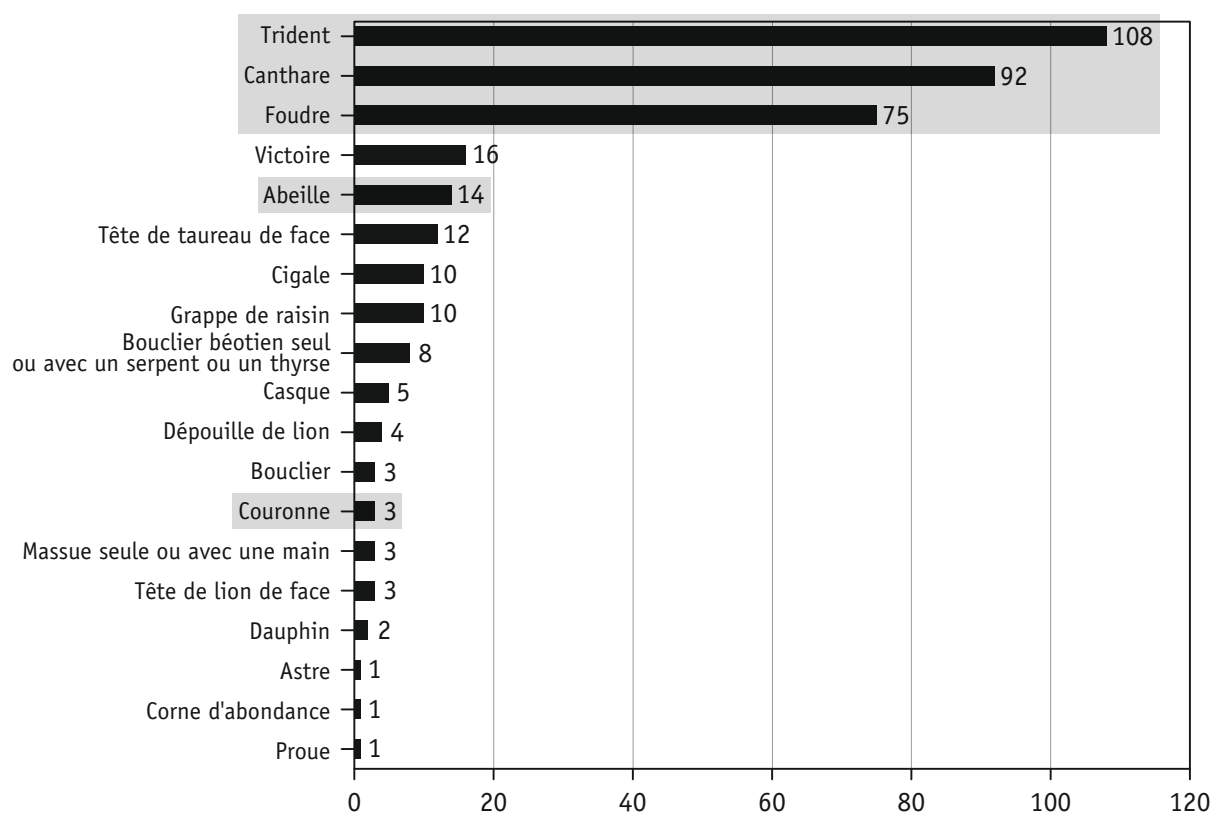

Figure 27 - Nombre de coins de droit des productions de statères aux types de Philippe II en fonction de la variété à Pella.

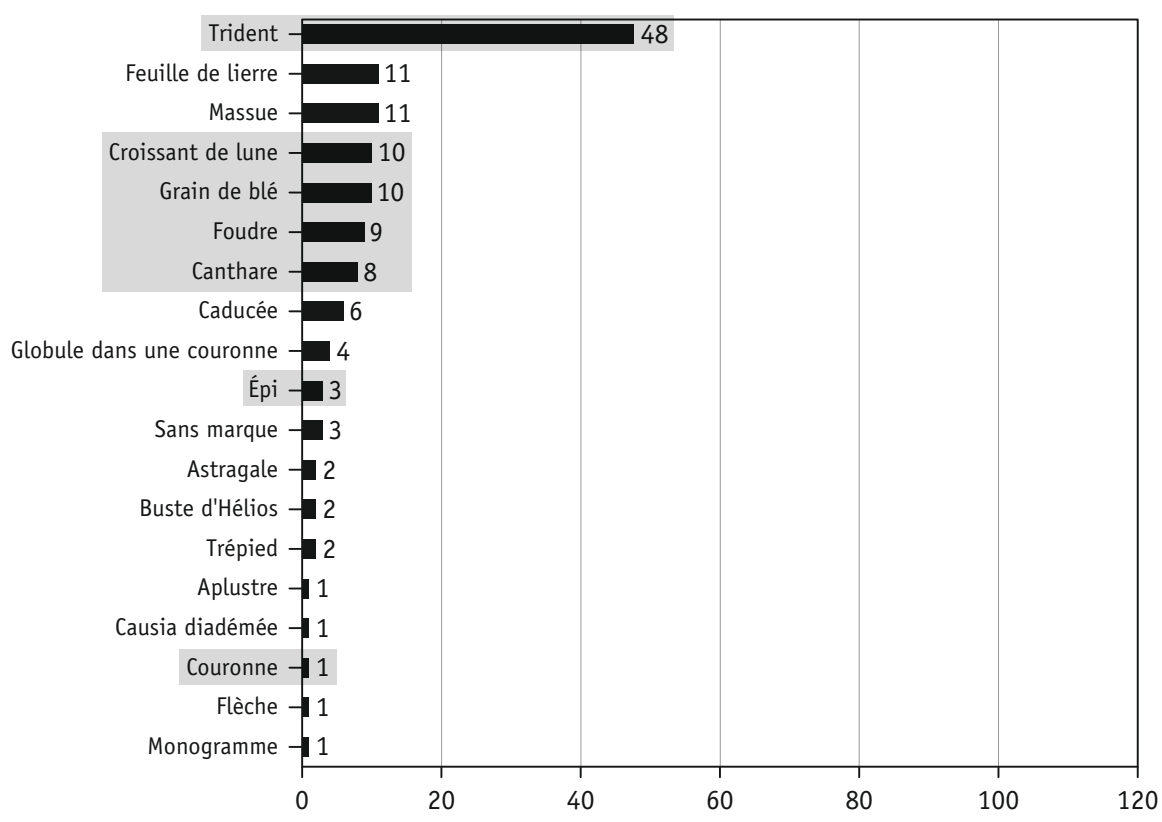

Figure 28 - Nombre de coins de droit des productions de statères aux types de Philippe II en fonction de la variété à Amphipolis. 
Les volumes émis ont donc un impact évident : les ateliers dont le produit a été retrouvé en Gaule sont les plus gros émetteurs de philippes. Toutefois, ce critère ne suffit pas à justifier la présence des monnaies de «Lampsaque » et «Abydos». Au-delà des volumes respectifs émis, la localisation des ateliers doit être prise en compte. Il est établi que les productions attribuées aux deux ateliers micrasiatiques doivent être placées dans le nord de l'Asie Mineure ou en Thrace ${ }^{139}$. Ici, la concentration des quatre ateliers qui nous intéressent dans le nord de l'Égée paraît faire sens et suggère que la proximité des lieux de frappes doive également être prise en considération.

Le critère quantitatif peut encore être invoqué en ce qui concerne le volume des émissions prises une à une. Le décompte du nombre de coins par variété indique que les plus massivement frappées sont systématiquement représentées en Gaule (voir les encadrés, figures 27-28). Sur ce point, les cas macédoniens sont corroborés par ceux de «Lampsaque » et «Abydos » où les variétés les plus frappées sont respectivement celle à la tête d'Hélios et au monogramme $\mathrm{A} \Pi$ (12 coins) et celle à l'étoile et au monogramme $\mathrm{MO}$ (6 coins). Toutefois, les graphiques ci-dessus montrent également que des séries plus réduites ont été retrouvées ou imitées en Gaule : par exemple les statères à l'abeille de Pella, au croissant ou à l'épi d'Amphipolis ou bien à l'épi/foudre/ $A P$ et à la patte de cheval à "Abydos». Ici encore, le fait quantitatif ne peut donc pas suffire à expliquer l'intégralité du phénomène.

Dans son étude des statères macédoniens, G. Le Rider met en évidence deux modèles de productions distincts. Dans beaucoup de cas, les variétés semblent se succéder les unes après les autres suivant un schéma linéaire. Par ailleurs, le savant met en évidence plusieurs séquences d'émissions compactes avec de nombreuses liaisons de coins de droit unissant deux, trois et jusqu'à six variétés, toutes ayant de fait été produites parallèlement ${ }^{140}$. Il est remarquable que ces principales séquences associent précisément les variétés attestées en Gaule.

\begin{tabular}{|l|c|c|c|}
\hline VARIETÉS & Foudre & Canthare & Trident \\
\hline Foudre & & 16 & 11 \\
\hline Canthare & 16 & & 29 \\
\hline Trident & 11 & 29 & \\
\hline
\end{tabular}

Figure 29 - Nombre des liaisons de coins au sein du groupe II-1 de l'atelier de Pella d'après Le RIDER 1977.

139. Supra, p. 201.

140. LE RIDER 1977, p. 415-416 et 421-424 (Pella) et p. 425-427 (Amphipolis). 


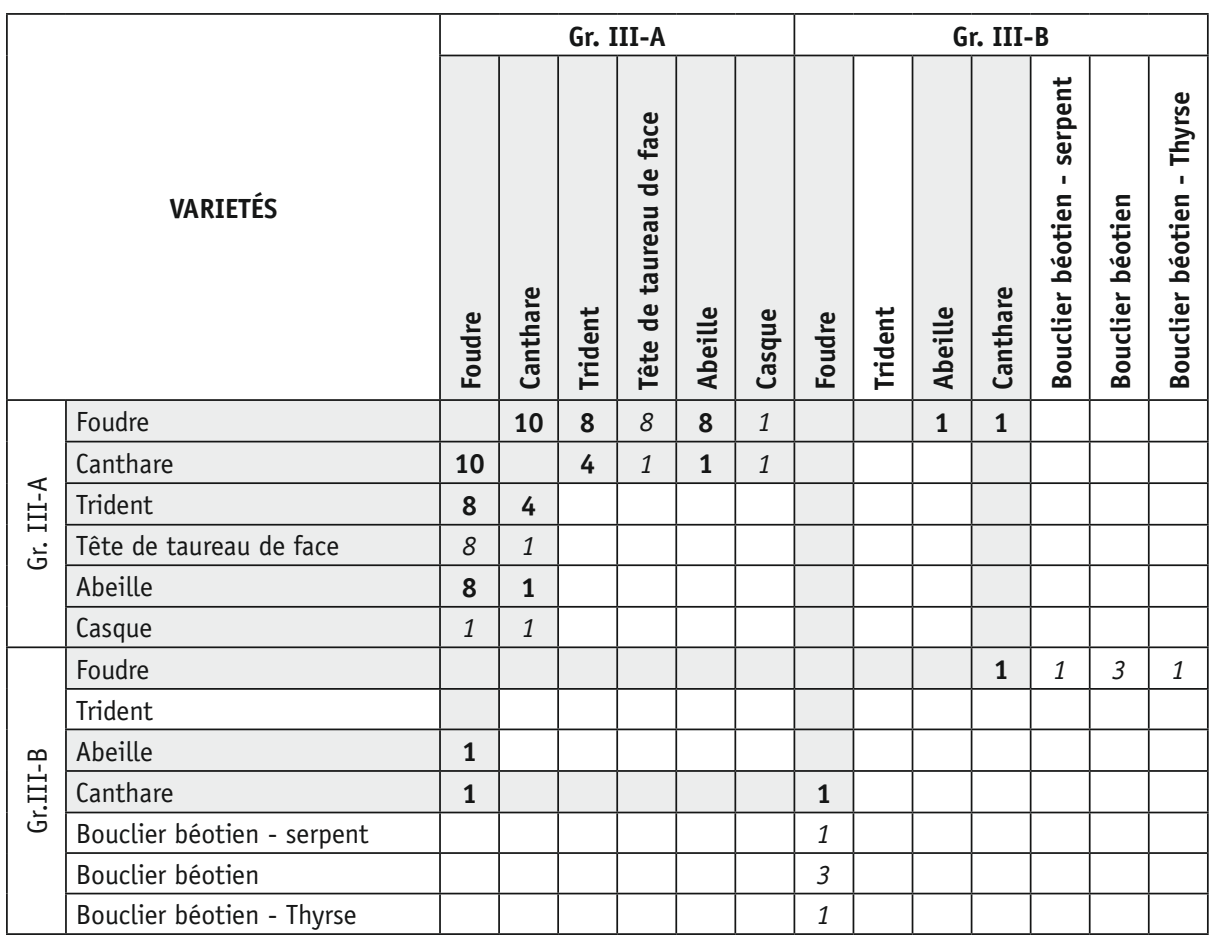

Figure 30 - Nombre des liaisons de coins au sein des groupes III-A et III-B de l'atelier de Pella d'après Le RIDER 1977.

\begin{tabular}{|c|c|c|c|c|c|c|c|c|c|c|c|}
\hline & & & & ir. II & & & & & III & & \\
\hline & VARIETES & 䒕 & 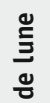 & & & & & & & & $\frac{5}{\frac{5}{\pi}}$ \\
\hline & \begin{tabular}{|l|} 
Feuille de lierre \\
\end{tabular} & & 1 & & & & & & & & \\
\hline 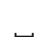 & Croissant de lune & 1 & & 1 & & & & & & & \\
\hline 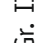 & Épi de blé & & 1 & & 1 & & & & & & \\
\hline & Trident & & & 1 & & & & & & & \\
\hline & Foudre & & & & & & & & & & \\
\hline & Canthare & & & & & & & 3 & 1 & & \\
\hline$\varangle$ & Trident & & & & & & 3 & & & & \\
\hline 当 & Trépied & & & & & & 1 & & & 1 & 1 \\
\hline ப் & Causia diadémée & & & & & & & & 1 & & \\
\hline & Grappe de raisin & & & & & & & & 1 & & \\
\hline
\end{tabular}

Figure 31 - Nombre des liaisons de coins au sein des groupes II et III-A de l'atelier d'Amphipolis d'après LE RIDER 1977. 
Chaque variété retrouvée ou imitée en Gaule est insérée dans un ou plusieurs réseaux de liaisons de coins associant au moins une autre variété « gauloise » ${ }^{141}$. Si les séries les plus volumineuses (trident, canthare et foudre) sont toujours les mieux représentées et les mieux connectées, elles sont associées à d'autres variétés plus modestes, celles pour lesquelles le fait quantitatif ne fournissait pas d'explication à leur présence en Gaule. À Pella, la variété du groupe III-A et III-B à l'abeille est liée avec celle au foudre (9 liaisons) et celle au canthare (1 liaison). À Amphipolis, au sein du groupe II, la variété au croissant de lune est connectée à celle à l'épi de blé qui est elle-même liée à celle au trident. Ce constat établi pour la Macédoine semble également être la règle au sein des productions des ateliers de «Lampsaque » et «Abydos».

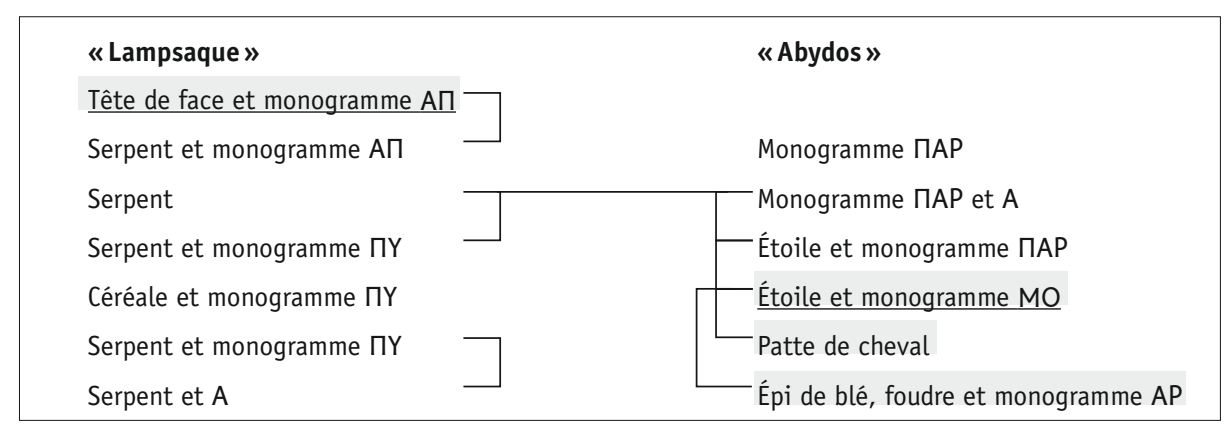

Figure 32 - Liaisons de coins entre les différentes variétés de statères aux types de Philippe II dans les ateliers de «Lampsaque» et «Abydos» selon THOMPSON $1991^{142}$.

L'établissement des séquences de production de ces ateliers parait solidement établie autant à partir de la succession des marques et monogrammes que des nombreuses liaisons de coins reliant les différentes variétés. À «Abydos », les trois variétés qui nous intéressent sont connectées par divers coins de droit. Surtout, ces dernières sont également liées aux productions de «Lampsaque » par une autre liaison de $\operatorname{coin}^{143}$. Bien que cette connexion n'atteigne pas les monnaies à la tête d'Hélios et au monogramme AП, il est possible d'affirmer sans trop de doute que toutes ces variétés ont été produites en un laps de temps assez court.

141. Les liaisons de ces variétés sont en gras, les réseaux sont eux matérialisés par un fond gris.

142. Les variétés dont un exemplaire a été retrouvé en Gaule sont soulignées, celles qui ont été imitées sont grisées.

143. Supra, n. 125. 
La production des philippes dure en Macédoine entre 30 et 35 années ${ }^{144}$. En Asie Mineure, malgré l'absence de séquence chronologique claire, tout indique que l'émission se poursuit au moins dix à quinze années ${ }^{145}$. Pourtant, les séries qui ont été retrouvées ou imitées en Gaule appartiennent à des émissions compactes dans lesquelles se côtoient des variétés massivement produites et d'autres plus réduites : toutes frappées uniquement dans les ateliers du nord de l'Égée. Ces concentrations des monnayages qui nous intéressent amènent à suggérer un nouveau critère de sélection des séries "gauloises», celui de la chronologie. Pour cela, il paraît utile de s'attarder sur les statères originaux importés en Gaule.

\begin{tabular}{|l|c|c|c|c|c|}
\hline Date & Pella & Amphipolis & Lampsaque & Abydos & Incertain \\
\hline Avant 325-323 & $1(+4)$ & 1 & & & \\
\hline Après 325-323 & 3 & $2(+1)$ & 3 & 1 & $1^{146}$ \\
\hline
\end{tabular}

Figure 33 - Répartition chronologique des exemplaires découverts en Gaule (les exemplaires incertains sont signalés entre parenthèses).

D'après ce tableau, il apparaît que seuls 2 exemplaires (ou 6 si l'on tient compte du trésor de Bordeaux) sont antérieurs aux années 325-323. Bien que ce ne soit pas une surprise pour les monnaies de «Lampsaque » et «Abydos» (dont les productions ne démarrent pas avant ces années), cette répartition interroge en ce qui concerne les monnaies macédoniennes.

\begin{tabular}{|l|l|c|c|}
\hline Groupe & Date & $\begin{array}{c}\text { Production totale, } \\
\text { en coins de droit }\end{array}$ & $\begin{array}{c}\text { Nombre d'exemplaires } \\
\text { découverts en Gaule }\end{array}$ \\
\hline Pella II & ca 340-328 ou ca 336-328 & 148 & $1(+4)$ \\
\hline Pella III & ca 323/322 - ca 310 & 88 & 3 \\
\hline Amphipolis II & ca 340-328 ou ca $336-328$ & 78 & 1 \\
\hline Amphipolis III & ca 323/322 - ca 315 & 49 & $2(+1)$ \\
\hline
\end{tabular}

Figure 34 - Répartition chronologique des exemplaires macédoniens découverts en Gaule.

Si l'on compare le nombre d'exemplaires originaux macédoniens trouvés en Gaule avec le total des productions de leurs groupes respectifs, on constate que les groupes II des ateliers de Pella et d'Amphipolis - pourtant de loin les plus volumineux - sont proportionnellement moins bien représentés que

144. Cf. figure 22 .

145. Cf. p. 200-201.

146. Il s'agit de l'exemplaire inédit de Carcassonne : supra, p. 184. 
les groupes III. L'impression d'une arrivée tardive des statères (pas avant ca 325323) est encore renforcée par la composition des trésors connus par ailleurs : les monnaies de «Lampsaque » et «Abydos » n'y apparaissent que lorsqu'y figurent les statères macédoniens de groupe III, soit à partir du tout début des années 310. Enfin, on note (figure 20) que les principaux modèles reconnus pour les séries celtiques imitant le type de Philippe appartiennent le plus souvent soit aux groupes III d'Amphipolis et de Pella, soit aux productions de «Lampsaque » ou «Abydos », de Magnésie et de Colophon, datés au plus tôt de la seconde moitié des années 320 . Ce n'est donc qu'à partir de ces années que serait parvenue en Gaule la totalité des variétés représentées.

Bien entendu, l'hypothèse d'arrivages de philippes en Gaule durant plusieurs années depuis les années 330, donc avant l'apparition du groupe III et des séries de Propontide, est toujours envisageable. Pourtant, le petit nombre de trouvailles d'exemplaires originaux tend plutôt à favoriser l'hypothèse d'un arrivage modeste et limité dans le temps. C'est notamment ce que suggère le cas de la série au monogramme AP, épi et foudre, abondamment imitée en Gaule et pour laquelle aucun prototype n'a été découvert en Europe. Cette série d'imitations comporte une erreur de graphie dans la légende dès les premières émissions (un I ajouté entre l' $O$ et le $Y$ de $\$ \mathrm{I} / \mathrm{II} \Pi \mathrm{IOY}$, figure 35$)^{147}$. Le fait que cette erreur soit reproduite à l'identique au fil des séries indique que les nouvelles imitations prennent pour modèle les anciennes, les graveurs n'ayant manifestement plus d'exemplaires originaux à disposition.
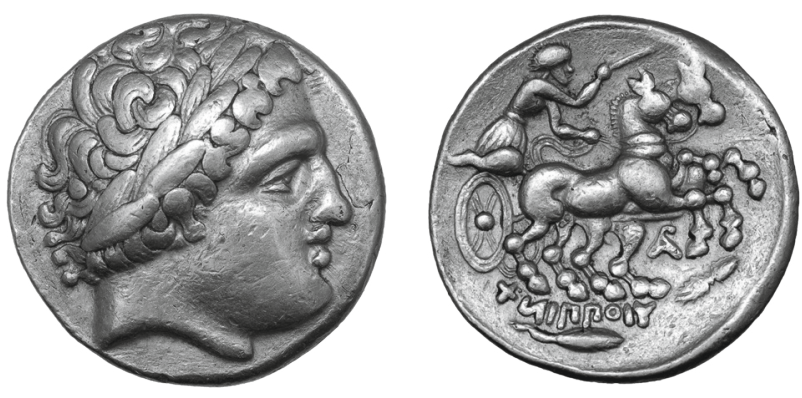

Figure 35 - Statère gaulois de la série au monogramme AP, épi et foudre (BnF 3614, éch 2:1).

147. Dans l'état actuel des connaissances, deux exemplaires sans cette erreur de graphie semblent répertoriés (BM 956, ex. coll. Morel ; SiLLS 2003, p. 23). La même erreur est reproduite sur les exemplaires de la série dite d'Essey qui reprennent au droit le type à la tête de Néapolis et au revers le bige de Philippe avec le monogramme AP/triskèle, l'épi et le foudre. 
Au final, la confrontation du corpus des philippes découverts en Gaule ainsi que des premières imitations avec ce l'on sait des émissions macédoniennes et micrasiatiques a permis de mettre en évidence quatre points principaux:

- les ateliers émetteurs / modèles. Ils sont concentrés dans une zone géographique déterminée, le nord de l'Égée ;

- les variétés. Les plus massivement frappées sont présentes mais pas seulement, presque toutes sont connectées entre elles et ont été émises en un laps de temps assez court;

- la chronologie. Inversement à l'importance des émissions, ce sont les monnaies frappées après 325-323 qui sont nettement majoritaires en Gaule ;

- l'ampleur. Seul un petit nombre d'exemplaires originaux a été retrouvé. On note également la persistance des erreurs de copie, comme si les pièces gréco-macédoniennes avaient rapidement disparu de la circulation.

Ces quatre points concordent pour esquisser les contours d'un épisode très circonscrit, voire limité. Ce constat vaut tant pour ce qui est de la chronologie - quelque part entre la fin des années 320 et la fin du siècle - que pour l'importance du phénomène, très probablement d'ampleur réduite.

L'étude détaillée du matériel grec a permis de confirmer le terminus post quem généralement admis en même temps que de mieux évaluer le mécanisme d'importation des exemplaires originaux. La confrontation des éléments rassemblés autant dans l'espace celtique que gréco-macédonien constitue une solide base pour nourrir la réflexion quant aux circonstances de l'introduction en Gaule du statère de Philippe II et plus largement du fait monétaire au second âge du Fer.

\section{Comprendre les découvertes des statères de Philippe II en Gaule}

A. Le contexte:

mutation et expansion du monde celtique (IVe-IIIe siècle av. J.-C.)

Considérés comme une période de transition ${ }^{148}$, le IVe et le IIIe siècle se caractérisent avant tout par l'expansion du monde celtique qui couvre désormais un vaste espace de la Bretagne aux rives de la mer Noire, du sud de la Pologne à l'Italie septentrionale (figure 36$)^{149}$.

148. BRUN 2007 et MARTIN 2015, p. 346 notamment mais avec des chronologies différentes. La période de transition s'étend de ca 325 à 130/120 av. J.-C. pour P. Brun, entre ca 425 et 275 av. J.-C. pour S. Martin.

149. BUCHSENSCHUTZ et alii 2012, p. 323 ; BUCHSENSCHUTZ et alii 2015, p. 177-222. 


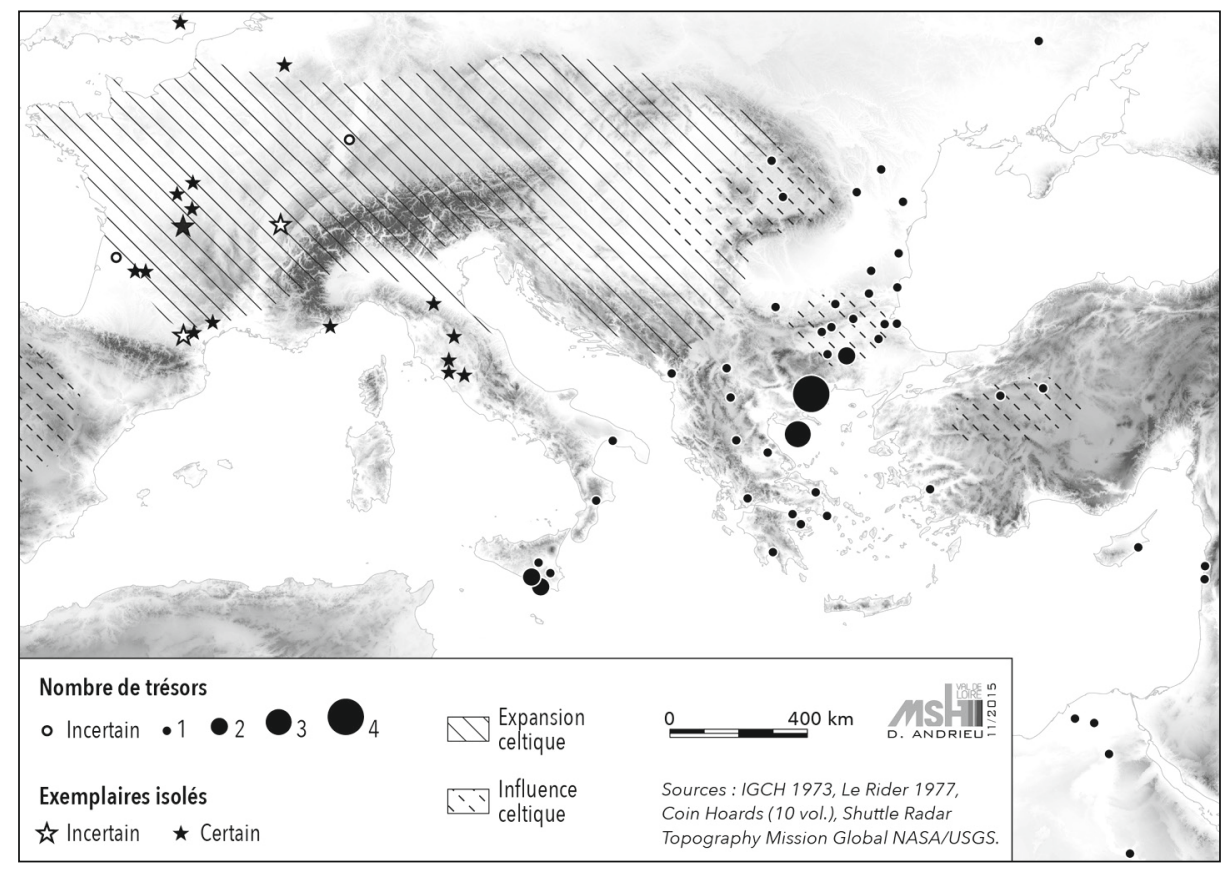

Figure 36 - Trésors et trouvailles de statères de Philippe II dans les mondes grec et celtique (zone d'expansion celtique d'après BUCHSENSCHUTZ et alii 2015, p. 179).

Les travaux menés ces dernières années sur différentes régions ${ }^{150}$ et les synthèses récentes qui en ont été réalisées ${ }^{151}$ ont permis de mieux caractériser la société celtique dans ses composantes les plus larges révélant une remarquable unité culturelle du domaine laténien ${ }^{152}$.

À partir du IVe siècle, les agglomérations qui caractérisaient les vie et ve siècles disparaissent au profit d'un habitat essentiellement rural et dispersé ${ }^{153}$. Cette société fortement hiérarchisée est dominée par des élites aristocratiques ouvertes sur le monde méditerranéen ${ }^{154}$ et dont la fonction militaire se développe considérablement, comme l'attestent le mobilier accompagnant les sépultures, les banquets et les sanctuaires ${ }^{155}$. Paradoxalement, les données

150. Plus particulièrement publiées dans les actes du colloque de l'AFEAF en 2007 consacré, pour la partie thématique, à «La Gaule dans son contexte européen aux IVe et IIIe siècles av. notre ère » (MENNESSIER-JouANNET et alii 2007). Voir également MARION 2013 et MENNESSIER-JouANNET 2013.

151. BUCHSENSCHUTZ et alii 2012 ; BUCHSENSCHUTZ et alii 2015.

152. BUCHSENSCHUTZ et alii 2015, p. 177-183.

153. BUCHSENSCHUTZ et alii 2012, p. 324 ; BUCHSENSCHUTZ et alii 2015, p. 176.

154. BUCHSENSCHUTZ et alii 2012, p. 300.

155. BUCHSENSCHUTZ et alii 2012, p. 324. 
archéologiques témoignent au IVe et au IIIe siècle d'une diminution considérable des importations méditerranéennes au regard des informations enregistrées pour la période précédente (VIIe-Ve siècles) ${ }^{156}$. Tout en restant prudente quant à la validité des provenances des objets recensés, A.-M. Adam met en avant l'aspect diffus et composite de ces découvertes qui ne paraissent plus correspondre à des courants de diffusion ${ }^{157}$. Parallèlement, l'artisanat et l'art se perfectionnent et les productions artisanales à l'échelle de l'Europe celtique s'uniformisent ${ }^{158}$.

Le IVe et le IIIe siècle voient également apparaître et se développer les sanctuaires d'abord dans le Belgium et dans la partie ouest de la Gaule au début du IVe siècle, puis à partir de La Tène B2 plus à l'est comme à La Villeneuveau-Châtelot (Aube) ou à Mirebeau (Côte-d'Or). Lieu de cohésion politique et sociale, ce nouveau type de site a organisé spatialement et politiquement les territoires et semble avoir joué un rôle dans la genèse de la cité159.

Les migrations celtes qui caractérisent cette période dans la péninsule italienne, dont l'évènement le plus retentissant chez les auteurs antiques est la prise de Rome en 390 av. J.-C., conduisent à l'occupation de la quasi-totalité de la plaine du Pô. Ces mouvements de populations ne sont pas limités aux régions septentrionales, des incursions vers le sud semblent fréquentes jusqu'au début du IIIe siècle. La victoire romaine de Sentinum en 295 puis la fondation de la colonie de Sena en 283 met un terme à l'expansion celtique dans cette région ${ }^{160}$.

Vers l'Est, la première vague de migration est attestée par les sources historiques qui situent des groupes celtiques dans les régions illyriennes et dans la cuvette des Carpates vers le milieu du Ive siècle ${ }^{161}$. L'envoi d'ambassades celtes à Alexandre le Grand en 335 et 323 témoignent peut-être du rôle que commencent à tenir ces populations dans la région ${ }^{162}$. Dans la première moitié du IIIe siècle, ces mouvements en direction des Balkans, jusqu'à Delphes et en Asie Mineure doivent être compris, à l'appui des textes et des données archéologiques, comme un phénomène de colonisation ${ }^{163}$. Ainsi, au IVe et au III siècle, des groupes celtiques occupent le nord des Balkans et les données archéologiques, comme les sources textuelles, témoignent sinon d'une colonisation pacifique au moins de mouvements qui ne paraissent pas avoir généré

156. ADAM 2007, p. 255.

157. Ibid.

158. BUCHSENSCHUTZ et alii 2012, p. 300-306.

159. FICHTL 2007, p. 288. Voir également SCHÖNFELDER 2007, p. 297.

160. BUCHSENSCHUTZ et alii 2012, p. 296.

161. BUCHSENSCHUTZ et alii 2012, p. 312 ; BUCHSENSCHUTZ et alii 2015, p. 206-207.

162. Strabon, Géographie, VII, 3, 8 ; Arrien, Anabase, I, 4, 6-8; VII, 15, 4. À propos des diverses interprétations relatives à ces ambassades, voir BUCHSENSCHUTZ et alii 2012, p. 311 ; BUCHSENSCHUTZ et alii 2015, p. 207 ; MARTIN 2015, p. 342.

163. L'influence considérable de la culture laténienne est visible dans les habitats, les sépultures et le mobilier (BUCHSENSCHUTZ et alii 2012, p. 312). 
de conflits importants avec les royaumes hellénistiques ou les populations locales ${ }^{164}$. L'échec des expéditions dans les Balkans en 280-279 marque l'arrêt de l'expansion celtique dans cette région.

Corollaire ou «ferment» de l'expansion celte du début du Ive siècle dans la péninsule italienne ${ }^{165}$, le mercenariat celtique est une pratique largement attestée au IVe et au IIIe siècle av. J.-C. Si S. Péré-Noguès souligne qu'il n'est pas toujours aisé de distinguer mercenariat et migrations de communautés celtes à travers les textes, l'inventaire des mentions de ces soldats dans les sources textuelles ${ }^{166}$ et la cartographie qu'en a proposée L. Baray donnent une image de l'ampleur du phénomène selon les périodes ${ }^{167}$ (figure 37).

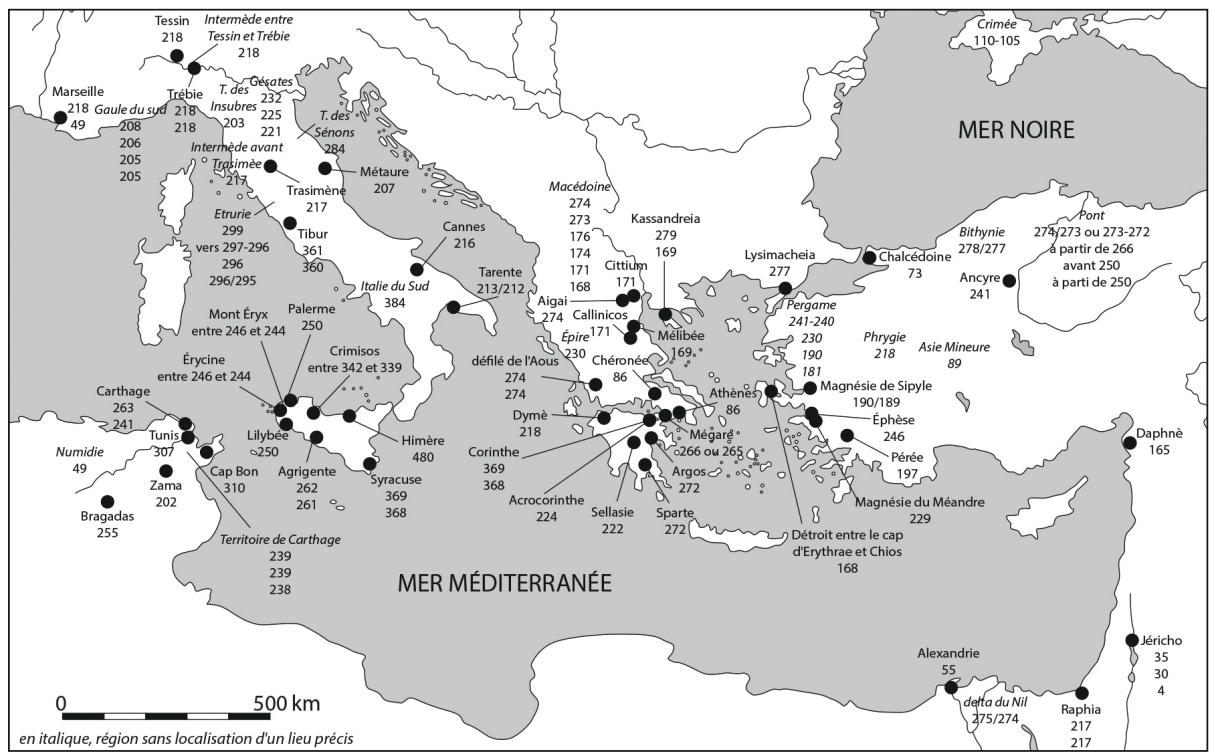

Figure 37 - Répartition des mentions de mercenaires et/ou d'auxiliaires celtes d'après les sources littéraires (d'après BARAY 2015, pl. I).

La première occurrence de mercenaires celtes se trouve chez Hérodote au moment de la bataille d'Himère en 480 . Au Ive siècle, des mercenaires celtes sont recrutés par Carthage, par des cités grecques au premier rang desquelles figure Syracuse sous les règnes de Denys l'Ancien puis d'Agathocle, ainsi que par des cités étrusques et latines. À partir de la fin du Ive siècle et du début du

164. ADAM, FicHTL 2011, p. 117-118; BUCHSENSCHUTZ et alii 2012, p. 313.

165. PÉRÉ-NoguÈs 2007, p. 355.

166. Notamment pour l'Occident PÉRÉ-NoguÈs 2007 et 2011a ; pour l'Orient ADAM, FiCHTL 2011.

167. BARAY 2014, p. 18 ; 2015, pl. I. Nous remercions L. Baray qui nous a autorisés à reproduire la carte dans le présent article. 
III siècle, ces mercenaires sont également à la solde des royaumes hellénistiques en Grèce et en Asie Mineure ${ }^{168}$. Ils sont donc présents sur de très nombreux théâtres d'opérations en Méditerranée occidentale et orientale et, de fait, au contact de cultures qui utilisent l'outil monétaire.

\section{B. Comment expliquer l'arrivée des «philippes» en Gaule : l'hypothèse des mercenaires révisée}

Plusieurs hypothèses ont été émises pour expliquer l'arrivée des statères aux types de Philippe II en Gaule dont la synthèse a été faite par S. Scheers ${ }^{169}$ et que nous reprenons brièvement ici.

En toute logique, ce sont d'abord les relations que les Gaulois ont pu entretenir avec la Macédoine qui ont retenu l'attention des numismates. Dès 1763, J. Pellerin, l'un des premiers à signaler des imitations gauloises du statère de Philippe II, explique leur existence par les expéditions gauloises en Macédoine et en Grèce sous le commandement de Brennus ${ }^{170}$. C'est précisément le pillage du temple de Delphes en 279 av.J.-C. puis le rôle des mercenaires celtes enrôlés dans les armées des royaumes hellénistiques qui, pendant un temps, ont permis d'expliquer l'arrivée des philippes en Gaule ${ }^{171}$. Peut-être de façon plus ponctuelle dans l'historiographie, Marseille, à l'appui d'un passage de Strabon ${ }^{172}$, et Rome, avec les butins rapportés des victoires en Grèce et en Asie Mineure au IIe siècle, ont également été perçues comme des intermédiaires possibles dans l'introduction du statère de Philippe en Gaule ${ }^{173}$. Des contacts commerciaux ont aussi été invoqués pour expliquer notamment l'imitation dans le nord de la Gaule de statères tarentins ${ }^{174}$.

Mais c'est l'hypothèse du mercenariat en Méditerranée occidentale entre 320 et 270 av. J.-C., exposée par S. Scheers dès 1978 mais surtout à partir des années 1990, qui a suscité le plus d'intérêt et d'adhésion ${ }^{175}$. S. Scheers propose

168. PÉRÉ-NOGUÈs $2011 b$.

169. SCHEERS 1978,1999, p. $49 ; 2004$, p. 12-13.

170. PELLERIN 1763, p. 15.

171. SCHEERS 2004, p. 12.

172. Strabon, Géographie, IV , 1, 5 («la dot la plus forte chez eux est de cent pièces d'or»). Ce passage de Strabon dans lequel il est question de la dot en or chez les Massaliotes a été notamment utilisé pour faire de Marseille sinon un vecteur au moins une cité dans laquelle les statères d'or, voire les «philippes », étaient en usage. Or, comme l'avait souligné $\mathrm{X}$. Loriot suite à la communication de S. Scheers qui faisait état de ces quelques lignes, le texte de Strabon mentionne seulement le terme de "pièces d'or » (chrysoi). En outre, il n'est pas certain que l'information provienne de Poseidonios, principale source de Strabon, elle pourrait aussi venir d'un panégyriste anonyme d'Auguste (SCHEERS 1978, p. 450).

173. SCHEERS 1999 , p. $49 ; 2004$, p. 12-13.

174. SCHEERS 1978, p. 446.

175. SCHEERS 1978, p. $446 ; 1993 ; 1999$, p. 49-50 ; 2004, p. 13-14. Voir BARAY 2014, p. 141 pour la synthèse bibliographique. 
de rechercher les liens qui auraient permis aux Gaulois d'être en contact avec la monnaie macédonienne non plus à l'est mais dans la partie occidentale de la Méditerranée. Pour cela, elle se fonde sur les imitations gauloises de monnaies de Tarente et de Néapolis ainsi que sur le rayonnement du statère de Philippe en Sicile. Des monnaies d'or d'Agathocle ${ }^{176}$ reprennent en effet les types de Philippe II à l'exception de l'ethnique syracusaine qui demeure. L'auteur signale enfin l'existence de plusieurs trésors composés de statères de Philippe II et d'Alexandre le Grand découverts en Grande-Grèce et en Sicile et datés entre 320 et 270 av. J.-C. Or cette période est marquée, en Méditerranée occidentale, par de nombreux conflits qui opposent Carthage, Syracuse, Tarente et Rome. À l'appui des sources textuelles qui attestent le recrutement de mercenaires celtes par Carthage et certaines cités grecques, S. Scheers en déduit que les statères aux types de Philippe II ont été introduits en Gaule avant la première guerre punique par des mercenaires gaulois à la solde des différents belligérants.

Les récents travaux de L. Baray sur le mercenariat celtique proposent de reconsidérer le postulat de S. Scheers, jusque-là communément accepté par les numismates. Si l'auteur reconnaît le «synchronisme chronologique » qui conforte cette hypothèse ${ }^{177}$, il relève cependant que le nombre des statères originaux en Gaule est faible au regard des effectifs mobilisés et souligne qu'aucun trésor de philippes n'y a été enregistré. Ce constat conduit L. Baray à reprendre ou formuler diverses hypothèses pour arriver à la conclusion que si l'on connaît si peu d'originaux en Gaule c'est qu'ils ont été peu nombreux à y être introduits. Voici, de façon synthétique, les arguments qu'il développe : - la refonte des statères originaux pour frapper des imitations, explication couramment donnée, est exclue pour L. Baray qui s'interroge sur l'intérêt d'une telle pratique dans la mesure où les originaux et les imitations sont de poids et de titre identiques ${ }^{178}$. Les trésors de Bordeaux et de Gamshurst iraient par ailleurs, selon lui, à l'encontre de cette explication ${ }^{179}$. Des refontes pour la fabrication d'objets sont également envisagées, L. Baray postulant que seule la valeur intrinsèque de la monnaie grecque aurait, dans un premier temps, retenu l'attention des Celtes ;

176. HOOVER 2012, no 1276 (hémistatère) et 1286 (quart de statère). S. Scheers ajoute à ces monnayages ceux d'Hikétas (HOOVER 2012, no 1277) mais dans ce cas l'influence des monnaies de Philippe II nous paraît moins probante (tête de Perséphone au droit, Niké conduisant un bige au revers).

177. BARAY 2014, p. 144.

178. BARAY 2014, p. 149. Nous sommes toutefois moins catégoriques que L. Baray, les études en cours et les données actuellement disponibles montrent que le poids et le titre des exemplaires gaulois frappés sont globalement plus faibles que ceux des statères macédoniens (SCHEERS, BARRANDON 1994, p. 81-99; étude en cours S. Nieto-Pelletier).

179. BARAY 2014, p. 148. Voir supra pour les réserves formulées à propos de ces deux dépôts. 
- la monnaie n'a pas été introduite par les mercenaires mais par d'autres voies comme le butin ou le commerce. Il exclut toutefois le fait que ces monnaies aient pu servir à payer des importations, les données archéologiques ne le corroborant pas. Nous avons évoqué précédemment l'analyse d'A.-M. Adam à propos de la baisse sensible des importations d'objets d'origine grecque ou italique au IVe et au IIIe siècle ${ }^{180}$. Il convient de préciser qu'elle pondère toutefois son propos en considérant Marseille comme un probable relais dans la diffusion vers l'intérieur de la Gaule de produits méditerranéens d'origine plus ou moins lointaine mais dont les quantités n'ont cependant rien à voir avec celles connues pour les périodes antérieures et postérieures. En outre le petit nombre de statères macédoniens en Gaule n'est pas, selon L. Baray, en faveur de l'hypothèse commerciale, hypothèse également réfutée par D. Wigg-Wolf ${ }^{181}$;

- l'Europe celtique ne disposant pas de l'outil monétaire, les mercenaires se seraient débarrassés de leur solde sur le chemin du retour ;

- peut-être faut-il envisager une pluralité des modes de rémunérations des mercenaires par exemple des lingots de métal brut ou des objets manufacturés, la monnaie n'intervenant que ponctuellement à partir du IIIe siècle ${ }^{182}$.

180. ADAM 2007, p. 260.

181. WIGG-WoLF 2011, p. 305. L. Baray appuie par ailleurs son raisonnement en reprenant le postulat de $\mathrm{M}$. Thompson à propos des frappes massives (que l'auteur qualifie d' « exceptionnelles ») de monnaies d'or et d'argent de la fin du règne d'Alexandre (325-323) qui auraient servi à payer la solde des armées démobilisées de retour de campagne (THOMPSON 1984). L'hypothèse de $\mathrm{M}$. Thompson s'appuie notamment sur la concordance de l'augmentation sensible des frappes de monnaies d'or et d'argent (en Asie Mineure et en Macédoine) avec le mouvement général des trésors depuis l'est (Asie Mineure, Chypre et Levant) vers l'ouest (Grèce, Macédoine, Balkans principalement). Bien que l'hypothèse de $\mathrm{M}$. Thompson ait été discutée par G. Le Rider (LE RIDER 2003, p. 86-101), d'autres études de cas ont montré des phénomènes similaires et contemporains pour d'autres régions, par exemple Arados (DUYRAT 2000, p. 48-51). Suivant cette idée, B. Fischer avait envisagé que le statère inédit de Carcassonne, exemplaire probablement original mais non attesté dans les productions macédoniennes (supra partie 1), serait le témoin de ces frappes dites «exceptionnelles», c'est-à-dire des frappes, si nous comprenons bien la pensée de l'auteur, destinées uniquement à la solde des mercenaires sur le chemin du retour (FISCHER 1991, p. 154). Pour démentir l'idée d'une introduction des philippes avec les mercenaires celtes, L. Baray argue au contraire du fait que les originaux trouvés en Europe celtique sont également présents dans le monde grec. À ce stade, les raisonnements avancés par B. Fischer et L. Baray ne nous paraissent pas recevables, notamment car ils semblent se fonder sur l'idée que ces frappes sont «exceptionnelles » parce qu'exclusivement motivées par le paiement des mercenaires alors que c'est avant tout leur ampleur qui les distingue.

182. On dispose pour les III et II siècles de sources textuelles fiables mentionnant le versement de soldes monnayées aux mercenaires celtes (BARAY 2014, p. 152-153). 
Ainsi, Luc Baray conclut qu' «il n'existe aucun lien univoque entre mercenariat et la monnaie ${ }^{183}$ » et explique son succès en Gaule avant tout par la «renommée» du statère aux types de Philippe. Les États celtiques et/ou les chefs des grandes familles se seraient progressivement approprié l'outil monétaire à partir de quelques exemplaires circulant en Europe celtique ${ }^{184}$.

Le lien avec le mercenariat n'est pas non plus complètement satisfaisant pour J.-L. Brunaux ${ }^{185}$. S'il est probable que des stocks considérables d'or sous forme de monnaies ou d'objets manufacturés ont été récupérés par les contingents armés celtiques, il s'interroge sur les quantités effectivement arrivées en Gaule. Il souligne que tous les mercenaires ne revenaient pas et que pour ceux qui revenaient, le retour pouvait s'effectuer plusieurs années après leur départ. Une partie de la solde ou des butins était très certainement dépensée avant qu'ils ne rentrent chez eux.

Surtout, l'hypothèse du mercenariat se heurte à la documentation des trésors de monnaies d'or enfouis en Italie du sud et en Sicile, les zones où auraient exercé ces mercenaires gaulois. Il a déjà été rappelé que les philippes avaient circulé dans de nombreuses régions du pourtour méditerranéen et des Balkans ${ }^{186}$. Le décompte des trésors en fonction de leur localisation fournit à ce titre un tableau un peu plus nuancé (figure 38).

\begin{tabular}{|c|c|c|c|c|c|c|c|}
\hline Régions & $\begin{array}{l}\bar{\pi} \\
\stackrel{0}{0}\end{array}$ & 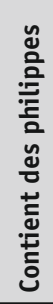 & 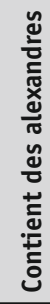 & 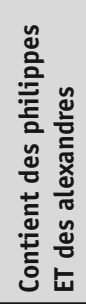 & 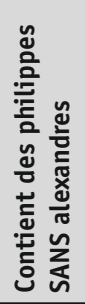 & 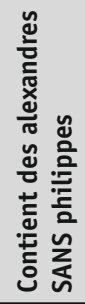 & 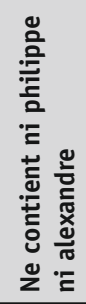 \\
\hline Italie et Sicile & 37 & 7 & 8 & 6 & 1 & 2 & 28 \\
\hline Balkans & 49 & 32 & 35 & 21 & 11 & 14 & 3 \\
\hline Grèce & 13 & 9 & 10 & 8 & 1 & 2 & 2 \\
\hline Asie Mineure & 7 & 5 & 6 & 4 & 1 & 2 & 0 \\
\hline
\end{tabular}

Figure 38 - Nombre de trésors contenant des numéraires d'or en Italie, en Sicile, dans les Balkans, en Grèce et en Asie Mineure entre le dernier tiers du IVe siècle et le premier tiers du IIIe siècle ${ }^{187}$.

183. BARAY 2014, p. 162.

184. Ibid.

185. BRUNAUX 2009, p. 69-71.

186. Supra, p. 197, également figure 36.

187. Les autres régions (Levant, Égypte, ...) n'ont pas été représentées car elles ne présentent pas d'intérêt majeur dans le cadre du sujet abordé. 
S'il se confirme que les philippes occupent une place de choix dans les trouvailles enfouies dans les Balkans en premier lieu, sur les bords de l'Égée ensuite, la situation est bien différente en Occident. Les statères de Philippe II ne sont présents que dans une petite partie des trésors (7 seulement sur les 37 recensés). Il est remarquable qu'ils soient généralement associés à des statères d'Alexandre, eux aussi présents dans un assez petit nombre de trouvailles ${ }^{188}$. De plus, la chronologie des enfouissements ne coïncide que très partiellement avec celle des mentions attestant de l'emploi de mercenaires dans la région ${ }^{189}$. Celles-ci sont principalement datées soit du deuxième tiers du Ive siècle (en Sicile uniquement) soit des années ca 260 à ca 200 (en Afrique du nord, en Sicile et en Grande Grèce). Même si cette absence de mentions n'est pas la preuve de l'arrêt complet du recrutement des mercenaires celtiques en Méditerranée occidentale, il est notable que l'intervalle entre ces deux phases correspond à peu près exactement à la chronologie de l'enfouissement des quelques trésors qui nous concernent : entre ca 320 et ca $270^{190}$.

Ainsi, le nombre, la composition et la chronologie des trésors italiens et siciliens contenant des philippes concordent pour affaiblir l'hypothèse proposée par S. Scheers. Rien n'indique que les statères aux types de Philippe aient été à un moment un monnayage de référence dans la région, par exemple pour des mercenaires gaulois employés par Carthage ou Syracuse. Ces cités produisaient d'ailleurs elles-mêmes des numéraires d'or et d'électrum qui figurent en bonne place dans les trésors de la région et semblent plus à même d'avoir été employés pour rémunérer ces mercenaires celtes ${ }^{191}$.

\section{Que reste-t-il au final de l'hypothèse du mercenariat ?}

Pour comprendre les modalités d'introduction du statère aux types de Philippe II en Gaule, nous ne pouvons faire l'économie d'une analyse spatiale de la répartition de ces exemplaires d'une part à l'échelle du domaine laténien mais également à celle de l'ensemble du monde grec.

La carte de répartition des trésors et trouvailles de philippes apporte plusieurs informations (figure 36). Tous les dépôts contenant des philippes, à l'exception de deux, se localisent en dehors de la zone d'expansion celtique actuellement délimitée à partir de l'analyse du mobilier archéologique et des sources textuelles. Les exemplaires isolés, en revanche, à l'exception de 3 ou 4 statères en Italie centrale, se situent dans le domaine celtique. S’il est à peu près avéré

188. Sur les monnaies d'Alexandre dans l'ouest: WiLLIAMs, BuRnEtT 1998.

189. Voir figure 37.

190. Gela 1883 (IGCH 2143), ca 320 ?; Tarente 1883 (IGCH 1932 ; CH 1.51), après 302 ; Camarina 1980 (CH 7.59), 300 ; Buccheri 1904 (IGCH 2159), ca 300 ?; Gela 1918 (IGCH 2196), ca 282 ; Serra Orlando 1966 (IGCH 2204), ca 270 ; Tiriolo 1835 ? (CH 10.401).

191. Cette question des autres monnayages d’or de la région sera abordée dans la section 3.C. 
qu'aucun trésor n'a été découvert en Europe occidentale, il convient néanmoins d'être plus prudent quant aux trouvailles isolées dans le monde égéen, qui ne semblent en effet pas complètement absentes ${ }^{192}$.

Si cette carte traduit en premier lieu l'état d'avancement des recherches ${ }^{193}$, la répartition des dépôts et trouvailles de philippes, telle qu'elle apparaît aujourd'hui, semble être un argument en faveur d'une arrivée de la monnaie en Gaule par le sud, comme l'avaient déjà suggéré S. Scheers puis J. Sills ${ }^{194}$.

Quant à la question du rôle des mercenaires, si plusieurs arguments abondent en ce sens, d'autres amènent à nuancer considérablement cette explication. Le contexte des années 320-270 av. J.-C. en Méditerranée occidentale, la présence de philippes dans les trésors en Grand-Grèce et en Sicile, l'imitation de monnaies de Tarente par des pouvoirs émetteurs du nord de la Gaule ${ }^{195}$ suggèrent une arrivée par l'intermédiaire de mercenaires. A contrario, le nombre peu élevé de monnaies recensées et l'absence de dépôts monétaires en Europe celtique ne sont pas en faveur d'une introduction de la monnaie par des mercenaires. En outre, dans le détail, la chronologie n'est finalement pas si satisfaisante que l'on confronte les mentions de mercenariat aux trésors de Grande-Grèce et de Sicile (supra) ou aux contextes actuellement connus pour les imitations. Comme le souligne à juste titre S. Martin, l'essentiel des textes littéraires concernant les mercenaires celtes mentionnent des engagements après 280 av. J.-C. ${ }^{196}$, alors qu'il est généralement admis que les statères aux types de Philippe II sont arrivés en Gaule entre 320 et 280/270 av. J.-C. ${ }^{197}$ Â partir de la cartographie des mentions de mercenaires et d'auxiliaires celtes dans les sources littéraires ${ }^{198}$, nous avons recensé en Méditerranée occidentale 8 mentions pour le IVe siècle (entre 384 et 307 av. J.-C.) et 35 mentions pour le IIIe siècle. Parmi ces 35 mentions, 5 seulement sont antérieures à 270 av. J.-C. En Méditerranée orientale, 2 attestations concernent le IVe siècle (369 et 368 av. J.-C.) et 30 le III siècle, la plus ancienne est 279 et 10 sont comprises entre 279 et 272 av. J.-C.

192. Le caractère dispersé de la documentation actuellement disponible ne nous a pas permis de proposer une cartographie de ces trouvailles dans le cadre de cette étude.

193. Dans l'état actuel des connaissances, il semble avéré qu'il n'y a pas de statère aux types de Philippe II dans la partie occidentale des Balkans. Nous remercions B. Woytek (Académie des Sciences autrichiennes) et M. Rudnicki (Université de Varsovie) pour cette information.

194. SCHEERS 1999, 2004 ; SILLS 2003, p. 8.

195. SCHEERS 2004.

196. MARTIN 2015, p. 348.

197. Avec quelques variations toutefois: SILLS 2003, p. 123 : 320-270 av. J.-C.; SCHEERS 2004, p. 14-15 : période précédant la première guerre punique (264-241 av. J.-C.) ; GUIHARD 2012, p. 60 : 323-300 av. J.-C. ; PION 2012, p. 152 : 320-270 av. J.-C. ; MARTIN 2015, p. 333-334 : 320-270 av. J.-C.

198. BARAY 2014, p. 18. 
La chronologie de ces attestations n'est donc que très imparfaitement corrélée aux contextes actuellement connus pour des imitations qui présentent déjà une évolution certaine du type : Ribemont-sur-Ancre (La Tène C1b 250220 av. J.-C.), mais également La Grande-Borne (La Tène C1b 250-200 av. J.-C.) et plus encore par la sépulture d'Hostomice ( $1^{\text {re }}$ moitié du IIIe siècle av. J.-C. $)^{199}$. Mais rappelons que ces trois contextes présentent encore des incertitudes ou sont trop peu précis pour être pleinement pris en compte.

Assurément, l'absence de contextes archéologiques fiables et précis pour les imitations gauloises des statères aux types de Philippe II et plus encore pour les statères originaux arrivés en Gaule ne permet pas d'appuyer la réflexion sur des bases suffisamment solides.

Quoi qu'il en soit, l'introduction du statère aux types de Philippe II en Europe celtique ne relève très probablement pas d'un seul et unique phénomène. Les mercenaires ont pu jouer un rôle certes mais pas seulement (particulièrement si l'on retient l'hypothèse de L. Baray de modes de rémunération divers). O. Buchsenschutz et alii soulignent que le dynamisme des élites aristocratiques, ouvertes sur le monde méditerranéen, a joué « plus que les grandes expéditions guerrières relatées par les auteurs antiques un rôle essentiel dans la diffusion des biens et des savoirs ainsi que dans celle des formes de représentation sociale et artistique $»^{200}$. C'est peut-être également par ce biais que doit se comprendre la diffusion de l'outil monétaire en Gaule.

\section{Questionner le choix des statères aux types de Philippe II de Macédoine ou} comment poursuivre la réflexion sur les circonstances de l'arrivée en Gaule de ces monnaies?

Le type monétaire des statères de Philippe II parait absolument indissociable des monnaies gauloises : au-delà du modèle qui est d'abord fidèlement imité, ses principaux éléments constitutifs (une tête masculine au droit, un cheval au revers) persistent jusqu'aux dernières émissions. Malgré l'évidence de ce constat, la question du choix original d'imiter principalement les philippes a été posée à de nombreuses reprises sans jamais être résolue de manière satisfaisante. Sans prétendre être en mesure de répondre à ce problème, nous proposons de rappeler les hypothèses proposées et de les confronter aux données apportées par le matériel gréco-macédonien.

En l'absence d'imitation du statère d'Alexandre en Gaule ce sont bien souvent des considérations typologiques qui ont été avancées pour expliquer le choix des philippes, le bige au revers paraissant revêtir une importance particulière ${ }^{201}$. En effet, lorsque les autorités émettrices font le choix du

199. Voir supra, partie 1.

200. BUCHSENSCHUTZ et alii 2012, p. 300.

201. SCHEERS 1999, p. 51 ; GRUEL 2006. 
prototype de Lysimaque ou de Néapolis, le revers comporte systématiquement le bige des philippes ${ }^{202}$. K. Gruel propose alors de voir dans ce choix typologique « un besoin d'identification des chefs gaulois, émetteurs de monnaies, aux plus grands conquérants connus ${ }^{203}$.»

À ce stade, il nous semble qu'un fait important doit être rappelé : les quelques statères originaux de Philippe II catalogués plus haut sont à ce jour les seules monnaies d'or grecques retrouvées en Gaule. Ce point, logique si l'on considère les imitations suscitées, ne l'est pas au regard du paysage de l'or monnayé en Méditerranée dans le dernier quart du IVe siècle. En effet, où que l'on se tourne, les philippes constituent au mieux une part importante mais non majoritaire des exemplaires enfouis, c'est le cas des Balkans et de la péninsule grecque ; au pire ils sont minoritaires au sein de trésors contenant d'autres monnayages, comme par exemple en Méditerranée occidentale (ce constat vaut également pour l'Égypte et le Levant) ${ }^{204}$. Cette situation est d'autant plus surprenante que plusieurs bronzes (et même quelques pièces d'argent) carthaginois et grecs de Sicile et d'Italie du Sud du IVe et du IIIe siècle ont été découverts en Gaule ${ }^{205}$. Étant donné cet environnement, comment expliquer qu'aucune pièce d'or au type d'Alexandre, de Carthage ou de Syracuse n'ait été, en l'état actuel des connaissances, mise au jour en Gaule ${ }^{206}$ ?

$\mathrm{Au}$ regard de ces éléments, et à l'appui des conclusions tirées de l'étude du matériel gréco-macédonien, l'idée d'un type qui s'impose en Gaule suite au retour de mercenaires ne peut pas être retenue. Une telle éventualité impliquerait que des monnaies aux types d'Alexandre (plus massivement émises que les philippes à partir de ca 325-323) ${ }^{207}$ ou de Méditerranée occidentale (nettement plus nombreuses dans cette région) se retrouvent aussi en Gaule. Or, comment expliquer cette sélection ? Avec des critères de poids ou d'aloi ? Les monnaies d'Alexandre ${ }^{208}$ comme celles de Syracuse ${ }^{209}$ sont conformes à l'étalon attique, comme les philippes. L'or carthaginois utilise un étalon

202. Supra partie 1.

203. GRUEL 2006, p. 68.

204. Sur la circulation des philippes, on se rapportera à la figure 38 .

205. SAntrot, Aubin 2002; AdAM 2007, p. 258-259; FeugÈre, Py 2011, p. 402-405 (monnaies puniques), p. 419-424 (monnaies grecques).

206. J. Santrot et G. Aubin signalent néanmoins, mais de façon incertaine, « une monnaie d'or, peut-être statère de Syracuse (?)» à Nalliers en Vendée (SANTROT, AUBIN 2002, p. 223). En outre, l'exemplaire BnF 6422 qui présente au revers un cheval avec la tête retournée et un symbole solaire indéterminé pourrait s'inspirer du revers d'émissions carthaginoises en or et en électrum datées de la première guerre punique, vers 270-264 et 264-241 av. J.-C. : AleXANDRopoulos 2007, p. 65-66; catalogue des monnayages de la Carthage punique, p. 369, no 26 (pour la tête retournée) et p. 369-370, nos 29-30 et 32 (pour l'uraeus à rayons).

207. LE RIDER 1996, p. $72 ; 2003$, p. 77-79.

208. LE RIDER 2003, p. 11.

209. Sur les monnaies d'or frappées sous Agathocle, entre la fin du IVe et le début du IIIe siècle : RUTTER 1997, p. 172-175. 
punique spécifique, mais il est apparu aux spécialistes que les poids et fractions émis permettent une convertibilité aisée de ces numéraires en monnaies attiques $^{210}$. Toutefois, si le titre des alexandres est absolument comparable à celui des philippes ${ }^{211}$, l'affaiblissement de la teneur en or des monnaies carthaginoises et de certaines monnaies d'Agathocle à Syracuse peut les distinguer ${ }^{212}$. Ainsi, si on peut à la rigueur imaginer que les pièces d'or carthaginoises et peutêtre certaines monnaies de Syracuse aient pu être écartées par des utilisateurs gaulois - encore que ces numéraires circulent sans difficultés avec les autres monnaies grecques dans les trésors de la région - aucun critère technique ne peut être avancé pour distinguer les philippes des autres monnayages d'or grecs, particulièrement des alexandres. On a déjà constaté que ces deux types se retrouvent dans les mêmes trésors en Sicile et en Italie ainsi que dans la moitié des trouvailles en Grèce, dans les Balkans et en Asie Mineure. De plus, la chronologie des frappes indique que si les philippes prédominent encore du vivant d'Alexandre, ce sont les statères aux types du conquérant qui sont de loin les plus frappés à partir de la seconde moitié des années 320 : précisément lorsque que les philippes atteignent la Gaule ${ }^{213}$.

En plus de cette sélection qui semble échapper à tout critère matériel, il faut rappeler le petit nombre des philippes originaux découverts en Gaule, qui plus est toujours isolés ${ }^{214}$, et sans doute arrivés en un laps de temps assez réduit. Ces paramètres ne peuvent définitivement pas correspondre à un phénomène de retour de mercenaires au pays, tel qu'il est observé en Thrace avec les nombreux trésors indubitablement liés à la politique militaire des rois macédoniens ${ }^{215}$. Que le mercenariat revête des réalités différentes en Méditerranée occidentale et orientale qui ne permettent pas de comparer le cas gaulois à celui des Thraces, que l'on intègre des éventuelles refontes de ces statères macédoniens, il ressort néanmoins que les quelques découvertes de philippes relèvent manifestement d'un phénomène ponctuel. Plus largement, et peut-être de façon provocatrice, nous serions enclins à dire que les monnaies d'or du monde méditerranéen n'ont pas vocation à circuler dans l'espace gaulois.

210. AleXANDROPOUlOS 2007, p. 44-47, particulièrement p. 46.

211. GONDONNEAU 2001, p. 172-173; GONDONNEAU et alii 2002, p. 370-372.

212. Pour les monnaies puniques, J. Alexandropoulos note un affaiblissement continu du titre des monnaies d'or entre le milieu du Ive siècle et le milieu du IIIe siècle (ALEXANDROPOULOS 2007, p. 47). À Syracuse, G. S. Bouyssou constate que trois des cinq monnaies d'Agathocle analysées ont un titre de 90,3 à 92,2 \%, les deux autres contiennent $99 \%$ d'or. L'auteur évoque la possibilité de manipulations monétaires (BouYsSou 2013, p. 226-228).

213. Ibid. n. 207. Sur l'augmentation du volume des émissions de statères d'Alexandre à partir de la seconde moitié des années 320 : PRICE 1991, p. 71-74 ; CALLATAŸ 2012, p. 179.

214. S’il était avéré, le seul cas connu serait celui du trésor de «Gironde».

215. Voir n. 106. 
Que reste-t-il donc pour expliquer l'importation et l'imitation en Gaule des philippes ? Privé de la séduisante hypothèse du mercenariat, nous sommes bien dépourvus face à ce problème. En l'état de nos connaissances, l'hypothèse d'un choix sur la base de critères iconographiques - l'hypothèse soumise par K. Gruel et S. Scheers - paraît satisfaisante bien que les circonstances exactes qui amenèrent en Gaule ces monnaies demeurent totalement obscures ; peut-être car la modestie du phénomène le maintient hors de portée de nos outils d'investigation. Le choix d'imiter ces types précis ne serait finalement que la conséquence, ou le prolongement de ce choix initial.

\section{Conclusion}

Dans cette étude, nous proposions de réunir les documentations pertinentes tant dans le champ d'étude grec que gaulois pour tenter de mieux cerner l'épisode d'importation en Gaule des statères de Philippe II. Ce phénomène qui conduit à l'inauguration d'un monnayage d'or proprement gaulois revêt une importance considérable dans la littérature dédiée à ce matériel. En comparaison de sa nature fondatrice autant que par l'ampleur et la longévité des séries monétaires engendrées, la présence des philippes en Gaule apparaît fort modeste. Malgré l'accroissement sensible du nombre des exemplaires répertoriés depuis le XIXe siècle, ce ne sont qu'une à deux dizaines de statères qui ont pu être mis au jour. Ce constat tend à être conforté par l'étude des séries grecques avec l'idée que le processus d'importation fut autant limité dans le temps qu'en importance. Ainsi, contrairement à ce qu'on aurait pu envisager de prime abord, les Gaulois n'ont sans doute pas imité un monnayage qu'ils avaient l'habitude de manipuler, par exemple suite à l'embauche massive de mercenaires qui seraient revenus les poches pleines de philippes. $\mathrm{Au}$ contraire, il est sans doute plus juste d'estimer que l'inauguration des monnayages d'or gaulois a pour origine le choix délibéré de populations qui ont sélectionné un type monétaire comportant des éléments iconographiques familiers, propres à évoquer des concepts chers à une aristocratie militaire. Du point de vue numismatique et monétaire, on retiendra principalement le profond décalage entre un phénomène modeste et ponctuel - celui de l'importation en Gaule des philippes - et un autre que l'on peut qualifier de majeur à l'échelle de l'histoire régionale avec le déclenchement d'une dynamique menant à l'acquisition, en Gaule, du fait monétaire.

\section{Abréviations}

IGCH M. ThOMPSON, O. MøRKHOLM, C. M. KRAA, Inventory of Greek Coin Hoards, New York, 1973.

CH 1 M.J. PRICE, Coin Hoards I, London, 1975.

CH 7 M.J. PRICE, D. NASH, Coin Hoards VII, London, 1985.

CH 10 O. Hoover, A. Meadows, U. WARTEnBerg, Coin Hoards X, New York, 2010. 


\section{Bibliographie}

ADAM 2007 : A.-M. ADAM, Les importations méditerranéennes en Gaule interne aux IVe et IIIe siècles avant notre ère, dans La Gaule dans son contexte européen aux IVe et III siècles avant J.-C., Actes du XXVII ${ }^{\mathrm{e}}$ Colloque international de l'AFEAF, Clermont-Ferrand, 29 mai- $^{\text {er }}$ juin 2003, C. Mennessier-Jouannet, A.-M. Adam, P.-Y. Milcent (éd.), Lattes, 2007, p. 255-263.

ADAM, FiCHTL 2011: A.-M. ADAM, S. FichTL, Les Celtes dans les guerres hellénistiques : le cas de la Méditerranée orientale, dans Pratiques et identités culturelles des armées hellénistiques du monde méditerranéen. Hellenistic Warfare 3, J.-Chr. Couvenhes, S. Crouzet, S. Péré-Noguès (dir.), (Scripta Antiqua 38), Bordeaux-Paris, 2011, p. 117-128.

Alexandropoulos 2007 : J. AleXANDropoulos, Les monnaies de l'Afrique antique, 400 av. J.-C. - 40 ap. J.-C., Toulouse, 2007.

Aubin et alii 2011 : G. AUBIN, J.-N. BARRANDON (†), Cl. LAMBERT, Le dépôt monétaire des Sablons, Le Mans (Sarthe) : 152 statères gaulois en or allié, Trésors monétaires, XXIV, Paris, 2011, p. 1-90, Pl. 1-9, A-B.

BAR 1991 : M. BAR, Monnaies grecques et assimilées trouvées en Belgique, Bruxelles, 1991.

BARAY 2014 : L. BARAY, Les mercenaires celtes et la culture de La Tène : critères archéologiques et positions sociologiques, Dijon, 2014.

BARAY 2015 : L. BARAY, Les mercenaires celtes en Méditerranée, $v^{e-f e r}$ siècles avant J.-C., Chamalières, 2015.

Barboux 1874 : M. BARBouX, Mémoires, Congrès Archéologique de France, $X L^{e}$ session, Séances générales tenues à Châteauroux en 1873, Paris / Tours, 1874, p. 550-558.

BARTHELEMY s.d. : A. de BARTHELEMY, Albums de dessins de monnaies gauloises, vol. II ms., Paris, Cabinet des médailles de la BnF, s.d.

BASLEZ 1989 : M.-F. BASLEZ, La circulation et le rôle des dariques en Grèce d'Europe à la fin du ve siècle et au IV siècle. Apport des inscriptions phéniciennes et grecques, REA, XCI, 1989, nos 1-2, p. 237-246.

BLANCHET 1905 : A. Blanchet, Traité des monnaies gauloises, Paris, 1905.

Blet-Lemarquand et alii 2014 : M. Blet-Lemarquand, S. Nieto-Pelletier, Fl. Téreygeol, «Tracer » l'or monnayé : le comportement des éléments traces de l'or au cours des opérations de refonte et d'affinage, BSFN, 4, 2014, p. 90-95.

BONNEFOY 1869: M. de BONNEFOY, Rapport sur des médailles et les objets portatifs du musée de Carcassonne, Congrès archéologique de France, XXXV ${ }^{e}$ session, séances générales tenues à Carcassonne, à Narbonne, à Perpignan et à Béziers en 1868, Paris, 1869, p. 133-143.

BONNET 1896 : E. BONNET, Médaillier de la société archéologique de Montpellier. Description des monnaies, médailles et jetons qui composent ce médaillier, Montpellier, 1896.

BOUDET 1987 : R. BOUDET, L'Âge du Fer récent dans la partie méridionale de l'estuaire girondin du ve siècle au ser siècle avant notre ère, Périgueux, 1987.

BOUDET 1989: R. BOUDET, La circulation des monnaies d'or pré-augustéennes dans le sud-ouest de la Gaule, Études celtiques, 26, 1989, p. 23-59.

Boudet et alii 1994 : R. BOUdET, C. CHEVILLOT, H. FeuILle, J.-P. Noldin, Saint-Aubin-de-Lanquais, Bilan scientifique régional, Aquitaine - Découvertes fortuites (Dordogne), p. 132. 
Boudet et alii 1995 : R. Boudet, C. CHEVILLot, H. Feuille, J.-P. Noldin, Un statère macédonien original découvert à Saint-Aubin-de-Lanquais (Dordogne), BSFN, 4, 1995, p. 1023-1024.

BouYSSOU 2007 : G.-S. BouYsSOU, Aspects littéraires et numismatiques des expédients des tyrans, BSFN, 10, 2013, p. 224-230.

BRUN 2007 : P. BRUN, Une période de transition majeure en Europe : de la fin du IVe au début du IIe S. av. J.-C. (La Tène B2 et C), dans La Gaule dans son contexte européen aux IVe et III siècles avant J.-C., Actes du XXVII ${ }^{e}$ Colloque international de l'AFEAF (Clermont-Ferrand, 29 mai- $1^{\text {er }}$ juin 2003), C. Mennessier-Jouannet, A.-M. Adam, P.-Y. Milcent (éd.), Lattes, 2007, p. 377-384.

BRUNAUX 2009 : J.-L. BRUNAUX, L'or gaulois, mythe et réalité, dans Coinage in the Iron Age. Essays in honour of Simone Scheers, J. Van Heesch, I. Heeren (eds.), London, 2009, p. 65-74.

Buchsenschutz et alii 1982: O. Buchsenschutz, G. Coulon, A. Duval, Celtes et GalloRomains en Berry, Châteauroux, catalogue d'exposition, 1982.

BuCHSENSCHUTZ et alii 2012 : O. BUCHSENSCHUTZ, K. GRUEL, Th. LeJARS, L'âge d'or de l'aristocratie celtique, IVe et IIIe siècles av. J.-C., Annales. Histoire, Sciences sociales, 2012/2, 67e année, p. 295-324.

Buchsenschutz et alii 2015 : O. BuchsenschutZ, M.-B. ChARDENouX, K. Gruel, P.-Y. LAMBERT, Th. LEJARS, St. VERGER, L'Europe celtique à l'âge du Fer (VIII--Ier siècles), Paris, 2015.

CALlataŸ 1994 : Fr. de CALlataÿ, Réflexions sur les ateliers d'Asie Mineure d'Alexandre le Grand, Trésors et circulation monétaire en Anatolie antique, Paris, 1994, p. 19-35.

CALlATAŸ 2012 : Fr. de CALLATÄ̈, Royal Hellenistic Coinages: from Alexander to Mithradates, 175-190, dans The Oxford Handbook of Greek and Roman Coinage, W. E. Metcalf (ed.), Oxford, 2012.

Colbert de BeAulieu 1973 : J.-B. Colbert De BeAulieu, Traité de numismatique celtique, I. Méthodologie des ensembles, Paris, 1973.

Colbert de Beaulieu, Dayet 1962 : J.-B. Colbert de Beaulieu, M. Dayet, Catalogue des monnaies gauloises du Jura, Paris, 1962.

Coulon 1971 : G. Coulon, Les origines de Buzançais, Bulletin du groupe d'Histoire et d'Archéologie de Buzançais (Indre), 3, 1971, p. 30-41.

DEBERGE et alii 2007 : Y. DEBERGE, L. ORENGO, M. LOUGHTON, G. VERRIER, La culture matérielle de la Grande Limagne d'Auvergne du III au Ier s. av. J.-C., dans L'Archéologie de l'âge du Fer en Auvergne, Actes du XXVII colloque international de l'AFEAF (Clermont-Ferrand, 29 mai- ${ }^{\text {er }}$ juin 2003), Chr. Mennessier-Jouannet, Y. Deberge (éd.), Lattes, 2007, p. 167-204.

Delestrée 2001 : L.-P. Delestrée, L’or du trophée laténien à Ribemont-sur-Ancre (Somme), témoin d'une bataille oubliée, RN, 2001, p. 175-213, pl. VIII-X.

Delestrée, TACHe 2004 : L.-P. Delestrée, M. TACHe, Nouvel atlas des monnaies gauloises, II. De la Seine à la Loire moyenne, Saint-Germain-en-Laye, 2004.

Delestrée, TACHE 2007 : L.-P. DelestréE, M. TACHE, Nouvel atlas des monnaies gauloises, III. La Celtique, du Jura et des Alpes à la façade atlantique, Saint-Germain-en-Laye, 2007. Delestrée, Le BÉCHENNEC 2014 : L.-P. Delestrée, Y. Le BÉCHEnNEC, L'hémistatère de Thézy (Somme) trouvé en contexte archéologique, Cah. Num., 201, p. 5-10.

Dupoux 1976 : J. Dupoux Le statère d'or de Buzançais (Indre), Revue archéologique du Centre, 15, 1976, p. 241-245. 
DUYRAT 2000 : Fr. DUYRAT, Arados et la guerre de 333 à 37 avant notre ère, RN, 2000, 155, p. 47-58.

Duyrat, Olivier 2010 : Fr. Duyrat, J. Olivier, Deux politiques de l'or. Séleucides et Lagides au IIIe siècle av. J.-C., RN, 2010, p. 71-93.

FEUGÈRE, RichARD 2004 : M. FEUGÈRE, J.-Cl. RiChARD, Monnaies d'or antiques du département de l'Hérault : une mise à jour, BSFN, 5, 2004, p. 109-112.

FEUGÈRE, PY 2011 : M. FeUGÈRE, M. PY, Dictionnaire des monnaies découvertes en Gaule méditerranéenne (530-27 avant notre ère), Paris, 2011.

FichTL 2007 : S. FichtL, Le III s. av. n. è. : genèse des entités politiques en Gaule?, dans La Gaule dans son contexte européen aux IVe et IIIe siècles avant J.-C., Actes du XXVII ${ }^{\mathrm{e}}$ Colloque international de l'AFEAF (Clermont-Ferrand, 29 mai- $1^{\mathrm{er}}$ juin 2003), C. Mennessier-Jouannet, A.-M. Adam, P.-Y. Milcent (éd.), Lattes, 2007, p. 283-289.

FISCHER 1988 : B. FISCHER, Monnaies gauloises du Musée Bertrand à Châteauroux, Revue de l'Académie du Centre, 114, 1988, p. 29-60.

FISCHER 1991 : B. FISCHER, Les différents monétaires des premières imitations du statère de Philippe II de Macédoine, Études celtiques, 28, 1991, p. 137-155.

FORRER 1925 : R. FORRER, Les monnaies gauloises ou celtiques trouvées en Alsace, Mulhouse, 1925.

GONDONNEAU 2001 : A. GONDONNEAU, Développement et application des techniques ICP-MS et LA-ICP-MS à la caractérisation de l'or : circulation monétaire entre Orient et Occident dans l'Antiquité et au Moyen-Age, thèse de doctorat inédite, Université d'Orléans, 2001.

GONDONNEAU et alii 1996 : A. GONDONNEAU, M. F. GUERRA, J.-N. BARRANDON, Sur les traces de l'or monnayé : recherche de provenances par LA-ICP-MS, Revue d'archéométrie, 20, 1996, p. 23-32.

Gondonneau et alii 2002 : A. Gondonneau, H. Nicolet-Pierre, M.-F. Guerra, The Persian and Macedonian Gold from Darius to Alexander the Great, dans Proceedings of the $31^{\text {st }}$ Symposium in Budapest, April 26 - May 3 1998, Archaeometry 98, E. Jerem, K.T. Biró (eds.), (BAR International series 1043), vol. II, 2002, p. 369-374.

GoRPHE 2009 : J. GORPHE, Le trésor de Tayac, Saint-Germain-en-Laye, Paris, 2009.

GRUEL 2006: K. GRUEL, Les prototypes des monnaies gauloises, les raisons de leur choix, dans D. Frère (dir.), De la Méditerranée vers l'Atlantique. Aspects des relations entre la Méditerranée et la Gaule centrale et occidentale (VIII-II siècle av. J.-C.), Rennes, 2006, p. 67-74.

GUICHARD et alii à paraître : V. GUICHARD, L. ORENGO, G. VERRIER, Le fossé 12/13 du site de La Grand Borne à Clermont-Ferrand, dans Chronotypologie des mobiliers du second âge du Fer en Auvergne, Chr. Mennessier-Jouannet, Y. Deberge (éd.), (suppl. à la RACF), à paraître.

GUIHARD 2012 : P.-M. GUIHARD, Monnaie et société chez les peuples gaulois de la basse vallée de la Seine. Recherches sur les usages monétaires d'une région entre le début du III et la fin du rer siècle avant J.-C., Montagnac, 2012.

HARTMANN et NAU 1976 : A. HARTMANN, E. NAU, Über die spektralanalytische Untersuchung einiger griechischer Philipp-und Alexander-Statere sowie deren keltischer Nachprägungen, Beiträge zur süddeutschen Münzgeschichte. Festschrift zum 75jährigen Bestehen des Würtembergischen Vereins für Münzkunde e.V., Stuttgart, 1976, p. 7-34. 
HASELgRove 1999 : C. HASelgrove, The development of Iron Age coinage in Belgic Gaul, NC, 159, 1999, p. 111-168.

Hatzopoulos 1991 : M.B. Hatzopoulos, Actes de vente d'Amphipolis, MEAETHMATA 14, Athènes, 1991.

HIERNARD 1982 : J. HIERNARD, Corbilo et la route de l'étain, Bulletin de la Société des Antiquaires de l'Ouest, 16, fasc. 3, p. 497-578, p. 1-6.

HoOver 2012 : O.D. Hoover, Handbook of Coins of Sicily (including Lipara), Civic, Royal, Siculo-Punic, and Romano-Sicilian Issues, Sixth to First Centuries BC, The Handbook of Greek Coinage Series 2, Lancaster / London, 2012.

KELLNER 1970 : H.-J. KeLLNER, Der Fund von Tayac, ein Zeugnis des Cimbernzuges?, JNG, 10, 1970, p. 13-47, pl. 3-10.

KRUTA 1982 : V. KRUTA, Archéologie et numismatique : la phase initiale du monnayage celtique, Études celtiques, XIX, 1982, p. 69-82.

LAMBERT 1864 : E. LAMBERT, Essai sur la numismatique gauloise du nord-ouest de la France, Paris-Bayeux, II, 1864.

LEJARS 2007 :Th. LEJARS, Lieux de culte et pratiques votives en Gaule à La Tène ancienne, dans La Gaule dans son contexte européen aux IVe et IIIe siècles avant J.-C., Actes du XXVII ${ }^{\mathrm{e}}$ Colloque international de l'AFEAF (Clermont-Ferrand, 29 mai- $1^{\mathrm{er}}$ juin 2003), C. Mennessier-Jouannet, A.-M. Adam, P.-Y. Milcent (éd.), Lattes, 2007, p. 265-282.

LE RIDER 1977 : G. LE RIDER, Le monnayage d'argent et d'or de Philippe II frappé en macédoine de 359 à 294, Paris, 1977.

LE RIDER 1993 : G. LE RIDER, Les deux monnaies macédoniennes des années 323-294/290, $B C H, 117-1,1993$, p. 491-500.

LE RIDER 1996 : G. LE RIDER, Monnayage et finances de Philippe II, un état de la question,

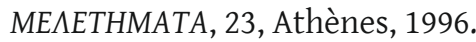

LE RIDER 2003 : G. LE RIDER, Alexandre le Grand : monnaie, finances et politique, Paris 2003.

MARCELLESI 2004 : M.-C. MARCELLESI, Milet des Hécatomnides à la domination romaine. Pratiques monétaires et histoire de la cité du IVe au IIe siècle av.J.-C., (Milesische Forschungen 3), Mayence, 2004.

MARION 2013 : S. MARION, L'économie du IIIe s. a.C., 20 ans après, dans L'âge du Fer en Europe. Mélanges offerts à Olivier Buchsenschutz, S. Krausz, A. Collin, K. Gruel, I. Ralston, Th. Dechezleprêtre (dir.), Bordeaux, 2013, p. 361-369.

MARTIN 1985 : T. R. MARTIN, Sovereignty and Coinage in Classical Greece, Princeton, 1985.

MARTIN 2015 : S. MARTIN, Du statère au sesterce. Monnaie et romanisation dans la Gaule du Nord et de l'Est (III' s. a.C./IIr s. p.C.), Bordeaux, 2015.

MATER 1891-1892 : D. MATER, Bulletin numismatique. Monnaies gauloises, Mémoires de la Société des Antiquaires du Centre, XVIII (1891), 1892, p. 385-495, pl. I-II.

MATER 1899: D. MATER, Bulletin numismatique et sigillographique, Mémoires de la Société des Antiquaires du Centre, XXII, 1899, p. 225-268.

MEADows, à paraître : A.R. MEADows, Invasion and Transformation. The Development of the Civic Alexander Coinage in Western Asia Minor, c. 323 to 223 B.C., dans Les alexandres après Alexandre : histoire d'une monnaie commune, actes du colloque international d'Athènes, 23-24 mai 2014, M.-C. Marcellesi, S. Kremydi (éd.), à paraître. 
MENNESSIER-JouANNET 2013 : Chr. MenNESSIER-JouANNET, Quelques indicateurs socioéconomiques d'une mutation en Limagne (Puy-de-Dôme) au IIIe siècle a.C., dans L'âge du Fer en Europe. Mélanges offerts à Olivier Buchsenschutz, S. Krausz, A. Collin, K. Gruel, I. Ralston, Th. Dechezleprêtre (dir.), Bordeaux, 2013, p. 371-386.

Mennessier-Jounannet, Provost 1994 : Chr. Mennessier-Jounannet, M. Provost, Carte archéologique de la Gaule, Le Puy-de-Dôme (63/2), Paris, 1994.

Mennessier-Jouannet et alii 2007 : Chr. Mennessier-Jouannet, A.-M. AdAm, P.-Y. MilCEnT (éd.), La Gaule dans son contexte européen aux IVe et IIIe siècles avant notre ère, Actes du XXVII ${ }^{\mathrm{e}}$ colloque international de l'AFEAF (Clermont-Ferrand, 29 mai- $1^{\text {er }}$ juin 2003), Lattes, 2007.

MiLCENT 2006 : P.-Y. MiLCENT, Examen critique des importations méditerranéennes en Gaule centrale et occidentale. Les attributions douteuses, erronées ou falsifiées, dans De la Méditerranée vers l'Atlantique. Aspects des relations entre la Méditerranée et la Gaule centrale et occidentale (VIIIe-IIe siècle av.J.-C.), D. Frère (dir.), Rennes, 2006, p. 117-133.

MonNET 1887-1890 : G. MonNET, Numismatique, Mémoires de la Société des Sciences Naturelles et Archéologiques de la Creuse, t. 6, 1887-1890, p. 395-400.

MÜLLER 1855 : L. MÜLLER, Numismatique d'Alexandre suivie d'un appendice contenant les monnaies de Philippe II et III, Copenhagen, 1855.

Muret, Chabouillet 1889 : E. Muret, A. Chabouillet, Catalogue des monnaies gauloises de la Bibliothèque nationale, Paris, 1889.

Newell 1923 : E.T. Newell, Alexander Hoards. Demanhur, 1905, Numismatic Notes and Monographs 19, 1923.

NASH 1978 : D. NASH, Settlement and coinage in central Gaul, c. 200-50 B.C., Part I\&II, (BAR Supplementary Series 39), Oxford, 1978.

Nieto-Pelletier et alii 2015 : S. Nieto-Pelletier, J. Olivier, Chr. Charlet, M. BletLEMARQUAND, Un statère d'or de Philippe II de Macédoine trouvé à Monaco en 1877, BSFN, 5, 2015, p. 106-111.

PELLERIN 1763 : J. PELLERIN, Recueil de médailles de peuples et de villes, qui n'ont point encore été publiées, ou qui sont peu connues, I, Paris, 1763.

PÉRÉ-NoguÈs 2007 : S. PÉRÉ-NoguÈs, Les Celtes et le mercenariat en Occident (IVe et IIIe s. av. n.è.), dans La Gaule dans son contexte européen aux IVe et IIIe siècles avant J.-C., Actes du XXVII ${ }^{\mathrm{e}}$ Colloque international de l'AFEAF (Clermont-Ferrand, 29 mai- ${ }^{\mathrm{er}}$ juin 2003), C. Mennessier-Jouannet, A.-M. Adam, P.-Y. Milcent (éd.), Lattes, 2007, p. 353-361.

PÉRÉ-NoguÈs 2011a : S. PÉRÉ-NoguÈs, Réflexions sur le mercenariat en Sicile et dans le monde grec occidental (du milieu du IVe s. au début du III s. a.C.) : « entre textes et témoignages monétaires », dans Pratiques et identités culturelles des armées hellénistiques du monde méditerranéen. Hellenistic Warfare 3, J.-Chr. Couvenhes, S. Crouzet, S. PéréNoguès (dir.), (Scripta Antiqua 38), Bordeaux / Paris, 2011, p. 147-163, p. 147-163.

PÉRÉ-NoguÈs 2011 b : S. PÉRÉ-NoguÈs, Aux limites de l'interprétation : mercenariat et mobilité au Second âge du Fer, dans L'âge du Fer en Aquitaine et sur ses marges. Mobilité des hommes, diffusion des idées, circulation des biens dans l'espace européen à l'âge du Fer, Actes du 35e colloque de l'AFEAF, A. Colin, Fl. Verdin (dir.), Bordeaux, 2011, p. 429-437. 
PION 2012 : P. PION, La monnaie mercenaire : une approche anthropologique des premiers monnayages celtiques du Nord-Ouest du complexe nord-alpin (IIIe siècle av. J.-C.), dans Monnaie antique, monnaie moderne, monnaies d'ailleurs... Métissages et hybridations, B. Formoso, P. Pion (dir.) avec la collaboration de R. Étienne, Paris, 2012, p. 151-164.

PolENZ 1982 : H. PolENZ, Münzen in latènezeitlichen Gräbern Mitteleuropas aus der Zeit zwischen 300 und 50 vor Christi Geburt, Bayerische Vorgeschichtblätter, 47, 1982, p. 28-222.

PRICE 1991 : M.J. PRICE, The coinage in the name of Alexander the Great and Philip Arrhidaeus, Zürich/London, 1991.

Provost et alii 1992 : M. Provost, G. Coulon, J. Holmgren, Carte archéologique de la Gaule. L'Indre (36), Paris, 1992.

Reymond, Dugand 1970 : G. Reymond, J.-F. Dugand, Monaco antique, Paris, 1970.

RICHARD 1980 : J.-Cl. RICHARD, Un aureus de Claude à Lattes et les trouvailles de monnaies d'or antiques dans le département de l'Hérault, Table ronde sur l'or monétaire, BSFN, 10, 1980, p. 789-792.

RICHARD RALITE 2012 : J.-Cl. RICHARD RALITE, Les monnaies antiques de la région minière d'Avène et Ceilhes (Hérault), Bulletin de la Société archéologique et historique des Hauts Cantons de l'Hérault, 35, 2012, p. 1-12.

Richard et alii 1982 : J.-Cl. RichARD avec la collab. de G. DEPEYROT, M. DHÉNIN, G. HENNEQUin, C. MorRisSON, L. VillarongA, Catalogue des monnaies du Musée de Carcassonne (Aude), I, Les monnaies d'or, Bulletin de la Société d'Études scientifiques de l'Aude, 82, 1982, p. 37-46.

Rufin-Solas 2014 : A. Rufin-Solas, Philippe II de Macédoine, l'argent et la guerre: les recrutements de guerriers thraces, REG, 127 (1), 2014, p. 75-96.

RUTTER 1997 : N. K. RUTTER, The Greek Coinages of Southern Italy and Sicily, London, 1997. SANTROT, Aubin 2002 : J. SANTRot, G. Aubin, Les monnaies antiques «exotiques » de Darun, en Nivillac (Morbihan), Revue archéologique de l'ouest, 19, 2002, p. 219-229.

SCHEERS 1978 : S. SCHEERS, Les débuts du monnayage d'or en Gaule concernant spécialement les imitations du statère de Philippe II de Macédoine, BSFN, 10, 1978, p. 442-450.

SCHEERS 1980 : S. SCHEERS, Les imitations en Gaule du statère de Philippe II de Macédoine, Proceedings of the International Numismatic Symposium, I. Gedai, K. Biro-Sey (éd.), Budapest, 1980, p. 41-53.

SCHEERS 1993 : S. SCHEERS, Les imitations de Philippe et les guerres puniques, BSFN, 8, 1993, p. 631-633.

SCHEERS 1999 : S. SCHEERS, La naissance du monnayage d'or en Gaule, Dossiers d'archéologie, 248, novembre 1999, p. 44-51.

SCHEERS 2004: S. SCHEERS, La naissance du monnayage d'or en Gaule d'après les influences étrangères, dans Forschungen zur Monetarisierung und ökonomischen Funktionalisierung von Geld in den nordwestlichen Provinzen des Imperium Romanonum. Die Entstehung eines europäischen Wirtschaftsraumes. Akten des 2. Trierer Symposiums zur antiken Wirtschaftsgeschichte, Kliomedia, K. Strobel, R. Loscheider (éd.), Trier, 2004, p. 7-26.

SCHEERS, BARRANDON 1994 : S. SCHEERS, J.-N. BARRANDON, Les imitations du statère de Philippe II de Macédoine, dans L'or gaulois. Le trésor de Chevanceaux et les monnayages de la façade atlantique, J.-N. BARRANDON et alii (éd.), (Cahiers Ernest Babelon 6), Paris, 1994. 
SCHÖNFELDER 2007 : M. SCHÖNFELDER, Considérations sur les élites celtiques des IVe-IIIe s. av. J.-C., dans La Gaule dans son contexte européen aux IVe et IIIe siècles avant J.-C., Actes du XXVII ${ }^{\mathrm{e}}$ Colloque international de l'AFEAF (Clermont-Ferrand, 29 mai- ${ }^{\text {er }}$ juin 2003), C. Mennessier-Jouannet, A.-M. Adam, P.-Y. Milcent (éd.), Lattes, 2007, p. 291-299. SiLlon 2014 : Ch. SiLLON, L'or monnayé dans le Nord de la Gaule. Recherches sur les monnaies d'or frappées dans le Nord de la Gaule entre le IIIe et le Ier siècle avant notre ère, Thèse d'Histoire soutenue à l'université d'Orléans, décembre 2014.

SILLS 1999 : J. Sills, A Philipp III stater from Kent, dans Chris Rudd, List 46, 1999, p. 4.

SiLLS 2003 : J. SiLls, Gaulish and Early British Gold Coinage, London, 2003.

SireIX et alii 1983 : M. SireiX, J.-P. Noldin, J.-B. ColBERT DE BEAULIEU, D. NONY, J.-Cl. RiCHARD, Les monnaies de Moulets-et-Villemartin (Gironde), Gallia, 41 (1), 1983, p. 25-57.

S.R. 1907 : S. R., Monnaies grecques trouvées en Hesbaye, Chronique archéologique du Pays de Liège, janvier 1907, p. 9-11.

THOMPson 1982 : M. Thompson, Posthumous Philip II Staters of Asia Minor, dans Studia Paulo Naster oblate 1, S. Scheers (ed.), Leuven, 1982, p. 57-61.

THompson 1983 : M. ThOMPson, Alexander's Drachm Mints. I: Sardes and Miletus, (Numismatic Studies 16), New York, 1983.

THOMPSON 1984 : M. THOMPson, Paying the Mercenaries, dans Festschrift für Leo Mildenberg, A. Houghton, S. Hurter, P. Erhart Mottahedeh, J. A. Scott (ed.), Wetteren, 1984, p. 241-247.

THOMPSON 1991 : M. ThOMPson, Alexander's drachm mints. II, Lampsacus and Abydus, (Numismatic Studies 19), New York, 1991.

THOMPSON, BelLinger 1955 : M. THOMPSON, A. R. Bellinger, Greek Coins in the Yale Collection, IV : A Hoard of Alexander Drachms, (Yale classical Studies XIV), Yale, 1955.

TRoxell 1997 : H. A. TROXell, Studies in the Macedonian Coinage of Alexander the Great (Numismatic Studies 21), New York, 1997.

WigG-Wolf 2011 : D. WigG-Wolf, The function of celtic coinages in northern Gaul, dans Barter, money and coinage in the Ancient Mediterranean ( $10^{\text {th }}-1^{\text {st }}$ Centuries BC), M.P. García-Bellido et alii (ed.), Madrid, 2011, p. 301-314.

Williams, Burnett 1998 : J.H. C. Williams, A. BurnetT, Alexander the Great and the Coinages of Western Greece, dans Studies in Greek Numismatics in Memory of Martin Jessop Price, R. Ashton, S. Hurter (eds.), London, 1998, p. 379-393.

WitTE 1863 : J. de WitTE, Chronique. Monnaies gauloises, RN, 1863, p. 76-77.

Yvon 1976 : J. Yvon, Chronique : Trouvailles monétaires de Gironde, Bulletin et Mémoires de la Société Archéologique de Bordeaux, 68, 1970-1973, 1976, p. 330-331.

Ziegaus 1999 : B. ZiegAus, Die Keltischen Münzen in den Gräbern von Dobian und Hostomitz - Addenda et Corrigenda, dans Fundmünzen aus Gräbern. Sitzungsbericht des zweiten internationalen Kolloqiums der Schweizerischen Arbeitsgemeinschaft für Fundmünzen (Neuenburg, 3. - 4. März 1995), O.F. Dubuis, S. Frey-Kupper, G. Perret (eds.), (Untersuchungen zu Numismatik und Geldgeschichte 2), Lausanne, 1999, p. 107-118. 


\section{ANNEXE}

\section{Principaux inventaires des statères de Philippe II découverts en Europe}

(un exemplaire pour chaque lieu de découverte, sauf mention contraire).

En grisé : les exemplaires mentionnés comme incertains par les auteurs concernés.

\begin{tabular}{|c|c|c|c|c|c|c|}
\hline $\begin{array}{l}\text { BLANCHET } \\
1905^{8}\end{array}$ & $\begin{array}{c}\text { SCHEERS } \\
1978^{9}\end{array}$ & $\begin{array}{l}\text { SCHEERS } \\
1980^{10}\end{array}$ & $\begin{array}{l}\text { RICHARD et alii } \\
1982^{11}\end{array}$ & $\begin{array}{l}\text { FISCHER } \\
1991^{12}\end{array}$ & $\begin{array}{l}\text { SILLS } \\
2003^{13}\end{array}$ & $\begin{array}{l}\text { SCHEERS } \\
2004^{14}\end{array}$ \\
\hline $\begin{array}{l}\text { Avène } \\
\text { (Hérault) }\end{array}$ & $\begin{array}{l}\text { «Olvène » } \\
\text { (Hérault) }\end{array}$ & $\begin{array}{l}\text { Avène } \\
\text { (Hérault) }\end{array}$ & $\begin{array}{l}\text { Avène } \\
\text { (Hérault) }\end{array}$ & $\begin{array}{l}\text { Avène } \\
\text { (Hérault) }\end{array}$ & $\begin{array}{c}\text { Avène } \\
\text { (Hérault) }\end{array}$ & $\begin{array}{l}\text { Avène } \\
\text { (Hérault) }\end{array}$ \\
\hline $\begin{array}{c}\text { Saint-Silvain- } \\
\text { Montaigut (Creuse) }\end{array}$ & $\begin{array}{l}\text { Landerrouat } \\
\text { (Gironde) }\end{array}$ & $\begin{array}{l}\text { Landerrouat } \\
\text { (Gironde) }\end{array}$ & $\begin{array}{l}\text { Buzançais } \\
\text { (Indre) }\end{array}$ & $\begin{array}{c}\text { Buzançais } \\
\text { (Indre) }\end{array}$ & $\begin{array}{l}\text { Env. de Bordeaux } \\
\text { (Gironde) }: 4 \mathrm{ex} \text {. }\end{array}$ & $\begin{array}{l}\text { Env. de Bordeaux } \\
\text { (Gironde) : } 4 \text { ex. }\end{array}$ \\
\hline $\begin{array}{c}\text { Mont-Mort } \\
\text { (Lons-le-Saulnier) }\end{array}$ & $\begin{array}{c}\text { Pons } \\
\text { (Charente-Maritime) }\end{array}$ & $\begin{array}{l}\text { Méry-sur-Cher } \\
\text { (Cher) }\end{array}$ & $\begin{array}{l}\text { Carcassonne } \\
\text { (Aude) : } 2 \text { ex. }\end{array}$ & $\begin{array}{l}\text { Carcassonne } \\
\text { (Aude) : } 2 \text { ex. }\end{array}$ & $\begin{array}{l}\text { Buzançais } \\
\text { (Indre) }\end{array}$ & $\begin{array}{l}\text { Buzançais } \\
\text { (Indre) }\end{array}$ \\
\hline $\begin{array}{l}\text { Ceffia } \\
\text { (Jura) }\end{array}$ & $\begin{array}{l}+2 \text { autres } \\
\text { non cités }\end{array}$ & $\begin{array}{c}\text { Pons } \\
\text { (Charente-Maritime) }\end{array}$ & $\begin{array}{l}\text { Landerrouat } \\
\text { (Gironde) }\end{array}$ & $\begin{array}{l}\text { Orléans } \\
\text { (Loiret) }\end{array}$ & $\begin{array}{l}\text { Carcassonne } \\
\text { (Aude) : } 2 \text { ex. }\end{array}$ & $\begin{array}{l}\text { Carcassonne } \\
\text { (Aude) : } 2 \text { ex. }\end{array}$ \\
\hline $\begin{array}{l}\text { Commenailles } \\
\text { (Jura) }\end{array}$ & & $\begin{array}{c}\text { Saint-Silvain-de- } \\
\text { Montaigut (Creuse) }\end{array}$ & $\begin{array}{l}\text { Méry-sur-Cher } \\
\text { (Cher) }\end{array}$ & $\begin{array}{c}\text { Saint-Silvain-de- } \\
\text { Montaigut (Creuse) }\end{array}$ & $\begin{array}{l}\text { Feusines } \\
\text { (Indre) }\end{array}$ & $\begin{array}{c}\text { Landerrouat } \\
\text { (Gironde) }\end{array}$ \\
\hline $\begin{array}{l}\text { Langres } \\
\text { (Haute-Marne) }\end{array}$ & & $\begin{array}{c}\text { Milton } \\
\text { (Kent, Angleterre) }\end{array}$ & $\begin{array}{c}\text { Pons } \\
\text { (Charente-Maritime) }\end{array}$ & & $\begin{array}{l}\text { Landerrouat } \\
\text { (Gironde) }\end{array}$ & $\begin{array}{l}\text { Méry-sur-Cher } \\
\text { (Cher) }\end{array}$ \\
\hline $\begin{array}{l}\text { Près du château } \\
\text { de Lardimalie } \\
\text { (Dordogne) }\end{array}$ & & $\begin{array}{l}\text { Ceffia } \\
\text { (Jura) }\end{array}$ & $\begin{array}{l}\text { Saint-Silvain-de- } \\
\text { Montaigut (Creuse) }\end{array}$ & & $\begin{array}{l}\text { Méry-sur-Cher } \\
\text { (Cher) }\end{array}$ & $\begin{array}{l}\text { Saint-Aubin- } \\
\text { de-Lanquais } \\
\text { (Dordogne) }\end{array}$ \\
\hline Dans la Loire & & $\begin{array}{c}\text { Malay } \\
\text { (Saône-et-Loire) }\end{array}$ & Monaco & & $\begin{array}{l}\text { Saint-Aubin- } \\
\text { de-Lanquais } \\
\text { (Dordogne) }\end{array}$ & $\begin{array}{c}\text { Saint-Silvain- } \\
\text { Montaigut (Creuse) }\end{array}$ \\
\hline $\begin{array}{c}\text { Louresse } \\
\text { (Maine-et-Loire) }\end{array}$ & & $\begin{array}{l}\text { Bondeval } \\
\text { (Doubs) }\end{array}$ & & & $\begin{array}{c}\text { Saint-Silvain- } \\
\text { Montaigut (Creuse) }\end{array}$ & $\begin{array}{c}\text { Milton } \\
\text { (Kent, Angleterre) }\end{array}$ \\
\hline \multirow[t]{4}{*}{$\begin{array}{l}\text { Buzançais } \\
\text { (Indre) }\end{array}$} & & $\begin{array}{l}\text { Toutencourt } \\
\text { (Somme) }\end{array}$ & & & $\begin{array}{c}\text { Milton } \\
\text { (Kent, Angleterre) }\end{array}$ & $\begin{array}{l}\text { Région d'Hesbaye } \\
\text { (Belgique) }\end{array}$ \\
\hline & & & & & Monaco & Ceffia (Jura) \\
\hline & & & & & $\begin{array}{l}\text { Région d'Hesbaye } \\
\text { (Belgique) }\end{array}$ & \\
\hline & & & & & $\begin{array}{l}\text { Gamshurst } \\
\text { (Baden-Württem- } \\
\text { berg, Allemagne) }\end{array}$ & \\
\hline
\end{tabular}

216. BLANCHET 1905, p. 210-211, n. 1 et 2.

217. SCHEERS 1978, p. 447.

218. SCHEERS 1980, p. 41-43.

219. RICHARD et alii 1982 , p. 38.

220. FISCHER 1991, p. 153.

221. SiLLS 2003, p. 6-8.

222. SCHEERS 2004 , p. 7-8, n. 2 et p. 24-25. 